\begin{abstract}
UNIVERSIDADE DE SÃO PAULO
ESCOLA DE ENFERMAGEM DE RIBEIRÃO PRETO

PROGRAMA DE PÓS-GRADUAÇÃO EM ENFERMAGEM FUNDAMENTAL
\end{abstract}

ROSICLER XELEGATI

DESENVOLVIMENTO DE UM AMBIENTE VIRTUAL DE APRENDIZAGEM SOBRE GERENCIAMENTO EM EVENTOS ADVERSOS NOS SERVIÇOS DE ENFERMAGEM 


\section{DESENVOLVIMENTO DE AMBIENTE VIRTUAL DE APRENDIZAGEM SOBRE GERENCIAMENTO EM EVENTOS ADVERSOS NOS SERVIÇOS DE ENFERMAGEM}

Dissertação apresentada ao Programa de PósGraduação em Enfermagem Fundamental da Escola de Enfermagem de Ribeirão Preto da Universidade de São Paulo para obtenção do Título de Mestre em Enfermagem.

Linha de Pesquisa: Ciência e Tecnologia em Enfermagem.

Orientadora: Profa. Dra. Yolanda Dora Martinez Évora 
Autorizo a reprodução e divulgação total ou parcial deste trabalho, por qualquer meio convencional ou eletrônico, para fins de estudo ou pesquisa, desde que citada à fonte.

\section{Ficha Catalográfica}

Xelegati, Rosicler

Desenvolvimento de um ambiente virtual de aprendizagem sobre gerenciamento em eventos adversos nos serviços de enfermagem / Rosicler Xelegati; orientadora Yolanda Dora Martinez Évora. - Ribeirão Preto, 2010.

$90 f$.

Dissertação (Mestrado - Programa de Pós-Graduação em Enfermagem Fundamental) - Escola de Enfermagem de Ribeirão Preto da Universidade de São Paulo.

1. Enfermagem. 2. Ambiente Virtual de Aprendizagem. 3. Eventos Adversos. 4. Ensino a Distância. 5. Software Educacional. 
Nome: Rosicler Xelegati

Título: Desenvolvimento de um ambiente virtual de aprendizagem sobre gerenciamento em eventos adversos nos serviços de enfermagem

Dissertação apresentada ao Programa de Enfermagem Fundamental da Escola de enfermagem de Ribeirão Preto da Universidade de São Paulo para obtenção do Título de Mestre em Enfermagem. Linha de Pesquisa: Ciência e Tecnologia em Enfermagem.

Aprovada em:

\section{Banca Examinadora}

Profa. Dra.

Instituição: Assinatura:

Profa. Dra. Instituição: Assinatura:

Profa. Dra. Instituição: Assinatura: 


\section{DEDICATÓRIA}

À Deus, que sempre me amparou e me conduziu para o melhor caminho.

Obrigada Senhor!

Aos meus pais, Rosangela e João, pela dádiva da vida e pela oportunidade de poder estudar. Mãe, obrigada por tudo! Ao meu irmão e a minha cunhada, Ricardo e Carolina, pelo incentivo e apoio.

Aos meus amados sobrinhos, Leonardo, Eduardo e Gabriela, pelos momentos de alegria.

Aos meus tios, tias e avós, pela torcida.

Amo vocês!

Ao meu amor, Rodrigo, pelo incentivo, pelo apoio, pelo companheirismo e pelo carinho durante esta jornada. Obrigada por estar ao meu lado!

Amo muito você! 


\section{AGRADECIMENTOS}

Especialmente, à Profa.Dra. Yolanda Dora Martinez Évora, pela orientação deste estudo e, mais do que isso, pelo aprendizado que me proporcionou enquanto profissional e pessoa. Muito obrigada!

À Profa.Dra. Carmen Silvia Gabriel e à Profa.Dra. Marcia Regina Antonietto da Costa Melo, pelas sugestões de melhoria apontadas no Exame de Qualificação.

À Profa.Dra. Elaine Maria Leite Rangel, pelo incentivo e pela ajuda durante o desenvolvimento deste trabalho.

À Fundação de Amparo a Pesquisa do Estado de São Paulo - FAPESP pelo apoio financeiro para remuneração do analista de sistema.

Ao Hospital São Francisco e ao Hospital das Clínicas da Faculdade de Medicina de Ribeirão Preto - USP, pela adequação dos meus horários de trabalho para cursar as disciplinas da Pós-Graduação.

A todos os docentes e funcionários da Escola de Enfermagem de Ribeirão Preto - USP, pelo apoio e pela formação acadêmica.

À Luciana Kakushi, Lívia Garbin, Luciana Castelar, Karina Dal Sasso, Fernanda Titarelli, Luíza Tayar e Maria Verônica Ferrareze pelo apoio, pela troca de idéias e pela paciência no dia-a-dia. 


\section{RESUMO}

XELEGATI, R. Desenvolvimento de um ambiente virtual de aprendizagem sobre gerenciamento em eventos adversos nos serviços de enfermagem. 2010. 90f. Dissertação (Mestrado) - Escola de Enfermagem de Ribeirão Preto, Universidade de São Paulo, Ribeirão Preto, 2010.

A busca do conhecimento para melhoria da assistência de enfermagem nos serviços de saúde faz-se rotineiramente e a adoção de novas tecnologias educacionais vem colaborar, de forma relevante, para educação permanente dos profissionais. Inúmeros assuntos pertinentes ao cuidado podem ser aprendidos e discutidos em ambientes virtuais, como, por exemplo, os eventos adversos. 0 presente estudo teve como objetivo desenvolver um ambiente virtual de aprendizagem (AVA) sobre gerenciamento em eventos adversos para educação permanente de enfermeiros, abordando as temáticas: úlcera por pressão, erros de medicação, flebite, queda e perda de sonda nasogastroenteral. O referencial pedagógico foi fundamentado nos estudos de Gagné (1980) que considera que o processo de aprendizagem é baseado na teoria de processamento de informação e constitui-se em oito fases (fase de motivação, de apreensão, de aquisição, de retenção, de rememoração, de generalização, de desempenho e de feedback). A metodologia, uma pesquisa aplicada, utilizou o Modelo de desenvolvimento de programas de Instrução Auxiliada pelo Computador (Computer Assisted Instruction - CAI) proposto por Price (1991), composto de três estágios: 1. planejamento inicial; 2 . planejamento e desenvolvimento do conteúdo instrucional; 3. avaliação e revisão. No estágio 1 foi caracterizado o público alvo, escolhido o tema abordado, bem como definidos os objetivos educacionais, os recursos disponíveis, o design instrucional e as técnicas de modelagem. 0 desenvolvimento do conteúdo (estágio 2) foi realizado em Módulos, estes constituídos das seguintes estruturas: Identificação do Módulo, Objetivos de Aprendizagem, Conteúdos, Exercícios, Referências e Textos de Apoio. A avaliação técnica e revisão do conteúdo inserido no AVA desenvolvido (estágio 3) será realizado por especialistas da área de informática e enfermagem em estudo futuro. O AVA foi desenvolvido na linguagem HTML (Hyper Text Makep Language) utilizando o programa Microsoft Office Word $2003^{\circledR}$. Os exercícios de avaliação inseridos em cada módulo foram criados pela autora deste estudo com a utilização do programa Hot Potatoes versão 6.0 para Windows. Conclui-se que a metodologia adotada na construção do AVA foi adequada para o alcance do objetivo proposto. Como metas futuras, a autora desse estudo avaliará o produto desenvolvido e verificará a possibilidade de seu uso nos serviços de enfermagem, contribuindo com a educação permanente dos enfermeiros. O AVA sobre gerenciamento em eventos adversos nos serviços de enfermagem está disponível para acesso no endereço eletrônico: <http://www.eerp.usp.br/nepien/eventosadversos>.

Palavras-Chaves: Enfermagem. Ambiente Virtual de Aprendizagem. Eventos Adversos. Ensino a distância. Software educacional. 


\begin{abstract}
XELEGATI, R. Development of a learning virtual environment on management in adverse events in nursing services. 2010. 90p. Thesis (Master's) - University of São Paulo at Ribeirão Preto College of Nursing, University of São Paulo, Ribeirão Preto, 2010.
\end{abstract}

The search for knowledge to improve nursing care in health services occurs on a routinely basis and the adoption of new educational technologies collaborates, in a relevant way, for professionals' permanent education. Countless subjects pertaining to care can be learned and discussed in virtual environments, such as adverse events. The present study aimed to develop a virtual learning environment (VLE) on management in adverse events for nurses' permanent education, addressing the themes: pressure ulcer, medication errors, phlebitis, fall and loss of nasogastroenteral feeding. The pedagogical framework was grounded in Gagné's (1980) studies, which considers that the learning process is based on the theory of information processing and consists of eight phases (phase of motivation, apprehension, acquisition, retention, remembering, generalization, performance and feedback). This applied research used the Model of development of Computer Assisted Instruction (CAI) programs proposed by Price (1991), consisting of three stages: 1. initial planning; 2. planning and development of instruction content; 3 . assessment and review. At stage 1 , target public was characterized, theme approached was chosen, and the educational objects, available resources, instructional design and modeling techniques were defined. The content development (stage 2) was carried out in Modules, comprised of the following structures: Identification of the Module, Learning objectives, Contents, Exercises, References and Support Texts. The technical assessment and review of the content inserted in the developed virtual learning environment (stage 3) will be carried out by informatics and nursing experts in a future study. The VLE was developed in HTML (Hypertext Makeup Language) using the program Microsoft Office Word $2003^{\circledR}$. The evaluation exercises inserted in each module were created by the study author using the program Hot Potatoes version 6.0 for Windows. It is concluded that the methodology used in the construction of the VLE was appropriate for achieving the proposed objectives. As future aims, the author will assess the developed product and verify the possibility of using it in nursing services, contributing for nurses' permanent education. The VLE on management in adverse events in nursing services is available at the URL: <http://www.eerp.usp.br/nepien/eventosadversos > .

Keywords: Nursing. Virtual Learning Environment. Adverse Events. Distance Teaching. Educational Software. 


\section{RESUMEN}

XELEGATI, R. Desarrollo de un ambiente virtual de aprendizaje sobre gerenciamiento en eventos adversos en los servicios de enfermería. 2010. 90h. Disertación (Maestría) - Escuela de Enfermería de Ribeirão Preto, Universidad de São Paulo, Ribeirão Preto, 2010.

La búsqueda de conocimiento para la mejoría de la atención de enfermería en los servicios de salud se hace rutineramente, y la adopción de nuevas tecnologías educacionales colabora, de forma relevante, para la educación permanente de los profesionales. Innúmeros asuntos pertinentes al cuidado pueden ser aprendidos y discutidos en ambientes virtuales, como los eventos adversos, por ejemplo. El presente estudio tuvo como objetivo desarrollar un ambiente virtual de aprendizaje (AVA) sobre gerenciamiento en eventos adversos para educación permanente de enfermeros, aproximando las temáticas: úlcera por presión, errores de medicación, flebitis, queda y pérdida de sonda nasogastroenteral. El referencial pedagógico fue fundamentado en los estudios de Gagné (1980), que considera que el proceso de aprendizaje es basado en la teoría de procesamiento de información y se constituye en ocho fases (fase de motivación, de aprehensión, de adquisición, de retención, de rememoración, de generalización, de desempeño y de feedback). La investigación aplicada utilizó el modelo de desarrollo de programas de Instrucción Auxiliada por la Computadora (Computer Assisted Instruction - CAI) propuesto por Price (1991), compuesto de tres etapas: 1. planificación inicial; 2. planificación y desarrollo del contenido de instrucción; 3. evaluación y revisión. En la etapa 1 fue caracterizado el público objetivo, escogido el tema aproximado, y definidos los objetivos educacionales, los recursos disponibles, el delineamiento de instrucción y las técnicas de modelaje. El desarrollo del contenido (etapa 2) fue realizado en Módulos, constituidos de las siguientes estructuras: Identificación del Módulo, Objetivos de Aprendizaje, Contenidos, Ejercicios, Referencias y Textos de Apoyo. La evaluación técnica y revisión del contenido inserido en el ambiente virtual de aprendizaje desarrollado (etapa 3) será realizado por especialistas del área de informática y enfermería, en estudio futuro. El AVA fue desarrollado en el lenguaje HTML (Hypertext Makeup Language), utilizando el programa Microsoft Office Word $2003^{\circledR}$. Los ejercicios de evaluación insertados en cada módulo fueron creados por la autora con la utilización del programa Hot Potatoes versión 6.0 para Windows. Se concluye que la metodología adoptada en la construcción del AVA fue adecuada para el alcance del objetivo propuesto. Como metas futuras, la autora evaluará el producto desarrollado y verificará la posibilidad de su uso en los servicios de enfermería, contribuyendo con la educación permanente de los enfermeros. El AVA sobre gerenciamiento en eventos adversos en los servicios de enfermería está disponible para acceso en la dirección electrónica: <http://www.eerp.usp.br/nepien/eventosadversos>.

Palabras Clave: Enfermería. Ambiente Virtual de Aprendizaje. Eventos Adversos. Enseñanza a distancia. Software educacional. 


\section{LISTA DE ILUSTRAÇÕES}

Figura 1. Fases de um ato de aprendizagem e os processos associados com as mesmas. Fonte: Gagné (1980)................... 39

Figura 2. Tela Inicial do programa Hot Potatoes........................ 45

Figura 3. Tela de criação do exercício do tipo JCross do programa Hot Potatoes................................................... 46

Figura 4. Tela de criação do exercício do tipo JQuiz do programa Hot Potatoes.....................................................

Figura 5. Estrutura de navegação do ambiente virtual de aprendizagem (AVA) sobre "Gerenciamento em Eventos Adversos nos Serviços de Enfermagem". Ribeirão Preto, 2010

Figura 6. Tela de acesso ao conteúdo do AVA sobre "Gerenciamento em Eventos Adversos nos Serviços de Enfermagem". Ribeirão Preto, 2010.

Figura 7. Tela de acesso a Apresentação do AVA sobre "Gerenciamento em Eventos Adversos nos Serviços de Enfermagem". Ribeirão Preto, 2010

Figura 8. Tela de acesso ao Módulo 1 - Úlcera por Pressão do AVA sobre "Gerenciamento em Eventos Adversos nos Serviços de Enfermagem". Ribeirão Preto, 2010

Figura 9. Tela de acesso ao Módulo 2 - Erros de Medicação do AVA sobre "Gerenciamento em Eventos Adversos nos Serviços de Enfermagem". Ribeirão Preto, 2010.

Figura 10. Tela de acesso ao Módulo 3 - Flebite do AVA sobre "Gerenciamento em Eventos Adversos nos Serviços de Enfermagem". Ribeirão Preto, 2010

Figura 11. Tela de acesso ao Módulo 4 - Queda do AVA sobre "Gerenciamento em Eventos Adversos nos Serviços de Enfermagem". Ribeirão Preto, 2010...........................

Figura 12. Tela de acesso ao Módulo 5 - Perda de Sonda Nasogastroenteral do AVA sobre "Gerenciamento em Eventos Adversos nos Serviços de Enfermagem". Ribeirão Preto, 2010 
Figura 13. Tela de acesso ao link Objetivos do Módulo 1 - Úlcera por Pressão do AVA sobre "Gerenciamento em Eventos Adversos nos Serviços de Enfermagem". Ribeirão Preto, 2010.......... 65

Figura 14. Tela de acesso ao link Definição do Módulo 2 - Erros de Medicação do Menu Principal do AVA sobre "Gerenciamento em Eventos Adversos nos Serviços de Enfermagem".

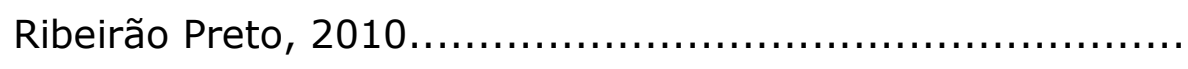

Figura 15. Tela de acesso ao link Fatores de Risco do Módulo 1 - Úlcera por Pressão do AVA sobre "Gerenciamento em Eventos Adversos nos Serviços de Enfermagem". Ribeirão Preto, 2010....

Figura 16. Tela de acesso ao link Incidência do Módulo 3 - Flebite do AVA sobre "Gerenciamento em Eventos Adversos nos Serviços de Enfermagem". Ribeirão Preto, 2010................

Figura 17. Tela de acesso ao link Fórmula para Cálculo do Módulo 3 Flebite do AVA sobre "Gerenciamento em Eventos Adversos nos Serviços de Enfermagem". Ribeirão Preto, 2010............

Figura 18. Tela de acesso ao link Exercícios - Palavras Cruzadas do Módulo 5 - Perda de Sonda Nasogastroenteral do AVA sobre "Gerenciamento em Eventos Adversos nos Serviços de

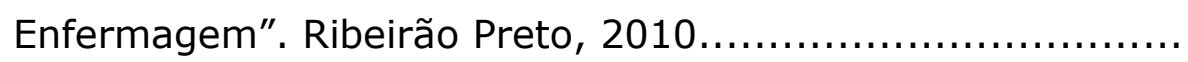

Figura 19. Tela de acesso ao link Exercícios - Múltipla Escolha do Módulo 5 - Perda de Sonda Nasogastroenteral do AVA sobre "Gerenciamento em Eventos Adversos nos Serviços de

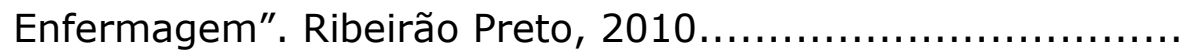

Figura 20. Tela de acesso ao link Referências do Módulo 4 - Queda do AVA sobre "Gerenciamento em Eventos Adversos nos Serviços de Enfermagem". Ribeirão Preto, 2010............. 70

Figura 21. Tela de acesso ao link Textos de Apoio do Módulo 4 - Queda do AVA sobre "Gerenciamento em Eventos Adversos nos Serviços de Enfermagem". Ribeirão Preto, 2010.................

Figura 22. Tela de acesso ao link Estágios do Módulo 1 - Úlcera por Pressão do AVA sobre "Gerenciamento em Eventos Adversos nos Serviços de Enfermagem". Ribeirão Preto, 2010............ 
Figura 23. Tela de acesso ao link Estágio III do Módulo 1 - Úlcera por Pressão do AVA sobre "Gerenciamento em Eventos Adversos nos Serviços de Enfermagem". Ribeirão Preto, 2010............ 71

Figura 24. Tela de acesso ao link Ilustrações do Estágio III do Módulo 1 Úlcera por Pressão do AVA sobre "Gerenciamento em Eventos Adversos nos Serviços de Enfermagem". Ribeirão Preto, 2010.....

Figura 25. Tela de acesso ao link Classificação do Módulo 3 - Flebite do AVA sobre "Gerenciamento em Eventos Adversos nos Serviços de Enfermagem". Ribeirão Preto, 2010..................

Figura 26. Tela de acesso ao link Graduação do Módulo 3 - Flebite do AVA sobre "Gerenciamento em Eventos Adversos nos Serviços de Enfermagem". Ribeirão Preto, 2010................ 73

Figura 27. Tela de acesso ao Vídeo inserido ao Módulo 3 - Erros de Medicação do AVA sobre "Gerenciamento em Eventos Adversos nos Serviços de Enfermagem". Ribeirão Preto, 2010. (Fonte: <www.youtube.com>) 


\section{SUMÁRIO}

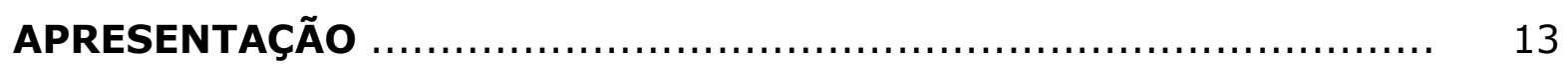

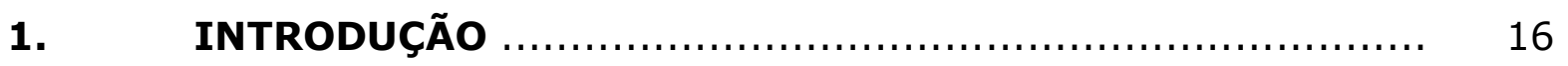

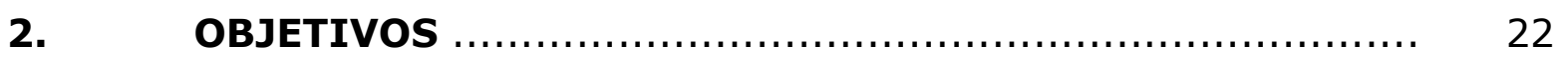

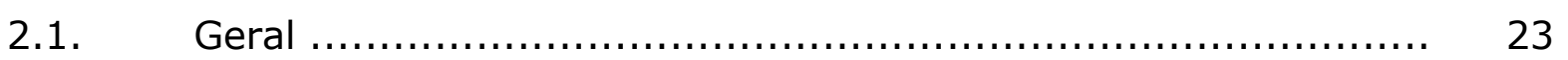

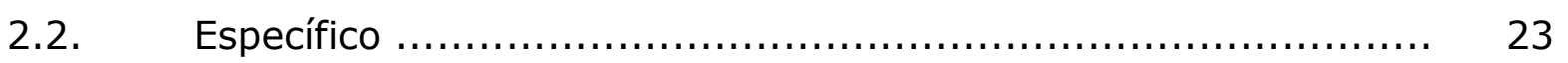

3. REVISÃO DA LITERATURA …................................. 24

3.1. Ambiente Virtual de Aprendizagem (AVA) ......................... 25

3.2. Eventos Adversos ................................................ 26

3.2.1. Úlcera por Pressão ................................................... 28

3.2.2. Erros de Medicação ..................................................... 30

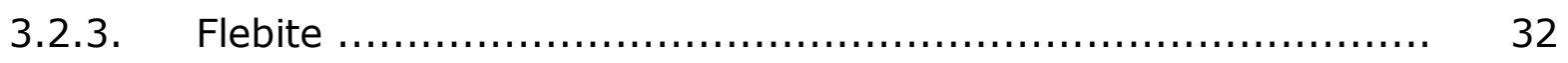

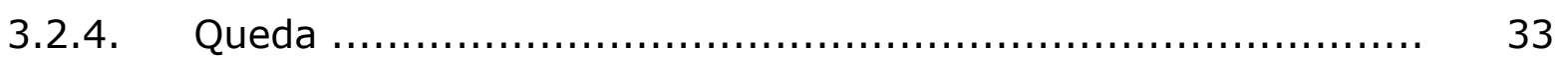

3.2.5. Perda de Sonda Nasogastroenteral ................................. 35

4. REFERENCIAL PEDAGÓGICO ............................... 37

5. PROCEDIMENTOS METODOLÓGICOS .......................... 41

5.1. Desenvolvimento do Ambiente Virtual de Aprendizagem (AVA)... 42

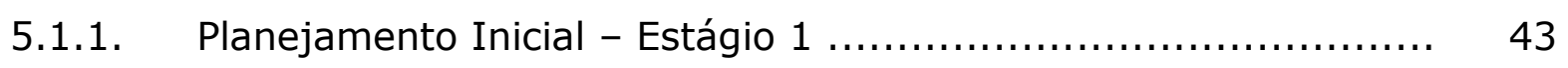

5.1.2. Planejamento e Desenvolvimento do Conteúdo Instrucional - 47 Estágio 2

5.1.3. Avaliação e Revisão - Estágio 3 ...................................... 57

6. RESULTADOS E DISCUSSÃO …............................. 58

6.1. Desenvolvimento do Diagrama de Navegação para o Usuário e 59 Exposição do Conteúdo.

6.2. Diretrizes para a Interface do Ambiente Virtual de 74 Aprendizagem (AVA) e Contextualização com a Área de Enfermagem.

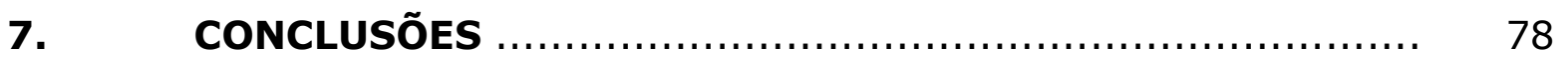

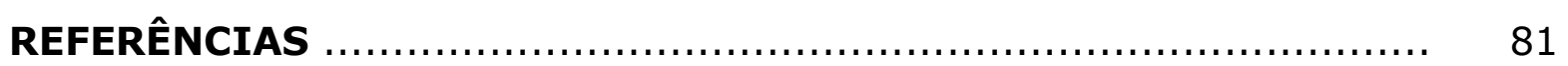


Apresentaçãa 
Minha experiência profissional iniciou-se em janeiro de 2002, quando recém-formada pela Escola de Enfermagem de Ribeirão Preto da Universidade de São Paulo, fui contratada pelo Hospital São Francisco de Ribeirão Preto (de caráter privado). Nesta instituição tive minhas primeiras vivências enquanto enfermeira $e$, pude amadurecer e crescer muito profissionalmente. No ano de 2003, fui transferida para o Centro de Terapia Intensiva deste hospital e, diante deste desafio, especializei-me na assistência ao paciente crítico (através da PósGraduação Lato Sensu em Enfermagem em Terapia Intensiva pela Pontifícia Universidade Católica de Campinas - PUC, concluída em 2004). Nesta unidade de cuidado intensivo atuei nos campos da assistência, gerenciamento e educação permanente em serviço.

Por se tratar de uma instituição de saúde com selo de qualidade da ISO (International Organization for Standardization), tive minha primeira aproximação com os indicadores da qualidade de um serviço hospitalar, surgindo então o interesse de entender os indicadores diretamente ligados à assistência de enfermagem.

Posteriormente, no ano de 2008, comecei a trabalhar no Hospital das Clínicas da Faculdade de Medicina de Ribeirão Preto da Universidade de São Paulo (de caráter público), e pude conhecer o processo de implementação de outro programa de certificação de qualidade chamado CQH (Compromisso com a Qualidade Hospitalar).

Enquanto enfermeira deparava-me com dúvidas em relação ao evento adverso que deveria ser considerado um indicador de qualidade, que fatores de risco deveriam ser atentados para prevenir a ocorrência desse evento, como notificar este evento e como calcular a incidência desse problema em potencial do serviço de enfermagem em que eu estava inserida.

Da mesma forma como eu apresentava dúvidas sobre eventos adversos na enfermagem, constatei que meus colegas de profissão também indagavam sobre essa questão, e diante disso acreditei que a construção de um material educativo sobre tal temática poderia estar contribuindo com os profissionais da minha área. 
Neste período, eu já estava cursando as disciplinas da Pós-Graduação Stricto Sensu no Programa de Pós-Graduação em Enfermagem Fundamental da Escola de Enfermagem de Ribeirão Preto.

Como proposta de investigação, optei pela disponibilização de um material educativo on line, em que o profissional de enfermagem pudesse estar acessando em qualquer local e horário, quantas vezes fosse necessário, para aprimorar seu conhecimento e auxiliar em eventuais dúvidas.

Nesta perspectiva, a finalidade deste estudo foi desenvolver um ambiente virtual de aprendizagem mediado pela Internet sobre eventos adversos que podem ocorrer na assistência de enfermagem, e desta maneira colaborar com a educação permanente de enfermeiros dos serviços de saúde. 
1. Intraduçãa 
Diante do desenvolvimento acelerado da informática no mundo atual, a aplicação rotineira desta tecnologia tende a ser utilizada em todas as áreas de conhecimento, inclusive na saúde e na educação. Estas por sua vez, estão sofrendo mudanças crescentes em virtude do processo de informatização global vigente.

O ensino presencial começa a ceder espaço para o ensino a distância. O professor deixa de ser apenas um transmissor de conhecimento, passando a direcionar o caminho para a aprendizagem, e o aluno torna-se um elemento participativo dentro deste processo, sendo respeitado sua individualidade e ritmo de aprendizado.

O ensino tradicional, em que o professor transmite e o aluno recebe os conhecimentos, está mudando. O professor instiga 0 aluno a realizar interrogações, experimentações, testes e reflexões sobre a temática em questão; e o aluno passa a participar ativamente do processo de ensino-aprendizagem por meio da construção e desenvolvimento contínuo de ações e questionamentos com adição da criatividade, desta forma adquirindo a responsabilidade de buscar e alcançar resultados (SEIXAS; MENDES, 2006).

Sabe-se que a modalidade de educação a distância não é uma inovação, sendo anteriormente empregada através dos meios de comunicação, tais quais: material impresso via correio, rádio, televisão, vídeos, entre outros. Leite (2000) relata que a inovação é caracterizada pela possibilidade de utilização de novos ambientes de aprendizagem, com bases de informação e recursos interativos, que transpõem limites temporais e geográficos por meio da rede mundial de computadores (Internet). Atualmente, as ferramentas da Internet, a tele e videoconferência, os softwares específicos e a incorporação da rede de satélites viabilizam a inclusão de diversos meios de comunicação (gráficos, áudio, vídeos, e outros), potencializando os efeitos educativos.

A partir da década de 1920, emprega-se o termo "tecnologia educacional" para especificar os conhecimentos científicos aplicados com efeitos educativos. Já a partir da década de 1980, nota-se o advento de novas tecnologias que acabaram contribuindo ainda mais efetivamente com o processo de ensinoaprendizagem. Gradualmente, formas de comunicação direcionadas a educação, 
como o ensino por correspondência, evoluíram para ambientes virtuais (VIANA, 2005).

Segundo Viana (2005), esses ambientes virtuais de aprendizagem (AVA) são compreendidos como espaços na Internet que viabilizam a interatividade entre alunos / professores / recursos de interação, disponibilizando diversos métodos de aprendizagem.

A Internet apresenta um alto nível de conectividade que possibilita oportunidades de acesso rápido e compartilhamento de informações. Os sites de busca, correio eletrônico, acesso à base de dados, fóruns, videoconferências e homepages exemplificam alguns dos recursos disponíveis nesta rede. Verifica-se que à distância entre centros educacionais e pesquisadores é minimizado, possibilitando um maior intercâmbio e desenvolvimento de estudos (ÉVORA, 2004).

A educação a distância também se beneficiou sobremaneira com esta otimização de recursos trazidas pela Internet. Novaes (2005) acredita que a criação de sites destinados ao ensino a distância na área de enfermagem proporcionou a capacitação profissional e a educação continuada dos profissionais e docentes.

O ensino e as pesquisas na área de Enfermagem têm procurado adequarse aos avanços da educação e da tecnologia. O emprego das tecnologias de informação, direcionadas à assistência ou cuidado dos pacientes e à educação dos profissionais de enfermagem, desde 1992 recebe a denominação de informática em enfermagem (HANNAH; SHAMIAN, 1992).

Já a informática em saúde pode ser definida como a área do saber que trata das aplicações e utilização de ferramentas de automação, processamento de dados e informações, nos vários segmentos de atividades relacionadas à saúde do indivíduo e da coletividade (BRASIL, 1988).

Segundo Dal Sasso e Barbosa (2000), o avanço da tecnologia na área da saúde tem mostrado a necessidade de uma busca intensa de atualização por parte dos profissionais. Os recursos tecnológicos utilizados na informática em saúde têm constituído um alicerce indispensável para o acesso rápido às 
informações, tanto para construção como para a atualização do conhecimento em enfermagem.

Diante do enorme crescimento na demanda por habilidades e conhecimentos especializados em enfermagem, existe uma tendência de um maior uso de tecnologias médicas sofisticadas. Além disso, a carência de profissionais com experiência suficiente em novas áreas de conhecimento está, também, influenciando a modelagem da educação em enfermagem nas últimas décadas (MOTTA, 2000).

Adequando-se as novas metodologias de educação e acompanhando as tecnologias vigentes, os enfermeiros têm pesquisado e desenvolvido cursos a distância, web site, software educacionais, AVA, entre outros.

De acordo com Évora (2000), o software pode ser uma ferramenta a mais para que o enfermeiro possa dinamizar suas ações, disponibilizando meios para aplicar seu conhecimento técnico-científico na assistência de enfermagem em detrimento de atividades administrativas.

Diogo (2001) desenvolveu um site sobre intervenção de enfermagem na aspiração de secreções traqueobrônquicas e Mitushima (2004) sobre monitorização hemodinâmica (o uso do cateter de Swan-Ganz). Fonseca, Witaker e Marin (2006) desenvolveram um web site educacional em Primeiros Socorros para alunos da área da saúde e público leigo. Alves et al. (2006) criaram um web site para enfermeiros sobre pé diabético.

Ribeiro e Lopes (2006) disponibilizaram um curso a distância sobre o tratamento de feridas para enfermeiros do município de Campinas e Telles Filho (2006) sobre a administração de medicamentos, utilizando uma plataforma aberta denominada de TelEduc.

Fonseca (2007) elaborou um CD-ROM sobre semiotécnica e semiologia de recém-nascido pré-termo e Évora et al. (2008) desenvolveram um software sobre o ensino da administração aplicada a enfermagem hospitalar.

Visualizam-se inúmeras evidências de que a informática vem revolucionando os processos de cuidado, de gerência e de ensino dentro das estruturas dos serviços de enfermagem em outros países (ÉVORA; DALRI, 2002), 
porém no Brasil, essas iniciativas de incorporação de novas tecnologias no ensino de enfermagem ainda são escassas.

A busca do conhecimento para melhoria da assistência de enfermagem nos serviços de saúde faz-se rotineiramente e a adoção de novas tecnologias educacionais colaboraria, de forma relevante, para educação permanente dos profissionais. Inúmeros assuntos pertinentes ao cuidado poderiam ser aprendidos e discutidos em ambientes virtuais, tal como os eventos adversos.

Segundo Gallotti (2004), os eventos adversos são definidos como complicações indesejadas decorrentes do cuidado prestado aos pacientes e não atribuídas à evolução natural de uma doença. Esses eventos afetam em média $10 \%$ das admissões hospitalares e constituem, atualmente, um dos maiores desafios para o aprimoramento da qualidade na área da saúde.

A idade dos pacientes, a gravidade do quadro clínico inicial, a existência de comorbidades, a duração e a intensidade do cuidado prestado, a fragmentação da atenção à saúde, a inexperiência de jovens profissionais envolvidos na assistência, a sobrecarga de trabalho dos profissionais e as falhas de comunicação são alguns dos fatores de risco para a ocorrência de eventos adversos. A presença desses eventos deve ser interpretada como decorrente de falências nos complexos sistemas técnicos e organizacionais relacionados à atenção à saúde e não como resultado de ações isoladas praticadas por profissionais incompetentes (GALLOTTI, 2004).

Murff et al. (2003) relataram que as pesquisas sobre segurança do paciente têm se voltado para a elaboração de metodologia para a detecção de eventos adversos utilizando meios eletrônicos. Mendes et al. (2005) também destacam a importância do desenvolvimento de programas eletrônicos de fácil execução para serem incorporados à rotina dos serviços de saúde, entretanto complementam que as metodologias que empregam dados disponíveis em meio eletrônico ainda não são factíveis de aplicação na maior parte dos países, inclusive no Brasil.

Diante do exposto, surgiram as seguintes questões para o norteamento do estudo: 
- O desenvolvimento de um AVA sobre gerenciamento em eventos adversos poderá contribuir para a conscientização dos profissionais de enfermagem em relação aos tipos de eventos, fatores de risco, classificação e incidência?

- A utilização de novas tecnologias educacionais, como um AVA, poderá colaborar com o serviço de educação permanente de enfermagem em relação à prevenção de ocorrência de eventos adversos? 
2. Objetivas 
O presente estudo teve como objetivos:

\subsection{GERAL}

- Desenvolver um ambiente virtual de aprendizagem (AVA) sobre gerenciamento em eventos adversos para a educação permanente de enfermeiros inseridos em serviços de saúde.

\subsection{ESPECÍfICO}

- Planejar e organizar o conteúdo programático do AVA sobre gerenciamento em eventos adversos na assistência de enfermagem. 
3. Reuisãa da Literatura 


\subsection{AMBIENTE VIRTUAL DE APRENDIZAGEM (AVA)}

Os primeiros projetos de construção de AVA destinados à educação iniciaram-se em meados da década de 1990, após uma significativa mudança na Internet, devido a dois acontecimentos: a criação do primeiro navegador para a web; e a Internet deixou de ser apenas uma rede acadêmica. A web tornou-se um espaço, cada vez mais comum, como recurso auxiliar nos cursos de graduação e pós-graduação, além de ser importante instrumento para o oferecimento de cursos a distância. Respondendo a essa demanda, foi construída, com as tecnologias disponíveis para a web, uma quantidade expressiva de ambientes informatizados, direcionados às atividades de educação e treinamento (FRANCO; CORDEIRO; CASTILHO, 2003).

Os AVA são sistemas computacionais disponíveis na Internet, destinados ao suporte de atividades mediadas pelas tecnologias de informação e comunicação. Esses ambientes permitem a integração de múltiplas mídias, linguagens e recursos, a apresentação de informações de maneira organizada, o desenvolvimento de interações entre pessoas e objetos de conhecimento e a elaboração e socialização de produções. As atividades se desenvolvem no tempo, ritmo de trabalho e espaço em que cada participante se localiza, de acordo com uma intencionalidade (ALMEIDA, 2003).

Segundo o mesmo autor, os recursos dos AVA propiciam a gestão da informação segundo critérios preestabelecidos de organização definidos de acordo com as características de cada software. Possuem bancos de informações representadas em diferentes mídias (como textos, imagens, vídeos, hipertextos), e interligadas com conexões constituídas de links internos ou externos ao sistema.

Almeida (2003) destaca que a leitura de um texto não linear (hipertexto) na tela do computador está baseada em indexações, conexões entre idéias e conceitos articulados por meio de links (nós e ligações) que conectam informações representadas em diferentes linguagens e formas tais como palavras, páginas, imagens, animações, gráficos, sons, vídeos, dentre outros. 
Dessa maneira, ao clicar sobre uma palavra, imagem ou frase definida como um nó de um hipertexto depara-se com uma nova situação, evento ou outros textos relacionados. Portanto, cada nó pode ser um ponto de partida ou de chegada, originando outras redes e conexões, sem que exista um nó fundamental.

A representação de informações em hipertextos com o uso de distintas mídias e linguagens permite o rompimento com as seqüências estáticas e lineares de caminho único, com início, meio e fim fixados previamente. 0 hipertexto disponibiliza um leque de possibilidades de informações que permitem ao leitor interligar as informações segundo seus interesses e necessidades, navegando e construindo suas próprias seqüências e rotas. Ao saltar entre as informações e estabelecer suas próprias ligações e associações, o leitor interage com o hipertexto e pode assumir um papel mais ativo do que na leitura de um texto do espaço linear do material impresso (ALMEIDA, 2003).

O uso de hipertextos na área de enfermagem tem um imenso potencial para profissionais que trabalham no cuidado direto ao paciente, podendo ser empregado como um meio rápido de acesso às informações clínicas e orientações sobre a assistência de enfermagem (CAETANO; PERES, 2007).

Segundo Dias e Cassiani (2003), o desenvolvimento de materiais a serem disponibilizados na Internet, em AVA para o ensino de enfermagem, vem ocupar um espaço importante e contribuir na formação de um profissional com competências compatíveis com a cultura tecnológica presente na área da saúde e em plena expansão.

Diante do exposto, a utilização de AVA configura uma nova possibilidade educacional que pode ser explorada pelos profissionais de enfermagem, seja no ensino em universidades como na educação permanente em serviço.

\subsection{EVENTOS ADVERSOS}

Os eventos adversos são definidos como uma lesão (injury) não intencional que resulte em incapacidade (disability) temporária ou permanente 
e/ou prolongamento do tempo de permanência ou morte como consequência de um cuidado de saúde prestado (LEAPE et al., 1991; MENDES et al., 2005).

Kohn, Corrigan e Donaldson (2000) também definem eventos adversos como agravos decorrentes de intervenções realizadas por profissionais de saúde e não relacionadas a condições intrínsecas do paciente, enfatizando que nem todos os eventos adversos estão coligados a erros humanos. É estimado que cerca de 100 mil norte-americanos morram em hospitais a cada ano vítimas de eventos adversos. Essa alta incidência resulta em uma taxa de mortalidade maior do que as atribuídas aos pacientes com Síndrome da Imunodeficiência Adquirida (AIDS), câncer de mama ou atropelamentos.

Mendes et al. (2005) realizaram uma revisão sistemática de estudos baseados na revisão retrospectiva de prontuários que avaliaram a ocorrência de eventos adversos no conjunto de ações dos hospitais. Os estudos inseridos nesta revisão foram realizados nos Estados Unidos, Austrália, Nova Zelândia, Reino Unido, França, Dinamarca e Canadá. Foi constatado que a incidência de eventos adversos variou de $2,9 \%$ a $16,6 \%$.

Nascimento et al. (2008), em um estudo de abordagem quantitativa, descritivo, retrospectivo e do tipo transversal, caracterizaram os eventos adversos ocorridos em pacientes adultos durante a internação em unidade de terapia intensiva, semi-intensiva e enfermaria de um hospital terciário e privado do município de São Paulo. Esse estudo também calculou a taxa de ocorrência de eventos, sendo constatado o predomínio de eventos relacionados à sonda nasogástrica $(57,6 \%)$ seguido pelas quedas $(16,6 \%)$ e erros de medicação $(14,8 \%)$.

No Brasil, a magnitude do problema que envolve a ocorrência de eventos adversos e suas consequências ainda é pouco investigada, mesmo existindo a iniciativa da Agência Nacional de Vigilância Sanitária (ANVISA) em notificar eventos adversos decorrentes de medicamentos (Farmocovigilância), de hemoterapia (Hemovigilância) e de equipamentos e artigos médico-hospitares (Tecnovigilância) (BRASIL, 2010).

A análise dos eventos adversos é uma ferramenta fundamental para apontar a qualidade do cuidado de enfermagem prestado e, atualmente está 
sendo utilizada como indicador de resultados da assistência por organizações como: CQH (Compromisso com a Qualidade Hospitalar), ONA (Organização Nacional de Acreditação) e JCAHO (Joint Commission on Accreditation of Healthcare Organizations).

O presente estudo optou pelo desenvolvimento de um AVA sobre gerenciamento em eventos adversos na assistência de enfermagem nas temáticas: úlcera por pressão, erros de medicação, flebite, queda e perda de sonda nasogastroenteral. Vale destacar que esses tipos de eventos podem ocorrer em qualquer setor e instituição de saúde. Neste momento, descartaramse eventos ocorridos em unidades específicas, como a extubação acidental em Unidades de Terapia Intensiva, lesão perioperatória no Centro Cirúrgico, entre outros.

\subsection{1. ÚlCERA POR PRESSÃO}

A úlcera por pressão é uma lesão localizada na pele e/ou no tecido ou estrutura subjacente, geralmente sobre uma proeminência óssea, resultante da pressão isolada ou de pressão combinada com fricção e/ou cisalhamento (NPUAP, 2007).

As úlceras por pressão são causadas por fatores intrínsecos e extrínsecos ao paciente, sendo os extrínsecos: a imobilidade, a pressão, o cisalhamento, a fricção e a umidade, e os intrínsecos: a idade, o estado nutricional, a perfusão tecidual, o uso de alguns medicamentos e as doenças crônicas como o diabetes mellitus e doenças cardiovasculares (FERREIRA; CALIL, 2001; FERNANDES; CALIRI, 2008).

Segundo a National Pressure Ulcer Advisory Panel - NPUAP (2007), as úlceras por pressão podem ser classificadas em estágios, sendo eles:

- Suspeita de Lesão Tissular Profunda: Área localizada de pele intacta de coloração púrpura, castanha ou bolha sanguinolenta devido a dano no tecido mole, decorrente de pressão e/ou cisalhamento. Esta área pode ser precedida 
por um tecido que se apresenta dolorido, endurecido, amolecido, espanjoso e mais quente ou frio comparativamente ao tecido adjacente.

- Estágio I: Pele intacta com hiperemia de uma área localizada que não embranquece, geralmente sobre proeminência óssea. A pele de cor escura pode não apresentar embranquecimento visível: sua cor pode diferir de pele ao redor.

- Estágio II: Perda parcial da espessura dérmica. Apresenta-se como úlcera superficial com o leito de coloração vermelho pálida, sem esfacelo. Pode apresentar-se ainda como uma bolha (preenchida com exsudato seroso), intacta ou rompida.

- Estágio III: Perda do tecido em sua espessura total. O tecido subcutâneo pode ser visível, sem exposição óssea, de tendões ou de músculos. Pode ser detectados descolamentos e túneis ("lojas"). O esfacelo pode estar presente sem prejudicar a identificação da profundidade da perda tissular.

- Estágio IV: Ocorre a perda total de tecido com exposição de osso, músculo ou tendão. Pode ser detectados descolamentos e túneis ("lojas") com frequência. Esfacelo ou escara pode estar presente em algumas áreas do leito da ferida.

- Úlceras que não podem ser classificadas: Lesão com perda total de tecido, na qual a base da úlcera está coberta por esfacelo e/ou escara.

Quanto à incidência de úlceras por pressão, o estudo de Rogenski e Santos (2005), que foi desenvolvido no Hospital Universitário da Universidade de São Paulo, apontou que dentre 211 pacientes de risco, 84 desenvolveram 134 úlceras por pressão, representando uma incidência global de 39,8\%. A incidência variou conforme a unidade pesquisada, apresentando a Clínica Médica o maior índice, seguindo-se a Unidade de Terapia Intensiva, a Clínica Cirúrgica e a Unidade de Cuidados Semi-Intensivo.

Peterlini e Pereira (2006) apontam que o desenvolvimento das úlceras por pressão, como eventos adversos, estão relacionados à avaliação incorreta da integralidade física e do estado nutricional do paciente, a falta de planejamento no cuidado de prevenção, a mobilização ineficaz do paciente acamado e o uso incorreto de dispositivos próprios para profilaxia dessas úlceras. 


\subsubsection{ERROS DE MEDICAÇÃO}

Um erro de medicação é caracterizado por qualquer evento evitável que pode causar ou induzir a utilização inadequada de um medicamento ou prejudicar o paciente, enquanto a medicação está sob o controle de um profissional de saúde, paciente ou consumidor. Esses eventos podem estar relacionados com a prática profissional, produtos, procedimentos e sistemas de atendimento a saúde, englobando prescrição, comunicação, rótulos, embalagem e nomenclatura do produto, assim como composição, preparo, distribuição, administração, educação, monitorização e utilização do mesmo (National Coordinating Council for Medication Error Reporting and Prevention - NCC-MERP, 1998).

Kohn, Corrigan e Donaldson (2000) definem os eventos adversos com medicamentos como danos ou prejuízos causados ao paciente decorrentes do uso de medicamentos, entretanto, nem todos esses eventos são atribuídos a erros. Tais autores exemplificam que uma reação alérgica medicamentosa apresentada pelo paciente e até então desconhecida pode ser classificada com evento adverso, porém, se o paciente apresentar uma reação a um medicamento ao qual consta na sua história prévia ser alérgico, deve ser considerado como um erro.

Os fatores de risco desencadeantes de erros de medicação podem ser: ilegibilidade, uso de abreviaturas, ordens verbais e informações incompletas nas prescrições médicas; ausência de padronização da nomenclatura de medicamentos nas instituições; deficiências da formação acadêmica e inexperiência dos profissionais; negligência, desatenção ou desatualização quanto aos avanços tecnológicos e científicos (como no manejo de equipamentos e durante procedimentos) e falhas do sistema de medicação como um todo. Portanto, os eventos adversos relacionados a erros de medicação devem ser analisados no âmbito do sistema e não apenas com enfoque no indivíduo (SILVA; CASSIANI, 2004). 
Segundo a American Association of Hospital Pharmacists - ASHP (1993) e Rodrigues (2004), os erros de medicação podem ser classificados em:

- Erros de Prescrição: ocorre pela seleção incorreta do medicamento (baseada na indicação, contra-indicação, alergias conhecidas previamente, etc); pela dose, velocidade de infusão e instruções de uso inadequadas feitas pelo médico; e devido à prescrição ilegível que possa induzir ao erro.

- Erros de Omissão: decorrentes da ausência da administração de uma dose de medicamento prescrita para o paciente.

- Erros de Horário: acontece quando o medicamento é administrado fora do intervalo de tempo pré-definido no prontuário do paciente.

- Erros de Administração de Medicamento Não Autorizado: ocorre devido à administração de medicamento não autorizado pelo médico responsável pelo paciente.

- Erros de Dose: acontece pela administração de uma dose maior ou menor que a prescrita ou administração de doses duplicadas ao paciente.

- Erros de Apresentação: decorrente da administração de um medicamento a um paciente em apresentação diferente da prescrita pelo médico.

- Erros de Preparo: ocorre quando o medicamento é formulado ou manipulado incorretamente antes da administração.

- Erros da Técnica de Administração: acontece devido ao uso de procedimentos inapropriados ou técnicas inadequadas na administração da medicação.

- Erros com Medicamentos Deteriorados: decorrente da administração de medicamentos com data de validade expirada / vencida ou quando a integridade física ou química está comprometida.

- Erros de Monitoramento: ocorre em virtude da falha em rever um esquema medicamentoso prescrito para a devida adequação ou detecção de problemas, ou falha em utilizar apropriadamente dados clínicos ou laboratoriais para avaliar a resposta do paciente à terapia prescrita. 
- Erros em Razão da Aderência do Paciente: se dá através do comportamento inadequado do paciente quanto a sua participação na proposta terapêutica.

- Outros Erros: quaisquer outros erros não enquadrados nos demais tipos.

Os erros ocorrem em todas as fases do sistema de medicação, sendo que $39 \%$ ocorrem durante a prescrição, $12 \%$ na transcrição, $11 \%$ na dispensação e $38 \%$ durante a administração. Os enfermeiros e os farmacêuticos interceptam $86 \%$ dos erros de medicação relacionados as etapas de prescrição, transcrição e dispensação, enquanto apenas $2 \%$ são interceptados pelos pacientes. Em contrapartida, não há nenhuma rede de segurança para os enfermeiros quando os medicamentos são administrados aos pacientes (LEAPE et al., 1995).

\subsubsection{FLEBITE}

A flebite é definida como um processo inflamatório da parede endotelial vascular (íntima venosa), que é caracterizada por rubor e calor locais, edema, formação de cordão fibroso palpável ao longo do trajeto venoso e dor, podendo ser classificada quanto à origem e apresentar graus de intensidade variáveis e progressivos (PHILLIPS, 2001; MACKLIN, 2003).

De acordo com Phillips (2001), os fatores que influenciam o desenvolvimento de uma flebite são: a técnica de inserção; a condição do paciente; a condição da veia; a compatibilidade, tipo e $\mathrm{pH}$ de medicamentos ou soluções infundidas; e filtração inefetiva, calibre, comprimento e material do cateter.

Phillips (2001) e Macklin (2003) classificam uma flebite, quanto a sua origem e sinais clínicos, em:

- Flebite Mecânica: ocorre quando a veia sofre irritação em decorrência de um esforço mecânico relacionado à inadequada fixação do cateter ou dispositivo, punção inapropriada, calibre inadequado do cateter em relação ao lúmen do vaso 
e/ou tipo de material utilizado na confecção do cateter. O sinal diferencial apresentado é de um eritema concentrado no sítio de inserção do cateter e ao longo de sua extensão.

- Flebite Química: acontece quando uma solução infundida lesa a túnica íntima da veia em decorrência de extremos de $\mathrm{pH}$ e osmolaridade, medicações diluídas ou misturadas inapropriadamente, presença de partículas de droga não totalmente dissolvidas durante a diluição, velocidade rápida de infusão e/ou administração de drogas vesicantes ou irritantes. O sinal diferencial observado é de um eritema visível acima da extremidade do cateter e ao longo do trajeto venoso.

- Flebite Bacteriana: ocorre uma inflamação da parede interna da veia associada com infecção bacteriana em decorrência de técnica asséptica inadequada, técnica de inserção do cateter inadequada, falha na detecção de quebras na integridade de dispositivos, fixação ineficaz do cateter, falha na realização de avaliação dos locais e/ou contaminação de soluções infundidas. Os sinais diferenciados apresentados são intenso calor local ao toque e presença de exsudato no sítio de inserção. Pode ocorrer sinais sistêmicos como febre, calafrios e tremores (bacteremia), e evolução para um quadro séptico grave.

- Flebite Pós-Punção: decorrente de uma inflamação da veia que usualmente torna-se evidente em 24 a 96 horas após a retirada do cateter, relacionada à técnica de inserção do cateter, condição da veia utilizada, tipo, compatibilidade e o pH da solução ou medicações infundidas, calibre, tamanho, comprimento e material do cateter e/ou tempo de permanência do cateter. 0 sinal diferenciado observado é formação do cordão fibroso ao longo do trajeto venoso.

Segundo a Intravenous Nurses Society (2000), a taxa aceitável de flebite em uma dada população de pacientes deve ser $5 \%$ ou menos.

\subsubsection{QUEDA}

A queda é definida como um deslocamento não-intencional do corpo para um nível inferior à posição inicial, com incapacidade de correção em tempo hábil, 
determinado por circunstâncias multifatoriais que comprometem a estabilidade. (TINETTI; SPEECHELEY; GINTER, 1988; SOCIEDADE BRASILEIRA DE GERIATRIA E GERONTOLOGIA, 2001).

As quedas em pacientes hospitalizados ocorrem dentro do quarto, durante transferência da cama, cadeira ou cadeira de rodas em mais de $70 \%$ dos casos e, na deambulação, durante o trajeto de ida e volta ao banheiro, em $19 \%$ dos eventos (ROHDE; MYERS; VLAHOV, 1990; RUBENSTEIN; POWERS; MACLEAN, 2001).

Idade menor que cinco anos ou maior que 65 anos, alterações do nível de consciência, síncope e hipotensão postural, incontinência vesical e/ou intestinal, déficits sensoriais, déficit motor e distúrbios músculo-esqueléticos, distúrbios do equilíbrio, uso de medicamentos (sedativos, antidepressivos, benzodiazepínicos, anti-hipertensivos, etc), patologias osteomioarticulares, neurológicas e cardiovasculares e história de queda anterior são fatores de risco intrínsecos para queda (SOCIEDADE BRASILEIRA DE GERIATRIA E GERONTOLOGIA, 2001; CQH, 2006; DICCINI, PINHO e SILVA, 2008).

Como fatores de risco extrínsecos para quedas têm-se: iluminação inadequada, superfícies escorregadias, tapetes soltos ou com dobras, degraus altos ou estreitos, obstáculos no caminho (como mobiliários), ausência de corrimãos em corredores e banheiros, ausência de grades de proteção na cama ou grades abaixadas, altura da cama elevada; campainhas fora do alcance do paciente, calçados inadequados, roupas excessivamente compridas, entre outros (SOCIEDADE BRASILEIRA DE GERIATRIA E GERONTOLOGIA, 2001; DICCINI, PINHO e SILVA, 2008).

Segundo Rohde, Myers e Vlahov (1990), 23\% das quedas em pacientes hospitalizados resultam em lesões, sendo que $83 \%$ das lesões são abrasões, lacerações e contusões e $9 \%$ são fraturas.

Paiva et al. (2010), analisaram Boletins de Notificação de Eventos Adversos, preenchidos por profissionais da saúde de um hospital universitário terciário durante 30 meses e encontraram o registro do evento queda em 80 boletins $(10,7 \%)$, o que implicou uma média de 2,6 quedas por mês. O mesmo 
estudo também calculou o índice de queda por paciente-dia, obtendo o valor de 0,302 por 1000 .

Quanto à caracterização das quedas, o estudo de Paiva et al. (2010) identificou como mais freqüentes as quedas do leito $(55 \%)$, seguidas pelas quedas da própria altura $(38,8 \%)$ e quedas a partir de cadeiras $(6,2 \%)$. As quedas do leito foram mais freqüentes nas enfermarias de neurologia $(22,7 \%)$, clínica médica $(20,4 \%)$ e moléstias infecciosas e parasitárias $(18,2 \%)$. As quedas da própria altura ocorreram mais na clínica médica $(38,7 \%)$ e cirurgia gastroenterológica (12,9\%).

A queda de pacientes hospitalizados pode ter como conseqüência o aumento no tempo de internação e no custo do tratamento, além de causar desconforto ao doente e ocasionar ceticismo em relação à assistência de enfermagem (MARIN; BOURIE; SAFRAN, 2000).

\subsubsection{PERDA DE SONDA NASOGASTROENTERAL}

A perda de sonda nasogastroenteral é um evento adverso que compreende a saída não programada ou acidental, o deslocamento ou a obstrução da sonda para alimentação (CQH, 2006; POTTER; PERRY, 2009). Existem inúmeras situações nos serviços de saúde que predispõem a perda de uma sonda nasogastroenteral, sendo estas:

- Agitação motora, uso de drogas sedativas, confusão mental, distúrbio neurológico, ocorrência de tosse ou vômito do próprio paciente;

- Manipulação inadequada do paciente durante troca de curativo, banho ou higiene, mudança de decúbito e transporte intra ou extra-hospitalar;

- Fixação inadequada ou incorreta da sonda sob o nariz e/ou região frontal;

- Administração de medicamentos macerados e pouco diluídos pela sonda; 
- Sedimentação de drogas no lúmen da sonda devido a incompatibilidade de fármacos;

- Administração de soluções enterais espessas e/ou diminuição do fluxo da nutrição enteral pela bomba infusora;

- Irrigação inadequada ou ausente da sonda após infusão de dietas ou administração de medicamentos macerados;

- Deterioração do produto da sonda (mudança da cor e coloração).

Nascimento et al. (2008) identificaram o predomínio do evento adverso perda de sonda nasogastroenteral em pacientes adultos internados $(57,6 \%)$ em unidade de terapia intensiva, semi-intensiva ou enfermaria de um hospital terciário e privado do município de São Paulo. 
4. Referencial Pedagágica 
O referencial pedagógico desta pesquisa está fundamentado nos estudos de Gagné (1980). Para tal estudioso, o processo de aprendizagem é baseado na teoria de processamento de informação, ou seja, o indivíduo aprende mediante tratamentos sucessivos de informações, incluindo as transformações da informação na mente. Segundo essa teoria, os processos que precisam ser compreendidos para explicar o fenômeno da aprendizagem, são aqueles que realizam determinados tipos de transformações de "insumos", estimulação proveniente do ambiente do aluno, para "exsumos", modificação de comportamento que é observado como desempenho humano, numa forma um tanto análoga às operações de um computador.

A função de ensinar origina-se a partir da determinação das condições de aprendizagem. Os meios para o ensino constituem os recursos de aprendizagem que, quando utilizados, são geralmente organizados de forma especial, constituindo uma modalidade de ensino (GAGNÉ, 1980). Estas são escolhidas com o propósito de criar condições adequadas à aprendizagem.

Na concepção de Gagné (1980) existem oito fases de aprendizagem, a seguir: fase de motivação, de apreensão, de aquisição, de retenção, de rememoração, de generalização, de desempenho e de feedback. Essas fases podem não ser observadas facilmente sob circunstâncias comuns e cada uma delas está associada a um processo interno operativo (Figura 1). 


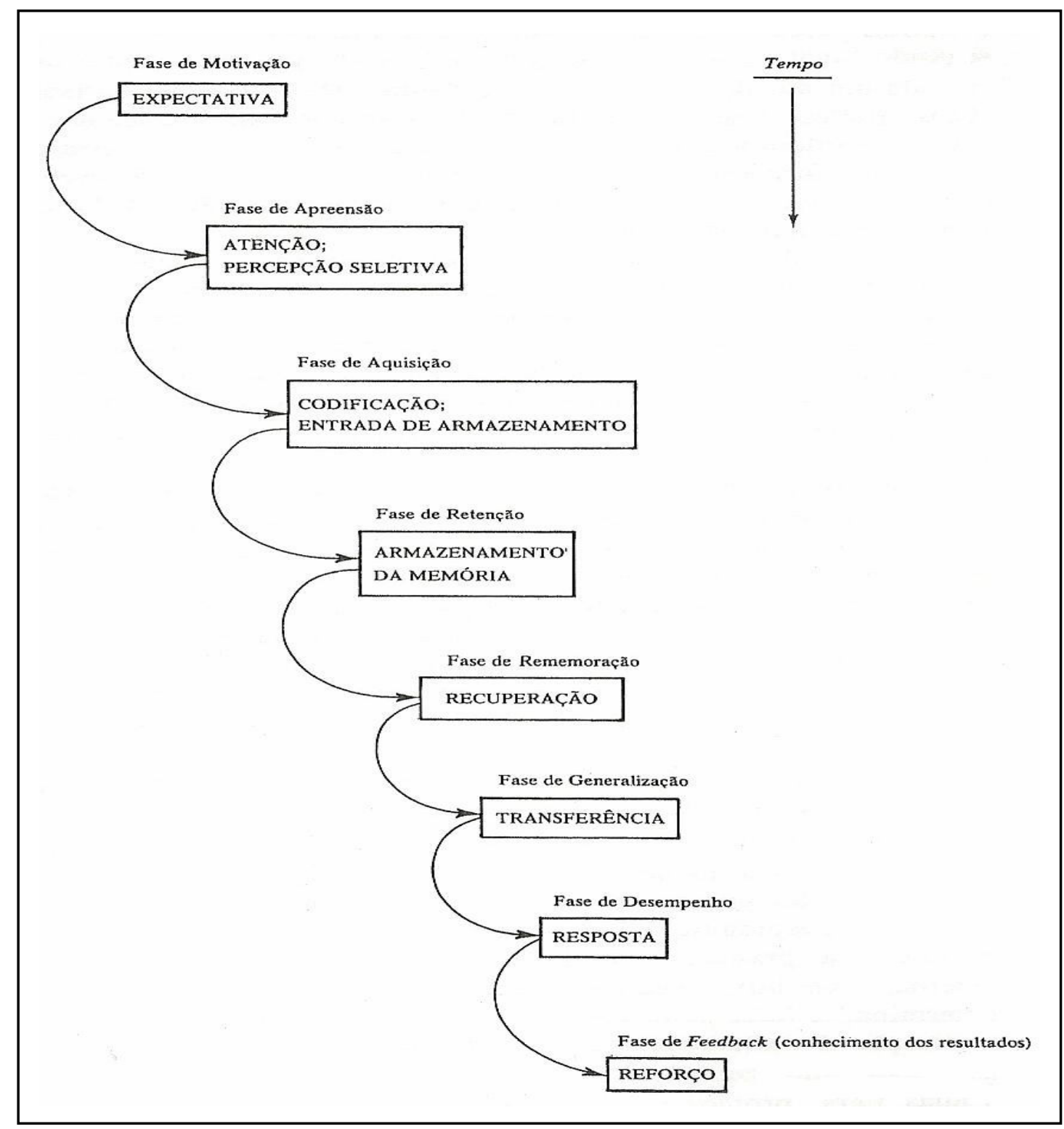

Figura 1. Fases de um ato de aprendizagem e os processos associados com as mesmas. (Fonte: Gagné, 1980).

A fase de motivação pode ser estabelecida por meio do desenvolvimento no aluno, da expectativa, que é uma antecipação da recompensa que ele obterá quando atingir um objetivo (GAGNÉ, 1980).

Na fase de apreensão, o estudante deve prestar atenção às partes de estimulação que são relevantes ao seu propósito de aprendizagem. O estado de atenção, segundo Gagné (1980), pode ser entendido como um estado interno temporário chamado conjuntos mentais que, quando estabelecido, opera como um tipo de processo de controle executivo. A atenção pode ser ativada por 
estimulação externa e persistir por um determinado período de tempo, alertando a pessoa para receber certos tipos de estimulação.

O momento no tempo em que o conceito recém-formado entra na memória de breve-duração, para ser mais tarde adicionalmente transformada em um "estado persistente", na memória de longa duração, ocorre na fase de aquisição (GAGNÉ, 1980). Nesta fase, acontece a codificação, que é a transformação do conceito percebido em uma forma que é mais facilmente armazenada.

Para o autor acima mencionado, nas fases de retenção e rememoração, o recurso para orientar a aprendizagem deve ser selecionado visando auxiliar o aluno a armazenar na memória e relembrar o que está aprendendo. O autor acrescenta ainda, que para intensificar a retenção e a recuperação do que foi aprendido, o aluno deve fazer revisões espaçadas do conteúdo estudado.

Na fase de generalização é utilizada a transferência da aprendizagem para promover uma nova aprendizagem dentro de um conteúdo (transferência no sentido vertical), sendo primordial que a aprendizagem antecedente seja suprida, tanto em termos de informação como de habilidades intelectuais. No caso da transferência de aprendizagem para outros campos de estudo ou para outra atividade, o apoio deve ser feito por meio de exemplos e situações variadas (GAGNÉ, 1980).

Ainda segundo o mesmo autor, na fase de desempenho ocorre a organização das respostas do aluno, permitindo-lhe exibir um desempenho que reflita o que foi aprendido. O desempenho possibilitado pelo ato da aprendizagem serve à relevante função de preparar o caminho para a retroalimentação (feedback). Este feedback ou reforço confirmará a expectativa estabelecida pelo aluno durante a fase de motivação, finalizando assim o processo de aprendizagem.

Cabe mencionar que com a utilização de programas educacionais por computador, os usuários podem voltar a qualquer momento para o tópico que quiserem recordar como também podem usar o ambiente virtual quantas vezes julgarem necessário, com a vantagem de poderem decidir quando e como utilizálo. A inclusão de exercícios nestes programas reforça o desempenho do aluno, devolvendo-Ihe um feedback dos conceitos aprendidos. 
5. Pracedimentas Metadalágicas 
Trata-se de uma pesquisa aplicada, que concentra seu foco na descoberta de uma problemática imediata e tem como objetivo final o planejamento científico de uma mudança induzida pela situação identificada (POLIT; BECK; HUNGER, 2004).

A pesquisa aplicada é definida por Santos e Parra (1998) como "a que objetiva a criação de novos produtos ou aumento da eficiência dos já existentes".

\subsection{DESENVOLVIMENTO DO AMBIENTE VIRTUAL DE APRENDIZAGEM (AVA)}

Segundo Falkembach (2005), a metodologia para o desenvolvimento de sistemas ou aplicações educacionais deve ser composta por um conjunto de normas, procedimentos, técnicas e ferramentas, definindo o padrão desejado para atender aos requisitos de padronização, flexibilidade, documentação, modularização e planejamento.

Dessa forma, o AVA foi construído utilizando-se o Modelo de três estágios para desenvolvimento de programas de Instrução Auxiliada pelo Computador (Computer Assisted Instruction - CAI) proposto por Price (1991): 1. planejamento inicial; 2. planejamento e desenvolvimento do conteúdo instrucional; 3. avaliação e revisão.

Os programas tipo CAI podem ser classificados nas categorias: Exercício e Prática, Tutorial e Simulação e Resolução de Problemas. O presente estudo optou pela categoria Tutorial como "livro interativo" de estrutura não-linear. Segundo Peres e Leite (2006), o tutorial utiliza técnicas de ramificação que permite ao usuário mover-se de um nível mais fácil de aprendizagem para um mais difícil e a estrutura de "livro interativo" não-linear dispõem de recursos como interação de hipertextos, vídeos, sons, imagens estáticas ou animações, entre outros.

Sendo assim, os estágios de desenvolvimento do AVA sobre gerenciamento em eventos adversos nos serviços de enfermagem foram: 


\subsubsection{PLANEJAMENTO INICIAL - ESTÁGIO 1}

Esta fase consistiu na base do projeto de desenvolvimento do AVA, onde foi caracterizado o público alvo, escolhido o tema a ser abordado, bem como foram definidos os objetivos educacionais, os recursos disponíveis, o design instrucional e as técnicas de modelagem.

\section{Caracterização da População Alvo}

O estudo foi desenvolvido para atender as necessidades de aprendizagem em educação permanente de enfermeiros inseridos em serviços de saúde.

\section{Formulação de Metas}

A meta primordial deste AVA é orientar os profissionais enfermeiros sobre o gerenciamento em eventos adversos nos serviços de saúde.

\section{Escolha do Tema}

O AVA oferece suporte teórico relativo ao ensino do gerenciamento em eventos adversos na assistência de enfermagem. Para a construção desse ambiente foram utilizados hipertextos e estratégias lúdicas no formato de módulos de trabalho, sendo propostos os seguintes temas:

I - ÚLCERA POR PRESSÃO;

II - ERROS DE MEDICAÇÃO;

III - FLEBITE;

IV - QUEDA;

V - PERDA DE SONDA NASOGASTROENTERAL. 


\section{Recursos Técnicos Necessários}

O conteúdo da apresentação e dos cinco módulos foi desenvolvido pela autora da pesquisa e formatado, inicialmente, no programa Microsoft Office PowerPoint $2003^{\circledR}$.

Com relação a recursos humanos, foi necessário o auxílio de um analista de sistemas para a elaboração do projeto gráfico, desenvolvimento da estrutura de navegação, construção do hipertexto, realização de testes e manutenção e montagem do material gráfico. O recurso financeiro para contratação dos serviços do analista de sistemas foi disponibilizado pela Fundação de Amparo a Pesquisa do Estado de São Paulo - FAPESP.

O AVA foi desenvolvido na linguagem HTML (Hyper Text Makep Language) utilizando-se o programa Microsoft Office Word $2003^{\circledR}$, uma vez que a linguagem é própria para desenvolvimento de websites. Para melhor visualização do ambiente, a configuração de vídeo da opção Painel de Controles deve estar na resolução máxima de tela.

Os exercícios de avaliação inseridos em cada módulo foram desenvolvidos pela autora do estudo com a utilização do programa Hot Potatoes versão 6.0 para Windows.

O programa Hot Potatoes é livre e encontra-se disponível para download no endereço eletrônico http://hotpot.uvic.ca/. Para a instalação do programa, existe a opção de interface em língua portuguesa (utilizada em Portugal), entretanto, não há abrangência deste idioma em todo o programa, sendo algumas orientações em língua inglesa, como por exemplo, o próprio tutorial. A Figura 2 apresenta a tela inicial do Hot Potatoes. 


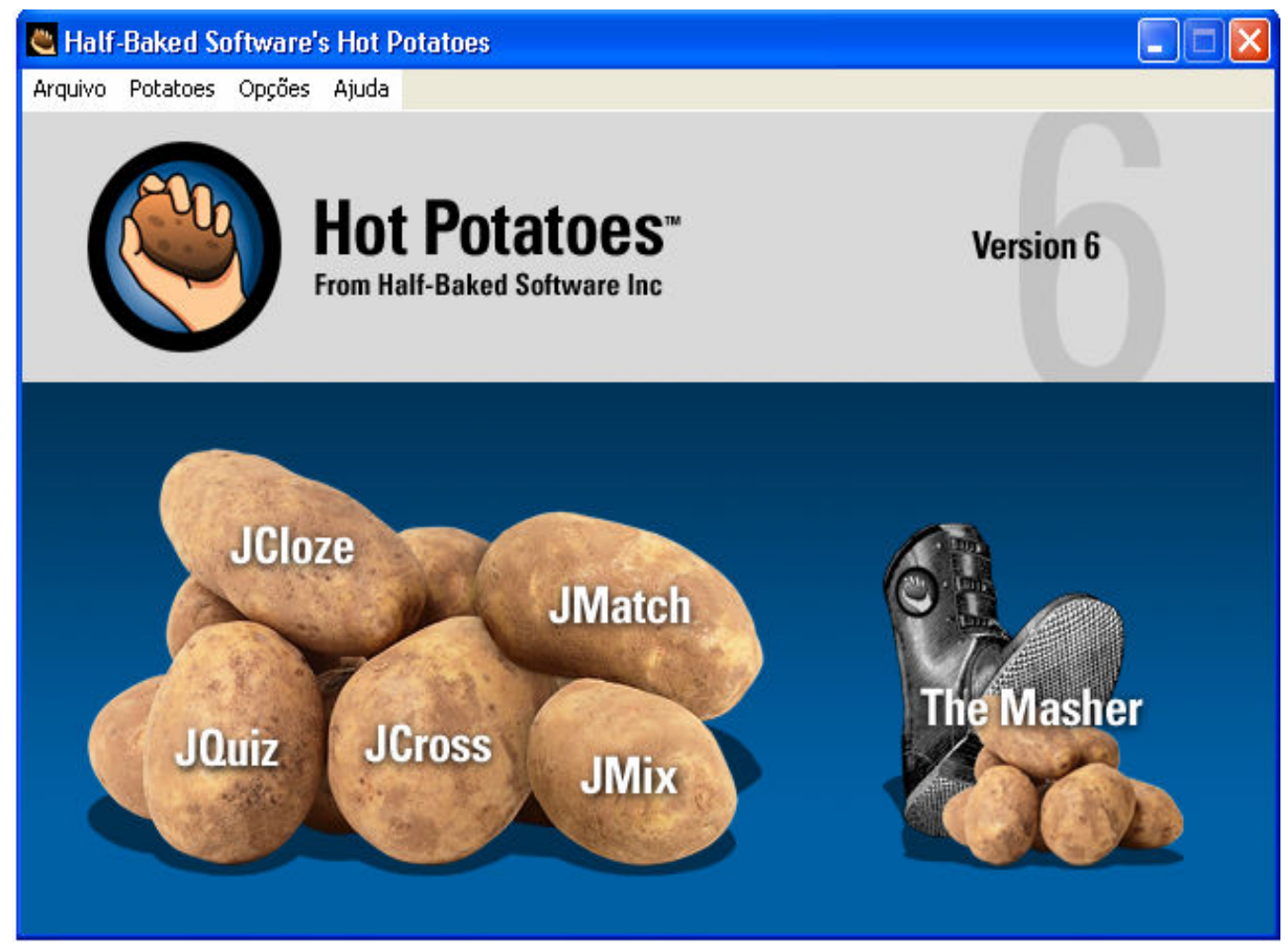

Figura 2. Tela inicial do programa Hot Potatoes.

O programa disponibiliza cinco tipos de exercícios que traduzindo significam: JCross - Palavras cruzadas, JQuiz - Teste de múltipla escolha, JMix Coloque a frase na ordem correta, JCloze - Preencha as lacunas e JMatch - Ache o par correto. No presente estudo, a pesquisadora desenvolveu um exercício no formato JCross e dois no formato JQuiz para cada módulo, disponibilizando aos usuários do ambiente virtual de aprendizagem um total de 15 exercícios de fixação.

Para criação de um exercício de Palavras-Cruzadas é preciso clicar na opção JCross na tela inicial do programa Hot Potatoes (Figura 2), para abrir a tela de montagem da grade das palavras cruzadas (Figura 3). Após introdução das palavras, clica-se o botão Juntar Pistas para abrir outra janela, onde são organizadas as pistas horizontais e verticais que nortearão o usuário a digitar a resposta correta. 


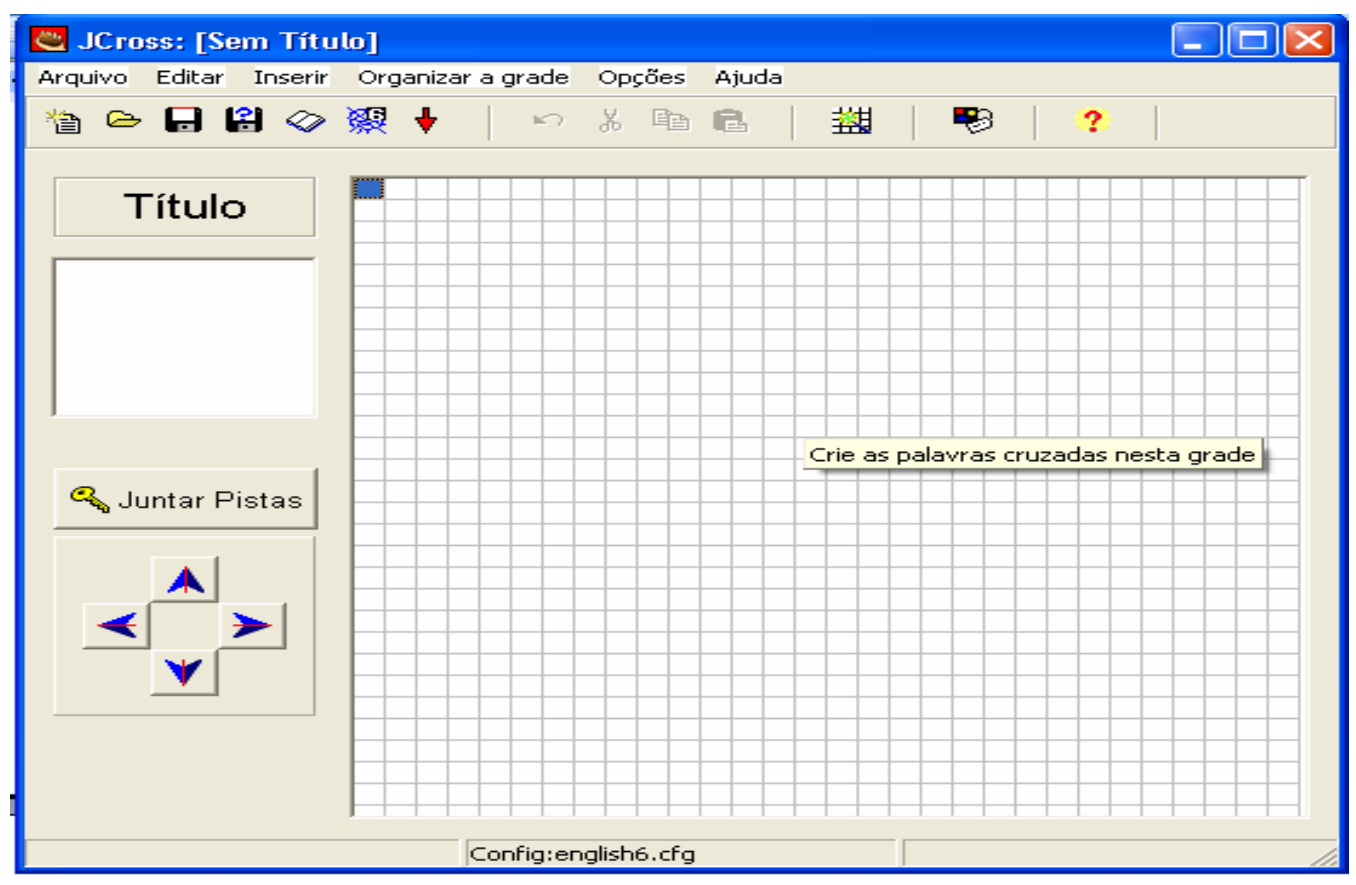

Figura 3. Tela de criação do exercício tipo JCross do programa Hot Potatoes.

Já para criação de um teste de Múltipla Escolha é preciso clicar na opção JQuiz na tela inicial do programa Hot Potatoes (Figura 2), para abrir a tela de montagem (Figura 4). Após, é introduzido o título, o enunciado e as opções de resposta do exercício.

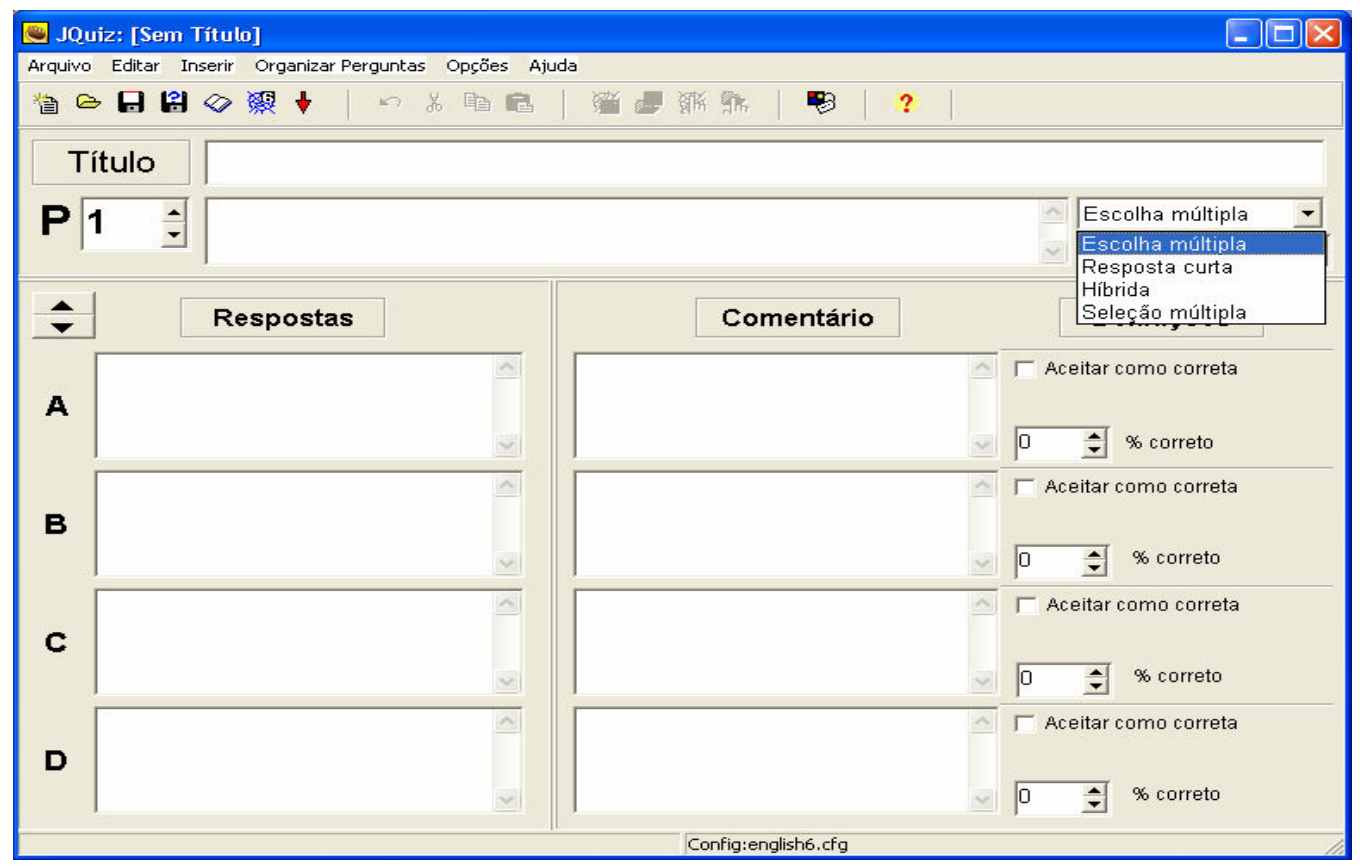

Figura 4. Tela de criação do exercício tipo JQuiz do programa Hot Potatoes. 
Para a configuração da interface dos exercícios é clicado o item Opções na barra de ferramentas e, a seguir, Configurar saída. Neste item é possível escolher o tamanho e tipo de letra, o aspecto visual da tela (como tipo e cores de fundo), os botões que aparecerão na tela de exercícios, as mensagens que serão exibidas com os acertos e erros do usuário e o tempo limite de resposta do exercício através do temporizador. Posteriormente, é clicado na Barra de Ferramentas, o menu Arquivo e em seguida Criar página da web.

\subsubsection{Planejamento e desenvolvimento do CONTEÚdo} INSTRUCIONAL - ESTÁGIO 2

\section{Organização do Conteúdo}

Após o levantamento dos objetivos dos módulos, procedeu-se a organização do conteúdo. Para tal foi realizada a reunião de material bibliográfico pertinente à temática, no sentido de organizá-lo em uma seqüência lógica para a apresentação do conteúdo de forma clara e abrangente.

Fizeram parte desse material o conteúdo de livros-textos, artigos científicos, figuras, sites, entre outros. De acordo com Freitas, Loyolla e Prates (2002), as imagens devem ser legendadas, os parágrafos e sentenças devem ser curtos, deve-se atentar para a credibilidade do texto com a utilização de fontes idôneas de citação e bibliografia e a utilização de passagem via hiperlinks deve ser estimulada ao final de cada tela.

O desenvolvimento do conteúdo foi realizado em Módulos, estes constituídos das seguintes estruturas: Identificação do Módulo, Objetivos de Aprendizagem, Conteúdos, Exercícios, Referências e Textos de Apoio.

Os Módulos apresentam os seguintes objetivos de aprendizagem, conteúdos, referências e textos de apoio: 


\section{MÓDULO I - ÚLCERA POR PRESSÃO}

Objetivos de aprendizagem:

- Compreender a definição e os fatores de risco desencadeantes das úlceras por pressão;

- Identificar os estágios de evolução de uma úlcera por pressão;

- Compreender o cálculo da incidência de úlcera por pressão que pode ser aplicado nos serviços de enfermagem.

\section{Conteúdos:}

- Definição, fatores de risco e estágios da úlcera por pressão;

- Definição e cálculo da incidência da úlcera por pressão.

Referências:

- NATIONAL PRESSURE ULCER ADVISORY PANEL (NPUAP). Pressure ulcer stages revised by NPUAP. February, 2007. Disponível em: <http://www.npuap.org>. Acesso em: 04/01/2010.

- PARANHOS, W.Y.; SANTOS, V.L.C.G. Avaliação do risco para úlceras de pressão por meio da Escala de Braden, na língua portuguesa. Revista da Escola de Enfermagem da USP, v.33, n.esp., p.191-206, 1999.

- PROgRAmA DE Qualidade hOSPITALAR (CQH). Manual de indicadores de enfermagem NAGEH. São Paulo: APM/CREMESP, 2006. 40p. Disponível em: <http://www.cqh.org.br/files/Manual\%20de\%20Indicadores\%20NAGEH\%20\%20V.FINAL.pdf>. Acesso em: 13/01/2010.

- SILVA, C.R.L.; SILVA, R.C.L.; VIANA, D.L. Compacto dicionário ilustrado de saúde. $4^{\circ}$ ed. Saõ Caetano do Sul (SP): Yendis Editora, 2009.

- uniVERsidAde de sÃo paUlo. escola de ENFERMAGEM de RiBeirÃo PRETO. CALIRI, M.H.L. Úlceras de pressão. Disponível em: 
<http://www.eerp.usp.br/projetos/ulcera>. Acesso em: 13 de janeiro de 2010.

- universidade de são paulo. escola de enfermagem de Ribeirão PRETO. CALIRI, M.H.L.; PIEPER, B.; CARDOZO, L.J. Úlceras de pressão. Disponível em: <http://www.eerp.usp.br/projetos/feridas/caupres.htm>. Acesso em: 13/01/2010.

\section{Textos de Apoio:}

- FERNANDES, L.M.; CALIRI, M.H.L.; HAAS, V.J. Efeito de intervenções educativas no conhecimento dos profissionais de enfermagem sobre prevenção de úlceras pressão. Acta paul. enferm. [online], v.21, n.2, p.305-311, $2008 . \quad$ Disponível em: <http://www.scielo.br/scielo.php?pid=S010321002008000200012\&script =sci_arttext\&tIng=pt $>$. Acesso em: 13/01/2010.

- FERNANDES, L.M.; CALIRI, M.H.L. Uso da escala de Braden e de glasgow para identificação do risco para úlceras de pressão em pacientes internados em centro de terapia intensiva. Revista Latino-Americana de Enfermagem [online], v.16, n.6, p.973-978, 2008. Disponível em: <http://www.scielo.br/scielo.php?script=sci_arttext\&pid=S010411692008 000600006\&lng=pt\&nrm=iso $>$. Acesso em: 13/01/2010.

- MEDEIROS, A.B.F.; LOPES, C.H.A.F.; JORGE, M.S.B. Análise da prevenção e tratamento das úlceras por pressão propostos por enfermeiros. Revista da Escola de Enfermagem da USP [online], v.43, n.1, p.223-228, 2009. Disponível em: <http://www.scielo.br/scielo.php?script=sci_arttext\&pid=S008062342009000100029\&Ing=en\&nrm=iso >. Acesso em: 13/01/2010.

- ROGENSKI, N.M.B.; SANTOS, V.L.C.G. Estudo sobre a incidência de úlceras por pressão em um hospital universitário. Revista LatinoAmericana de Enfermagem [online], v.13, n.4, p.474-480, 2005. Disponível em: <http://www.scielo.br/scielo.php?script=sci_arttext\&pid=S0104116920050 00400003\&lng=pt\&nrm=iso $>$. Acesso em: 13/01/2010. 


\section{MÓDULO II - ERROS DE MEDICAÇÃO}

Objetivos de aprendizagem:

- Compreender a definição e os fatores de risco desencadeantes dos erros de medicação, enfatizando os ligados a administração de medicamentos pelos profissionais de enfermagem;

- Identificar os "certos" na administração de medicamentos;

- Compreender o cálculo da incidência de erros ou não conformidades relacionados à administração de medicamentos pela enfermagem.

\section{Conteúdos:}

- Definição e tipos de erro de medicação;

- Erros na administração de medicamentos;

- Fatores de risco para ocorrência de erros de medicação;

- "Certos" na administração de medicamentos;

- Definição e cálculo da incidência de erros de medicação.

\section{Referências:}

- AMERICAN ASSOCIATION OF HOSPITAL PHARMACISTS (ASHP). Guidelines on preventing medication errors in hospitals. American Journal of Hospital Pharmacy, v.50, p. 305-314, 1993.

- NATIONAL COORDINATING COUNCIL FOR MEDICATION ERROR REPORTING AND PREVENTION (NCC-MERP), 1998. Disponível em: <http://www.nccmerp.org/>. Acesso em: 03/02/2010.

- PETERLINI, M.A.S. Incompatibilidade no preparo e administração de terapia intravenosa em crianças: associação entre fármacos, soluções e materiais dos cateteres e acessórios. Tese de Doutorado Universidade Federal de São Paulo (UNIFESP), 2003. 
- POTTER, P.; PERRY, A.G. Administração de Medicamentos. In: Fundamentos de enfermagem. 7aed. Rio de Janeiro: Elsevier, 2009. 1528p.

- PROGRAMA DE QUalidade hOSPITALAR (CQH). Manual de indicadores de enfermagem NAGEH. São Paulo: APM/CREMESP, 2006. 40p. Disponível em: <http://www.cqh.org.br/files/Manual\%20de\%20Indicadores\%20NAGEH\%20\%20V.FINAL.pdf>. Acesso em: 13/01/2010.

- SILVA, A. E. B. C.; CASSIANI, S. H. B. Administração de medicamentos: uma visão sistêmica para o desenvolvimento de medidas preventivas dos erros na medicação. Revista Eletrônica de Enfermagem, v. 06, n. 02, 2004. Disponível em: <http://www.fen.ufg.br/revista/revista6_2/administra.html>. Acesso em: 03/02/2004.

Textos de Apoio:

- CASSIANI, S.H.B. A segurança do paciente e o paradoxo no uso de medicamentos. Revista Brasileira de Enfermagem [online], v.58, n.1, p.95-99, 2005.2 Disponível em: <http://www.scielo.br/scielo.php?script=sci_arttext\&pid=S003471672005 000100019\&Ing=en\&nrm=iso $>$. Acesso em: 03/02/2010.

- PEdReirA, M.L.G.; PETERLINI, M.A.S.; HARADA, M.J.C.S. Erros de medicação: aspectos relativos à prática do enfermeiro. In: HARADA, M.J.C.S.; PEDREIRA, M.L.G.; PETERLINI, M.A.S.; PEREIRA, S.R. 0 erro humano e a segurança do paciente. $2^{\mathrm{a} e d . ~ S a ̃ o ~ P a u l o: ~ E d i t o r a ~ A t h e n e u, ~} 2006$.

- PEPPER, G. Pesquisas em segurança na administração de medicamentos. In: CASSIANI, S.H.B.; UETA, J. A segurança de pacientes na utilização da medicação. 1aed. São Paulo: Artes Médicas, 2004.

- SILVA, A.E.B.C.; CASSIANI, S.H.B. Erros de medicação em hospital universitário: tipo, causas, sugestões e providências. Revista Brasileira de Enfermagem [online], v.57, n.6, p.671-674, 2004. Disponível em: $<$ http://www.scielo.br/scielo.php?script=sci_arttext\&pid=S003471672004 $000600007 \&$ Ing $=e n \& n r m=i s o>$. Acesso em: 03/02/2010. 


\section{MÓDULO III - FLEBITE}

Objetivos de aprendizagem:

- Compreender a definição e os fatores de risco desencadeantes de flebite;

- Identificar a classificação e graduação de uma flebite;

- Compreender o cálculo da incidência de flebite nos serviços de saúde.

Conteúdos:

- Definição, fatores de risco, classificação e graduação da flebite;

- Definição e cálculo da incidência da flebite.

Referências:

- INTRAVENOUS NURSES SOCIETY. Infusion nursing standards of practice. Journal Intravenous Nursing, v.23, n.6, p.1-46, 2000.

- MACKLIN, D. Phlebitis: A painful complication of peripheral IV catheterization that may be prevented. American Journal of Nursing, v.103, n.2, p.55-60, feb. 2003.

- PHILLIPS, L. D. Complicações da Terapia Intravenosa. In: PHILLIPS, L. D. Manual de Terapia Intravenosa. Porto Alegre: Artmed, 2001. p. 236-268.

- PROgRAMA de QUalidade hospitalar (CQH). Manual de indicadores de enfermagem NAGEH. São Paulo: APM/CREMESP, 2006. 40p. Disponível em: <http://www.cqh.org.br/files/Manual\%20de\%20Indicadores\%20NAGEH\%20$\% 20 V . F I N A L . p d f>$. Acesso em: 13/01/2010.

- SILVA, C.R.L.; SILVA, R.C.L.; VIANA, D.L. Compacto dicionário ilustrado de saúde. $4^{\circ}$ ed. Saõ Caetano do Sul (SP): Yendis Editora, 2009.

- TAVARes, C.A.A. Orientações médicas - 0 que fazer em flebites superficiais? Disponível em: <http://drtavares.com/imagens/o-quefazer/6.jpg >. Acesso em: 09/02/2010. 
- universidade estadual do Oeste do PARANÁ. diAs, D.C. (Coordenação) Projeto Introdução à Terapia Intravenosa. Disponível em: $<$ http://www.unioeste.br/projetos/terapiaintravenosa/pdf/1.pdf>. Acesso em: 09/02/2010.

Textos de Apoio:

- FERNANDES, A.T.; RIBEIRO FILHO, N. Infecção do acesso vascular. In: FERNANDES, A.T.; FERNANDES, M.O.V.; RIBEIRO FILHO, N.; GRAZIANO, K.U.; GABRIELLONI, M.C.; CAVALCANTE, N.J.F.; LACERDA, R.A. (Editores). Infecção hospitalar e suas interfaces na área da saúde. São Paulo: Atheneu, 2000. p.556-79.

- MARTINHO, R.F.S.; RODRIGUES, A.B. Ocorrência de flebite em pacientes sob utilização de amiodarona endovenosa. Einstein, v.6, n.4, p.459-62, 2008. Disponível em: <http://apps.einstein.br/revista/arquivos/PDF/857Einsteinv6n4port459-462.pdf>. Acesso em: 04/02/2010.

- NETTO, P.S.; SECOLI, S.R. Flebite enquanto complicação local da terapia intravenosa: estudo de revisão. Revista Paulista de Enfermagem, v.23, n.3/4, p.254-9, 2004.

- PEREIRA, R.C.C.; ZANETTI, M.L.; RIBEIRO, K.P. Tempo de permanência do dispositivo venoso periférico, in situ, relacionado ao cuidado de enfermagem, em pacientes hospitalizados. Medicina (Ribeirão Preto), v.34, n.1, p.79-84, jan./mar. 2001. Disponível em: <http://www.fmrp.usp.br/revista/2001/vol34n1/tempo_permanencia.pdf> . Acesso em: 09/02/2010.

\section{MÓDULO IV - QUEDA}

\section{Objetivos de aprendizagem:}

- Compreender a definição e os fatores de risco intrínsecos / extrínsecos do evento queda;

- Conhecer a "Escala de Risco de Quedas de Downton"; 
- Compreender o cálculo da incidência de queda nos serviços de saúde.

Conteúdos:

- Definição, fatores de risco intrínsecos e extrínsecos de queda;

- Escala de Risco de Quedas de Downton;

- Definição e cálculo da incidência de quedas.

Referências:

- DICCINI, S.; PINHO, P.G.; SILVA, F.O. Avaliação de risco e incidência de queda em pacientes neurocirúrgicos. Revista Latino-Americana de Enfermagem, Ribeirão Preto, v. 16, n. 4, 2008. Disponível em: $<$ http://www.scielo.br/scielo.php?script=sci_arttext\&pid=S0104$11692008000400016 \&$ Ing=en\&nrm=iso $>$. Acesso em: 18/02/2010.

- DOWNTON, J.H. Escala de Riesgo de Caídas, 1993. In: CASTRO, A. M. et al. Protocolo de contención y prevención de caídas. Disponível em: <http://www.minsa.gob.ni/enfermeria/doc_inter/Protocolo_ca\%EDdas.pdf >. Acesso em: 20/02/2010.

- PROgRAMA De QUALidAde hOSPITALAR (CQH). Manual de indicadores de enfermagem NAGEH. São Paulo: APM/CREMESP, 2006. 40p. Disponível em: <http://www.cqh.org.br/files/Manual\%20de\%20Indicadores\%20NAGEH\%20\%20V.FINAL.pdf>. Acesso em: 13/01/2010.

- SOCIEDADE BRASileira DE GERIATRIA E GERONTOlOgia. PEREIRA, S.R.M.; BUKSMAN, S.; PERRACINI, M.; PY, L.; BARRETO, K.M.L.; LEITE, V.M.M. Quedas em Idosos. 2001. Disponível em: <http://www.projetodiretrizes.org.br/projeto_diretrizes/082.pdf>. Acesso em: 18/02/2010.

- TINETTI, M.E.; SPEECHELEY, M.; GINTER, S.F. Risk factors for falls among elderly persons living in the community. New England Journal of Medicine, v.319, n.26, p.1701-7, 1988.

Textos de Apoio: 
- BenedeTti, T.R.B.; BINOTTO, M.A.; PETROSKI, E.L.; GONÇALVES, L.H.T. Atividade física e prevalência de quedas em idosos residentes no sul do Brasil. Revista Brasileira de Geriatria e Gerontologia, v.11, n.2, Rio de Janeiro, $2008 . \quad$ Disponível em:

$<$ http://www.unati.uerj.br/tse/scielo.php?script=sci_arttext\&pid=S1809$98232008000200002 \&$ lng=pt\&nrm=iso $>$. Acesso em: 18/10/2010.

- MACHADO, T.R.; OliveirA, C.J.; COSTA, F.B.C.; ARAUJO, T.L. Avaliação da presença de risco para queda em idosos. Revista Eletrônica de Enfermagem, n.11, n.1, p.32-38, 2009. Disponível em: <http://www.fen.ufg.br/revista/v11/n1/v11n1a04.htm>. Acesso em: $18 / 02 / 2010$.

- MARIN, H.F.; BOURIE, P.; SAFRAN, C. Desenvolvimento de um sistema de alerta para prevenção de quedas em pacientes hospitalizados. Revista Latino-Americana de Enfermagem, Ribeirão Preto, v.8, n.3, 2000. Disponível em: <http://www.scielo.br/scielo.php?script=sci_arttext\&pid=S0104$11692000000300005 \&$ Ing=en\&nrm=iso $>$. Acesso em: 18/02/2010.

- MOREIRA, M.D.; COSTA, A.R.; CALDAS, C.P. Variáveis associadas à ocorrência de quedas a partir dos diagnósticos de enfermagem em idosos atendidos ambulatorialmente. Revista Latino-Americana de Enfermagem, Ribeirão Preto, v.15, n.2, 2007. Disponível em: <http://www.scielo.br/scielo.php?script=sci_arttext\&pid=S0104$11692007000200018 \&$ Ing=en\&nrm=iso $>$. Acesso em: 18/02/2010.

\section{MÓDULO V - PERDA DE SONDA NASOGASTROENTERAL}

\section{Objetivos de aprendizagem:}

- Compreender a definição e os fatores de risco do evento perda de sonda nasogastroenteral;

- Compreender o cálculo da incidência de perda de sonda nasogastroenteral nos serviços de saúde. 


\section{Conteúdos:}

- Definição e fatores de risco de perda de sonda nasogastroenteral;

- Definição e cálculo da incidência de perda de sonda nasogastroenteral.

Referências:

- POTTER, P.; PERRY, A.G. Nutrição. In: Fundamentos de enfermagem. 7aed. Rio de Janeiro: Elsevier, 2009. 1528p.

- $\quad$ PROgRAma de Qualidade hOSPITALAR (CQH). Manual de indicadores de enfermagem NAGEH. São Paulo: APM/CREMESP, 2006. 40p. Disponível em: <http://www.cqh.org.br/files/Manual\%20de\%20Indicadores\%20NAGEH\%20\%20V.FINAL.pdf>. Acesso em: 13/01/2010.

- SILVA, C.R.L.; SILVA, R.C.L.; VIANA, D.L. Compacto dicionário ilustrado de saúde. $4^{\circ}$ ed. Saõ Caetano do Sul (SP): Yendis Editora, 2009.

Textos de Apoio:

- HEYDRICH, J.; HEINECK, I.; BUENO, D. Observation of preparation and administration of drugs by nursing assistants in patients with enteral feeding tube. Brazilian Journal of Pharmaceutical Sciences, São Paulo, v.45, n.1, 2009. Disponível em: $<$ http://www.scielo.br/scielo.php?script=sci_arttext\&pid=S198482502009 $000100014 \&$ Ing=en\&nrm=iso $>$. Acesso em: 22/03/2010.

- MATSUBA, C.S.T. Obstrução de sondas nasoenterais em pacientes cardiopatas. Dissertação de Mestrado - Universidade Federal de São Paulo (Escola Paulista de Medicina - Curso de Enfermagem), 2003.

- UNAMUNO, M.R.D.L.; MARCHINI, J.S. Sonda nasogástrica/nasoentérica: cuidados na instalação, na administração da dieta e prevenção de complicações. Medicina (Ribeirão Preto), v.35, p.95-101, 2002. 


\subsubsection{AVALIAÇÃO E REVISÃO - ESTÁGIO 3}

Quanto à avaliação e revisão do ambiente virtual de aprendizagem sobre gerenciamento em eventos adversos na assistência de enfermagem será realizada por especialistas da área de informática e enfermagem em um estudo futuro, em continuidade aos projetos da autora. 
6. Resultadas e Discussãa 
O AVA sobre gerenciamento em eventos adversos nos serviços de enfermagem está disponível no endereço eletrônico: <http://www.eerp.usp.br/nepien/eventosadversos>.

\subsection{DesenVolvimento do diagrama de naVegação para O USUÁRIO E EXPOSIÇÃO DO CONTEÚDO}

O diagrama de navegação, quando examinado como um todo, pode mostrar ao autor se os elementos do programa estão onde queria, se as questões estão sendo usadas em intervalos apropriados e se existe um equilíbrio entre os aspectos visuais e textuais dentro do programa (PRICE, 1991). Abaixo segue a estrutura de navegação do AVA sobre gerenciamento em eventos adversos nos serviços de enfermagem (Figura 5).

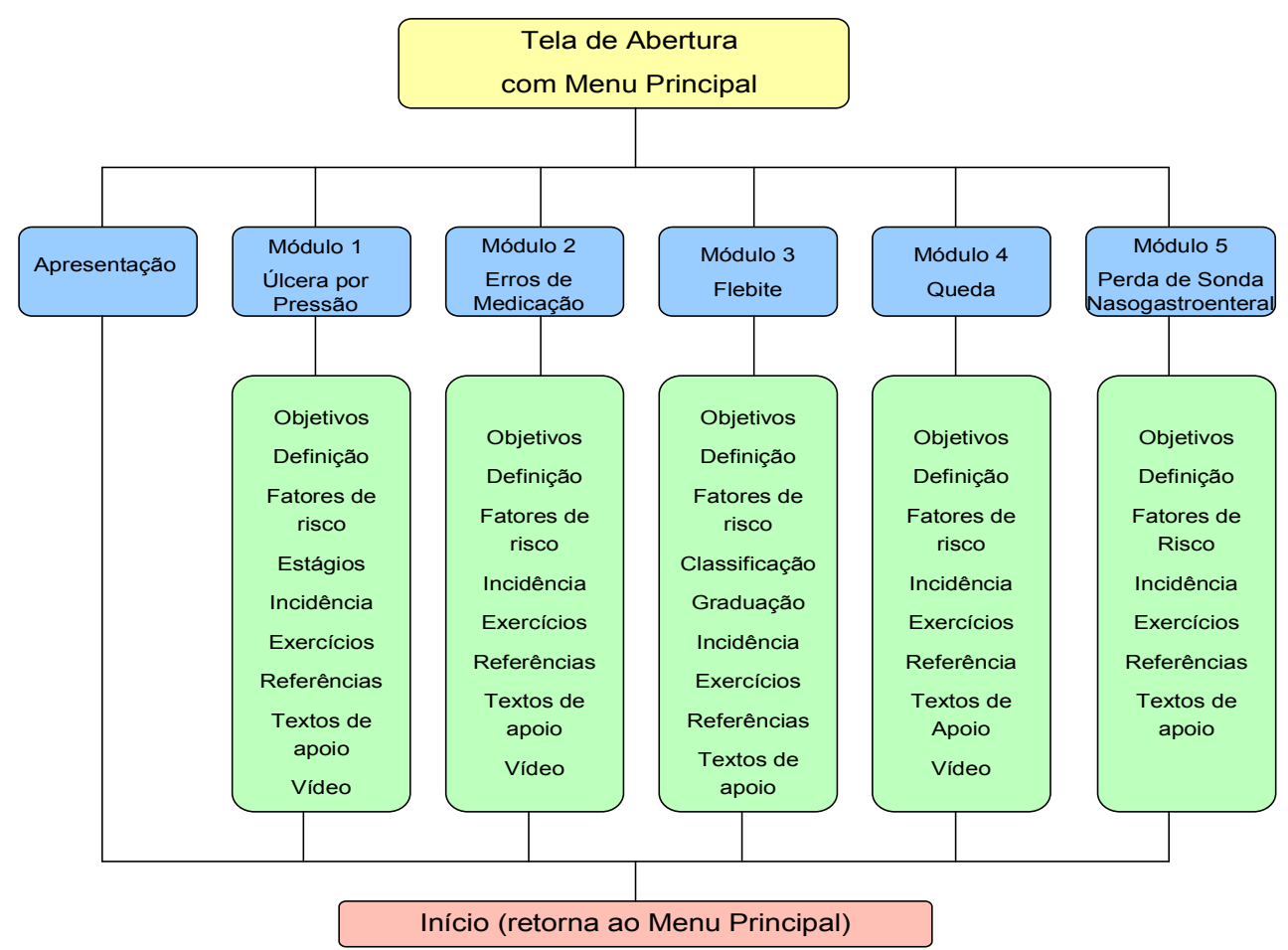

Figura 5. Estrutura de navegação do ambiente virtual de aprendizagem (AVA) sobre "Gerenciamento em Eventos Adversos nos Serviços de Enfermagem". Ribeirão Preto, 2010. 
Para a construção das interfaces foram utilizadas as regras e técnicas de desenvolvimento de interfaces propostas por Price (1991) e Pressman (1995). Tais autores abordam características como: disposição, tamanho e representatividade dos ícones, cores, equilíbrio de objetos dispostos na tela e demais pontos importantes para a obtenção de aplicações com recursos visuais em nível aceitável de interatividade.

A apresentação do ambiente desenvolvido é feita por uma tela de abertura composta pelo título, autoria e menu principal, sendo disposto neste menu a apresentação e os cinco módulos de navegação, conforme mostra a Figura 6.

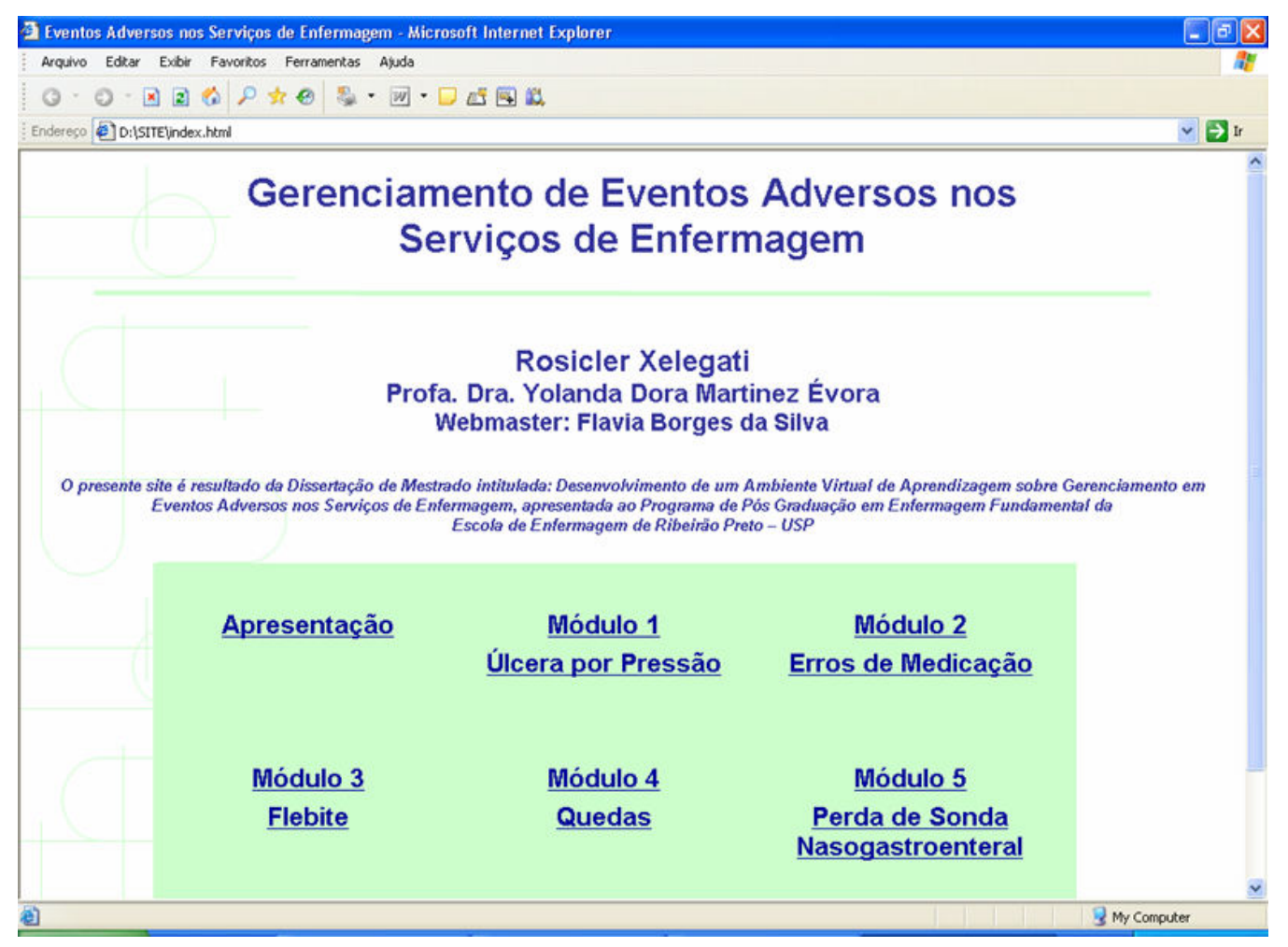

Figura 6. Tela de acesso ao conteúdo do AVA sobre "Gerenciamento em Eventos Adversos nos Serviços de Enfermagem". Ribeirão Preto, 2010.

O ambiente é composto por aproximadamente 123 páginas (linguagem HTML), sendo uma o Menu Principal e seis consideradas sub-menus, que norteiam as temáticas de interesse. A vantagem da utilização da linguagem HTML, ou seja, de hipertexto é a possibilidade de uma navegação rápida por uma grande quantidade de informações. Em conjunto, pode-se dizer que permite a 
exploração do assunto de forma não-linear, pois o acesso aos textos de interesse ocorre por meio de um "clicar" no link desejado (MITUSHIMA, 2004).

O link Apresentação do Menu Principal contém uma mensagem de boasvindas aos usuários, a descrição do objetivo geral do ambiente, o conteúdo a ser navegado e três links de organizações (duas nacionais e uma internacional) envolvidas com a temática abordada (Figura 7).

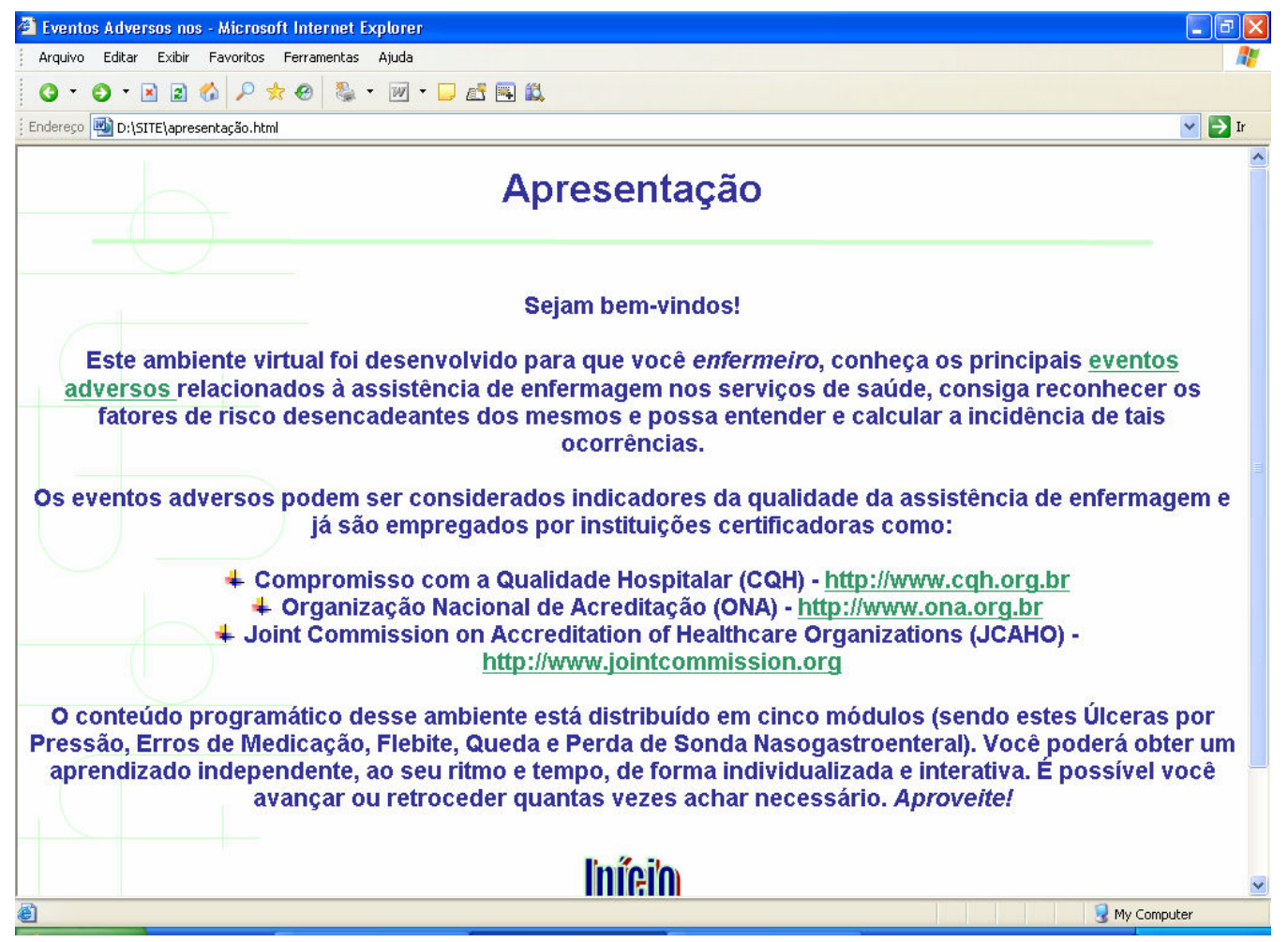

Figura 7. Tela de acesso a Apresentação do Menu Principal do AVA sobre "Gerenciamento em Eventos Adversos nos Serviços de Enfermagem". Ribeirão Preto, 2010.

Quando clicado sob o termo eventos adversos é aberto um sub-menu contendo a definição de eventos adversos, as referências sobre o tema e o link de um vídeo para reflexão da problemática.

As telas de acesso aos conteúdos dos cinco módulos, Úlcera por Pressão, Erros de Medicação, Flebite, Queda e Perda de Sonda Nasogastroenteral, são apresentados nas Figuras 8, 9, 10, 11 e 12. Cada módulo possui um padrão similar de distribuição de elementos. 


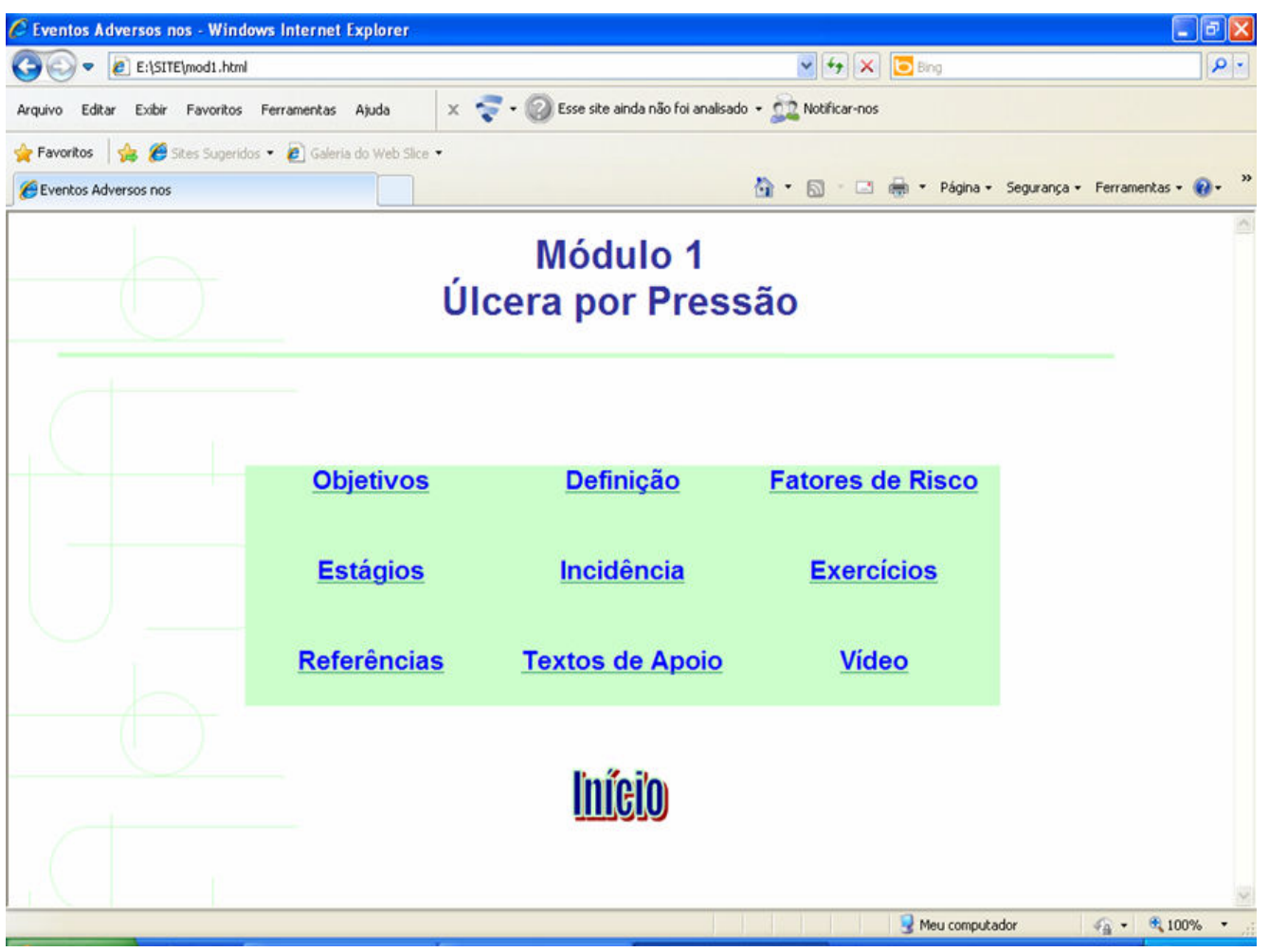

Figura 8. Tela de acesso ao Módulo 1 - Úlcera por Pressão do Menu Principal do AVA sobre "Gerenciamento em Eventos Adversos nos Serviços de Enfermagem". Ribeirão Preto, 2010.

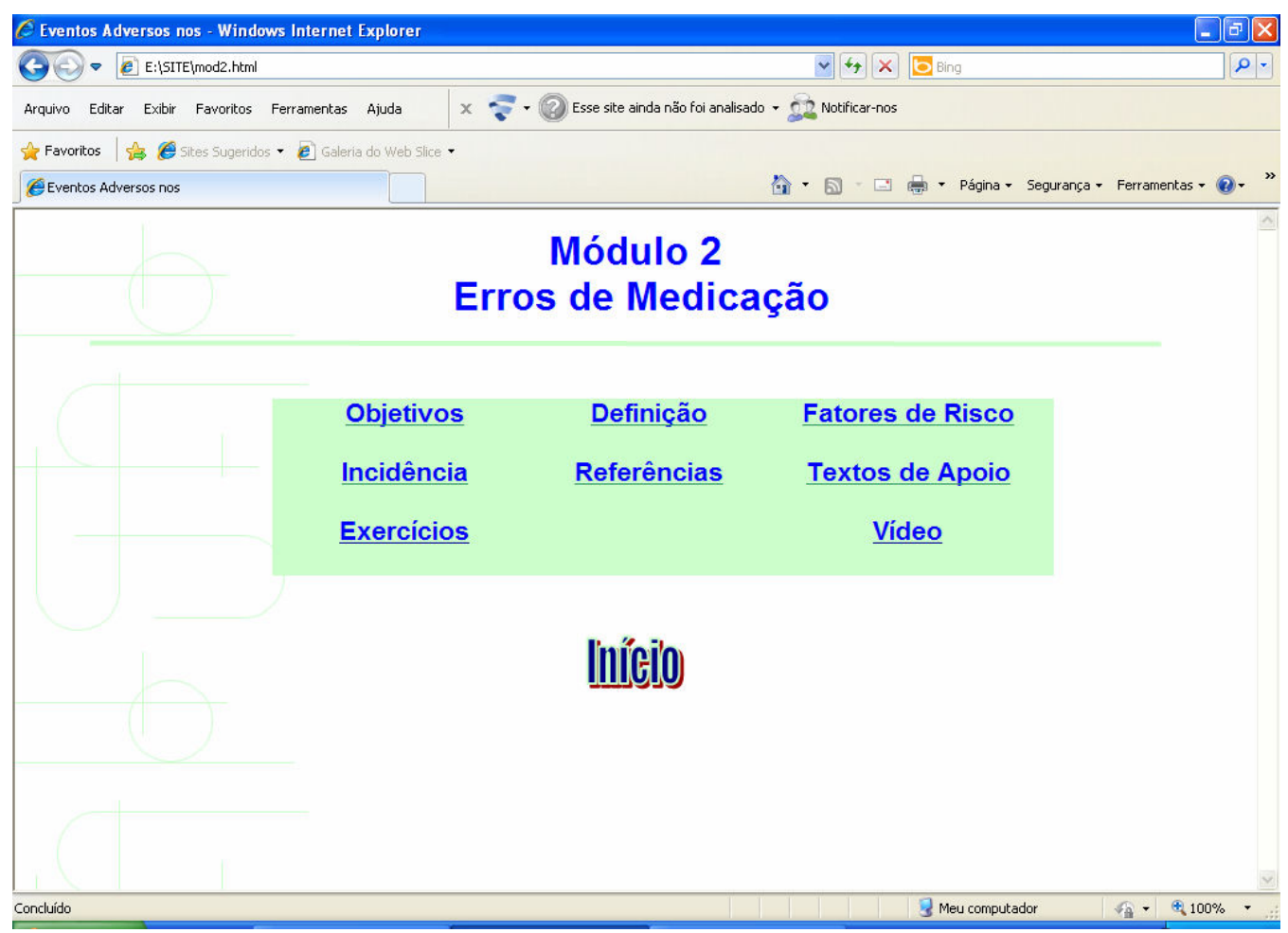

Figura 9. Tela de acesso ao Módulo 2 - Erros de Medicação do Menu Principal do AVA sobre "Gerenciamento em Eventos Adversos nos Serviços de Enfermagem". Ribeirão Preto, 2010. 


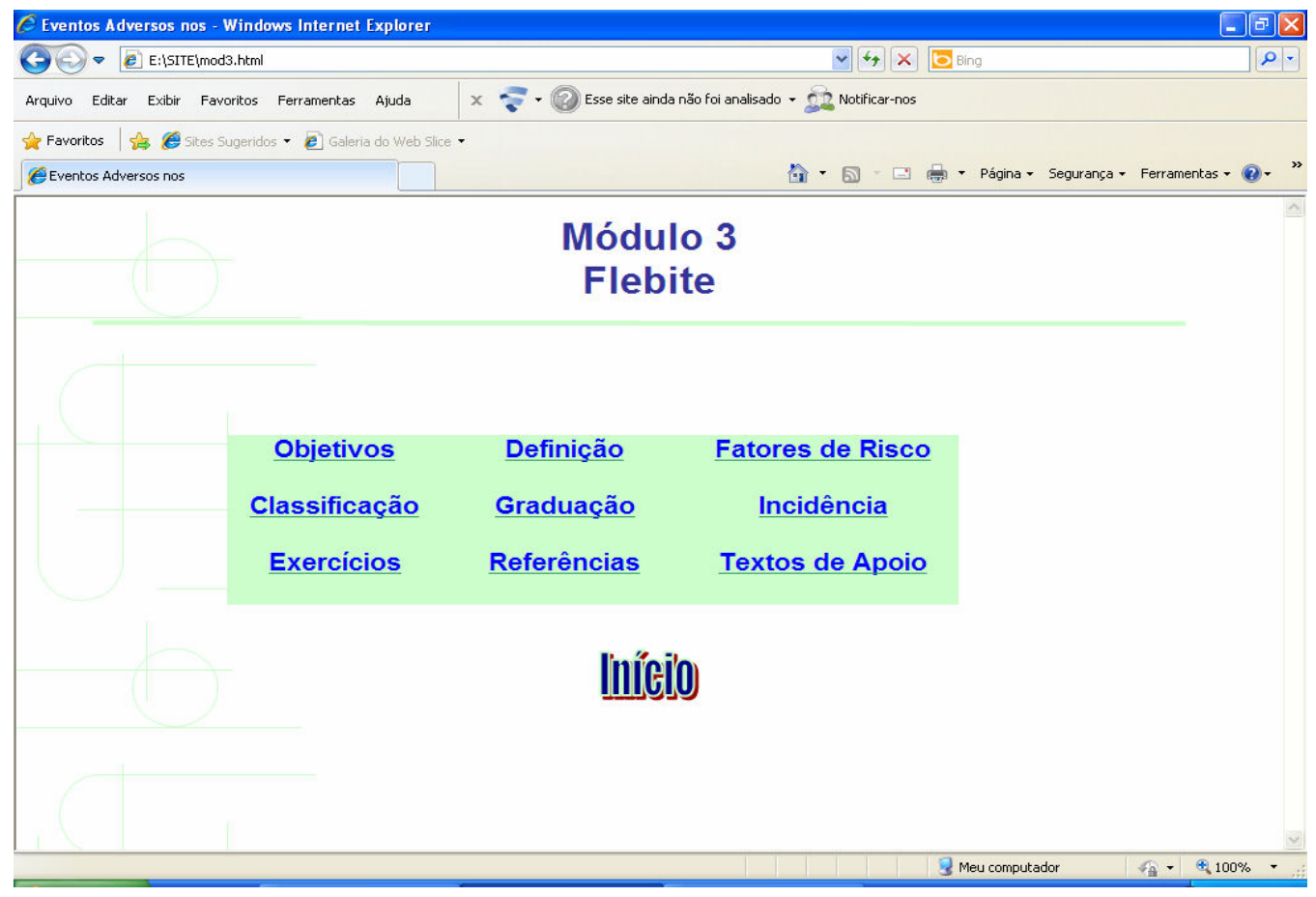

Figura 10. Tela de acesso ao Módulo 3 - Flebite do Menu Principal do AVA sobre "Gerenciamento em Eventos Adversos nos Serviços de Enfermagem". Ribeirão Preto, 2010.

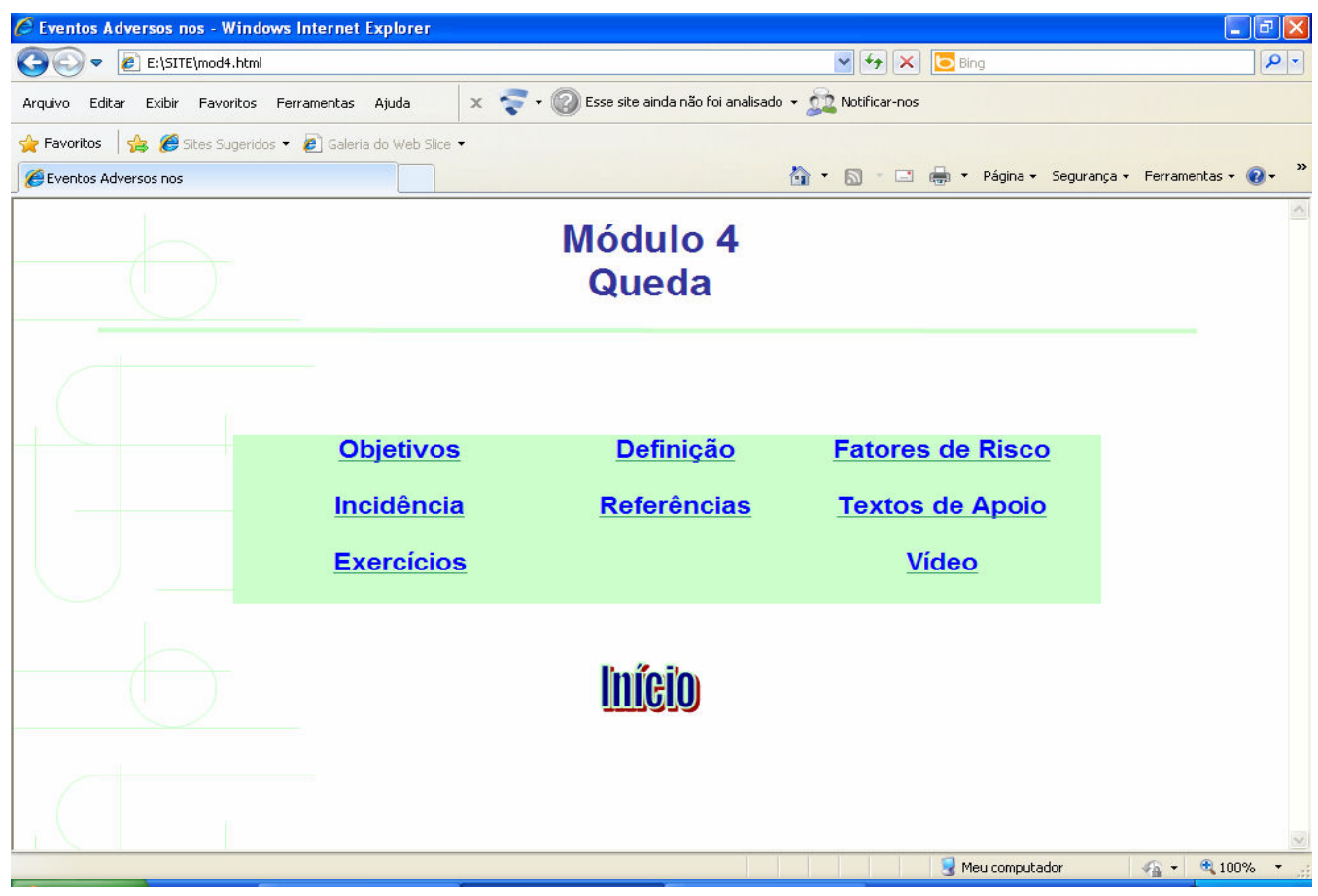

Figura 11. Tela de acesso ao Módulo 4 - Queda do Menu Principal do AVA sobre "Gerenciamento em Eventos Adversos nos Serviços de Enfermagem". Ribeirão Preto, 2010. 


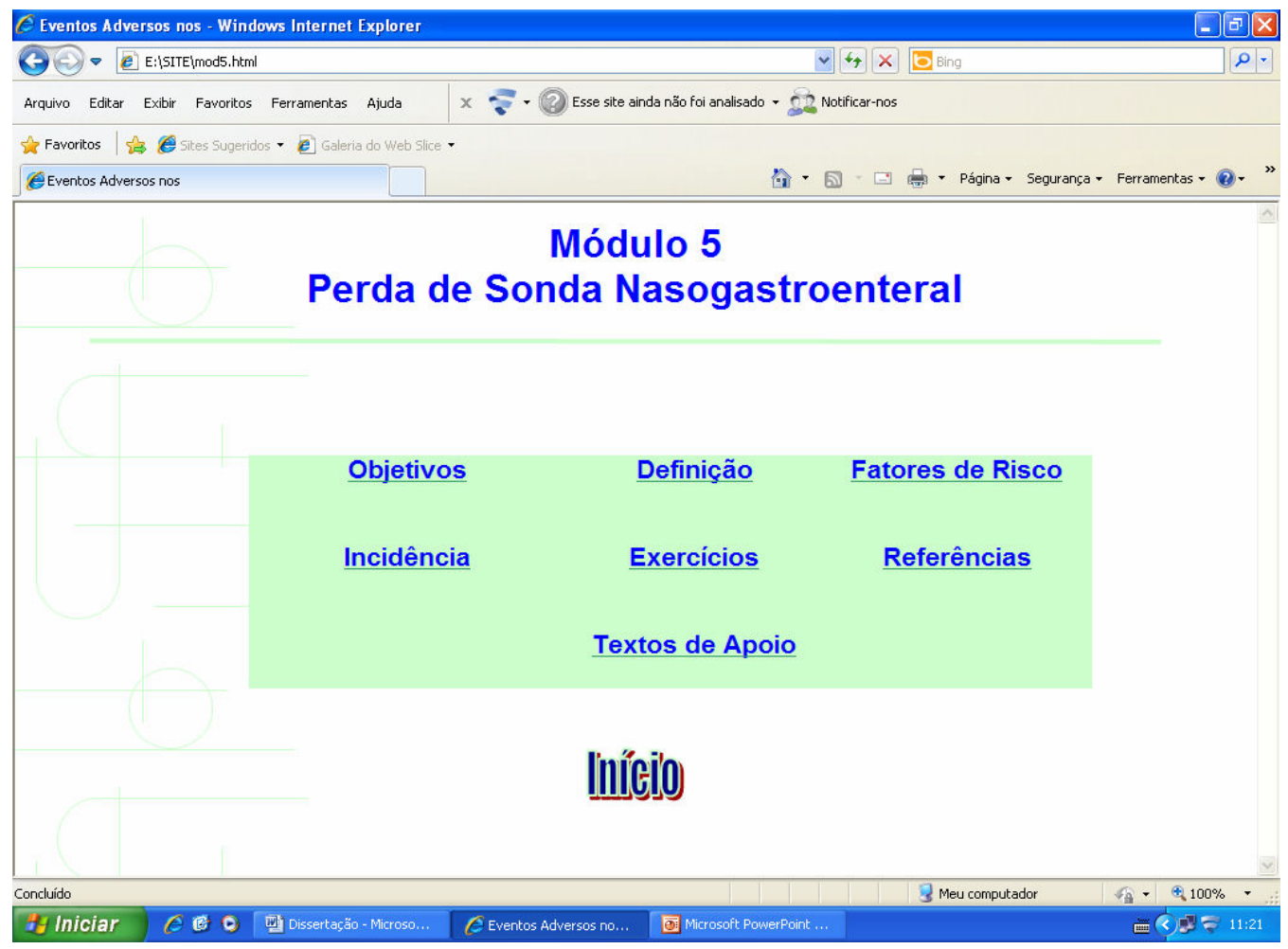

Figura 12. Tela de acesso ao Módulo 5 - Perda de Sonda Nasogastroenteral do Menu Principal do AVA sobre "Gerenciamento em Eventos Adversos nos Serviços de Enfermagem". Ribeirão Preto, 2010.

Na tela de acesso de cada módulo, o usuário encontra os objetivos de aprendizagem, a definição do evento adverso em questão, os fatores de risco que predispõe a ocorrência de tal evento, a incidência do evento, os exercícios de fixação, as referências utilizadas na construção do conteúdo e os textos de apoio indicados para o aprimoramento da temática. Existem também acesso a hipertexto conforme a especificidade do conteúdo do módulo, como o link de Estágios no Módulo 1 (Úlcera por Pressão) e o de Classificação e Graduação, no Módulo 3 (Flebite). Cabe ressaltar que nos Módulos 1 (Úlcera por Pressão), 2 (Erros de Medicação) e 4 (Queda), foram disponibilizados link de vídeo.

O link Objetivos, quando clicado, expõe os objetivos de aprendizagem de cada módulo (exemplificado na Figura 13). Dessa maneira, o usuário cria uma expectativa em relação ao conteúdo que será abordado, aumentando sua motivação para o aprendizado. 


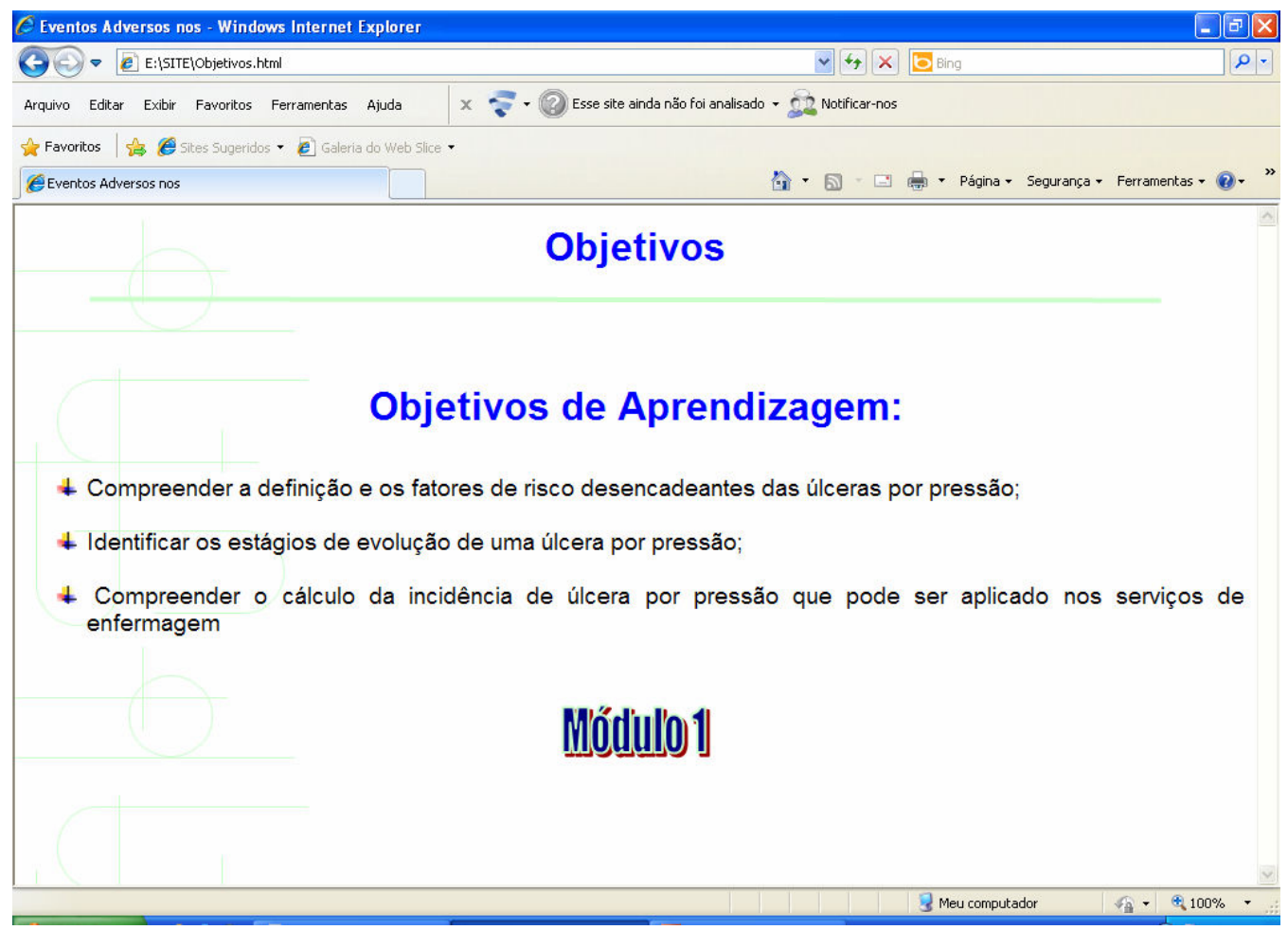

Figura 13. Tela de acesso ao link Objetivos do Módulo 1 - Úlcera por Pressão do AVA sobre "Gerenciamento em Eventos Adversos nos Serviços de Enfermagem". Ribeirão Preto, 2010.

Quanto aos links Definição e Fatores de Risco, seguem as telas de acesso nas Figuras 14 e 15. No link Fatores de Risco dos Módulos 1 (Úlcera por Pressão) e 4 (Queda) foi anexado também as Escalas de Risco para ocorrência de tais eventos, sendo estas, respectivamente, a Escala de Braden e a de Downton. 


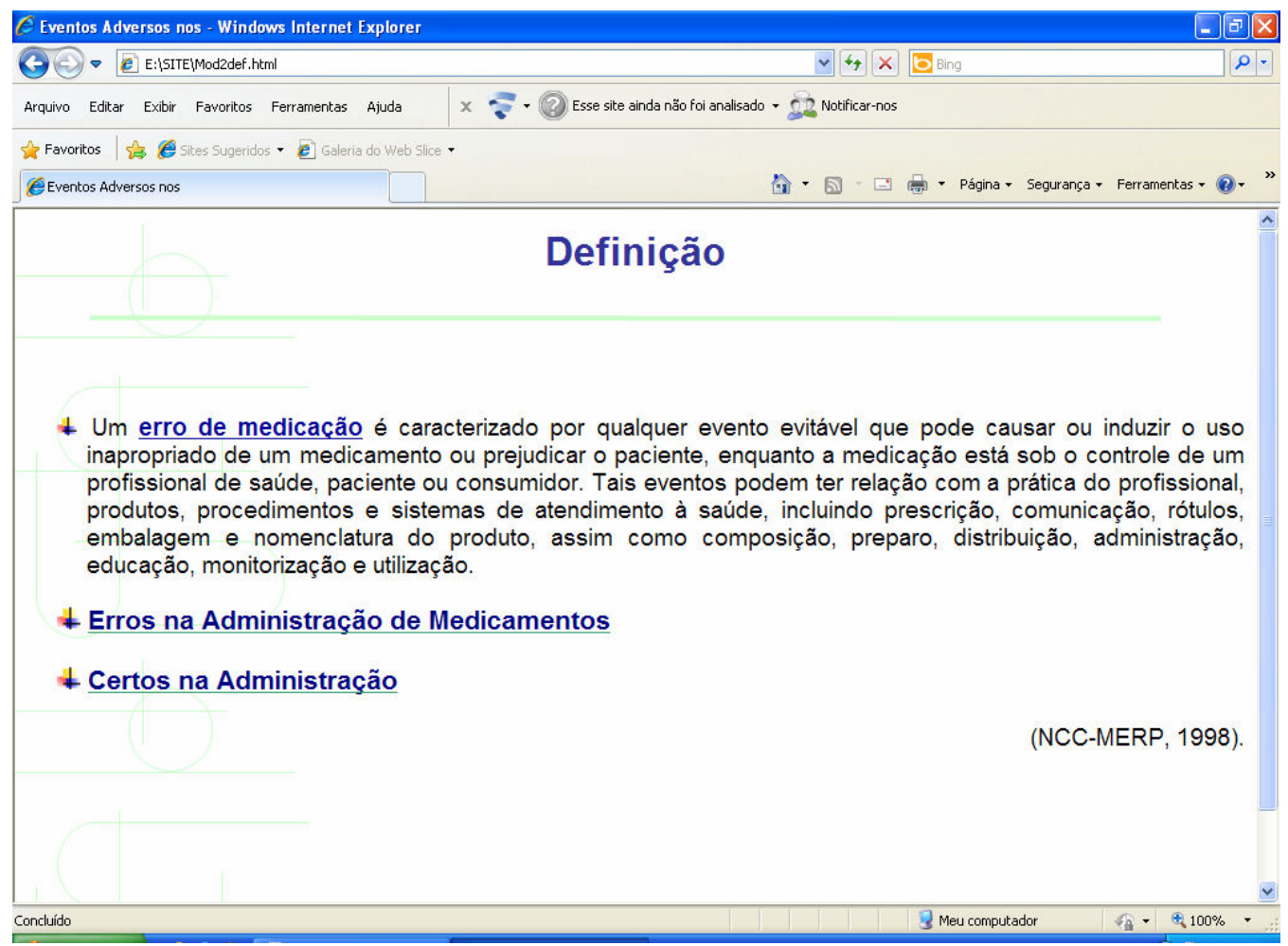

Figura 14. Tela de acesso ao link Definição do Módulo 2 - Erros de Medicação do AVA sobre "Gerenciamento em Eventos Adversos nos Serviços de Enfermagem". Ribeirão Preto, 2010.

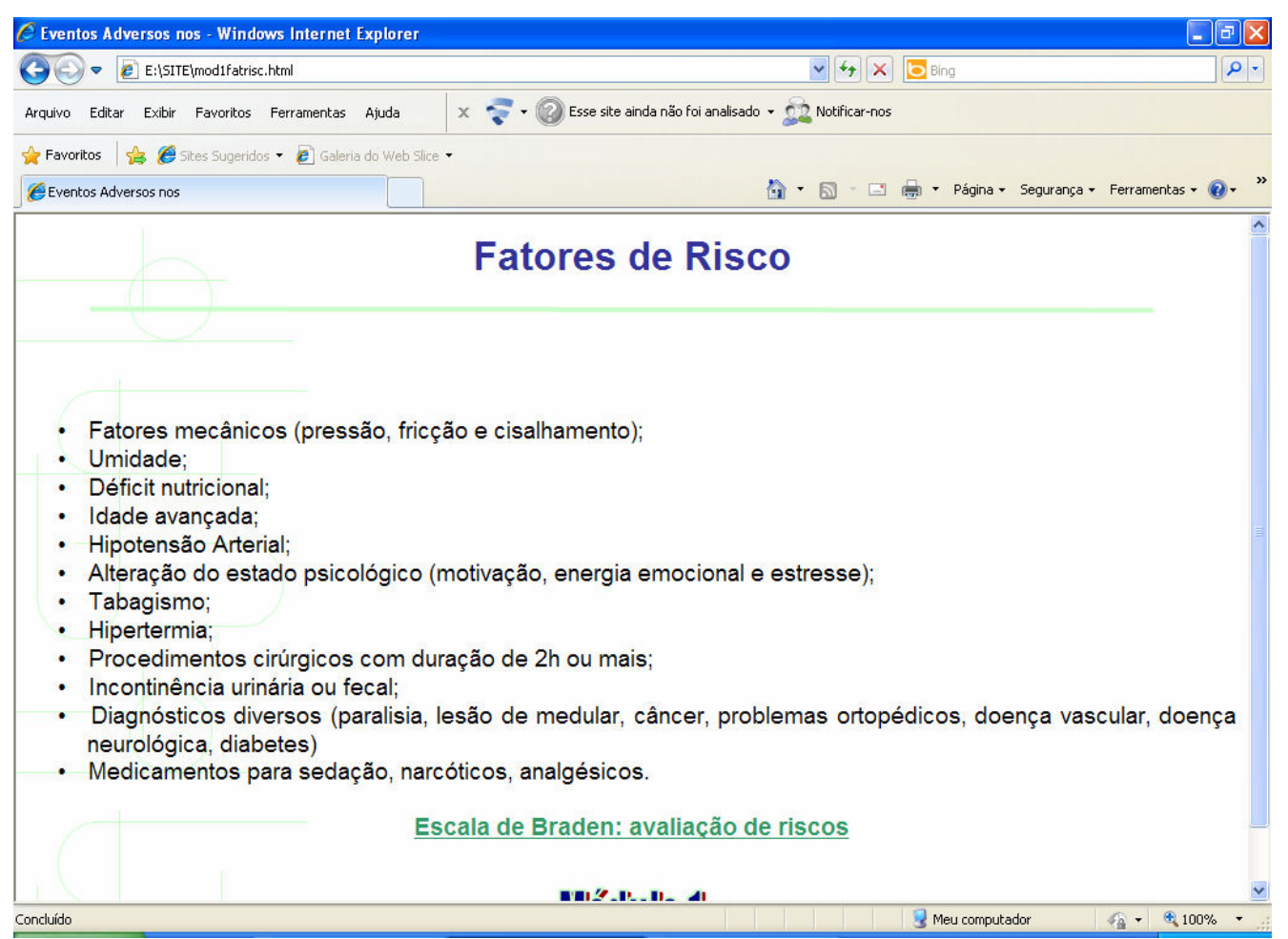

Figura 15. Tela de acesso ao link Fatores de Risco do Módulo 1 - Úlcera por Pressão do AVA sobre "Gerenciamento em Eventos Adversos nos Serviços de Enfermagem". Ribeirão Preto, 2010. 
Em relação ao link Incidência, foi apresentado a descrição e o cálculo da incidência de cada evento (como exemplos seguem as Figuras 16 e 17).

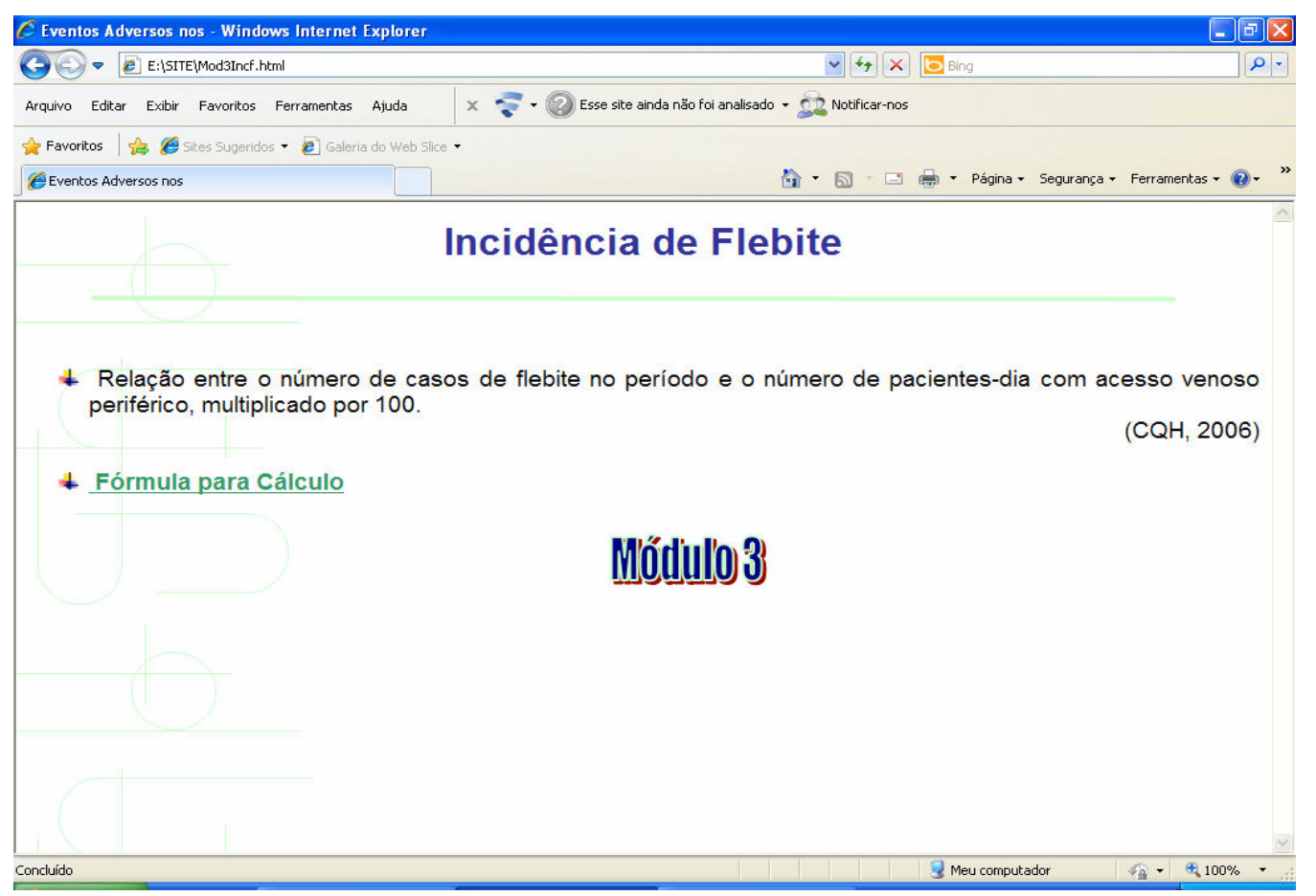

Figura 16. Tela de acesso ao link Incidência do Módulo 3 - Flebite do AVA sobre "Gerenciamento em Eventos Adversos nos Serviços de Enfermagem". Ribeirão Preto, 2010.

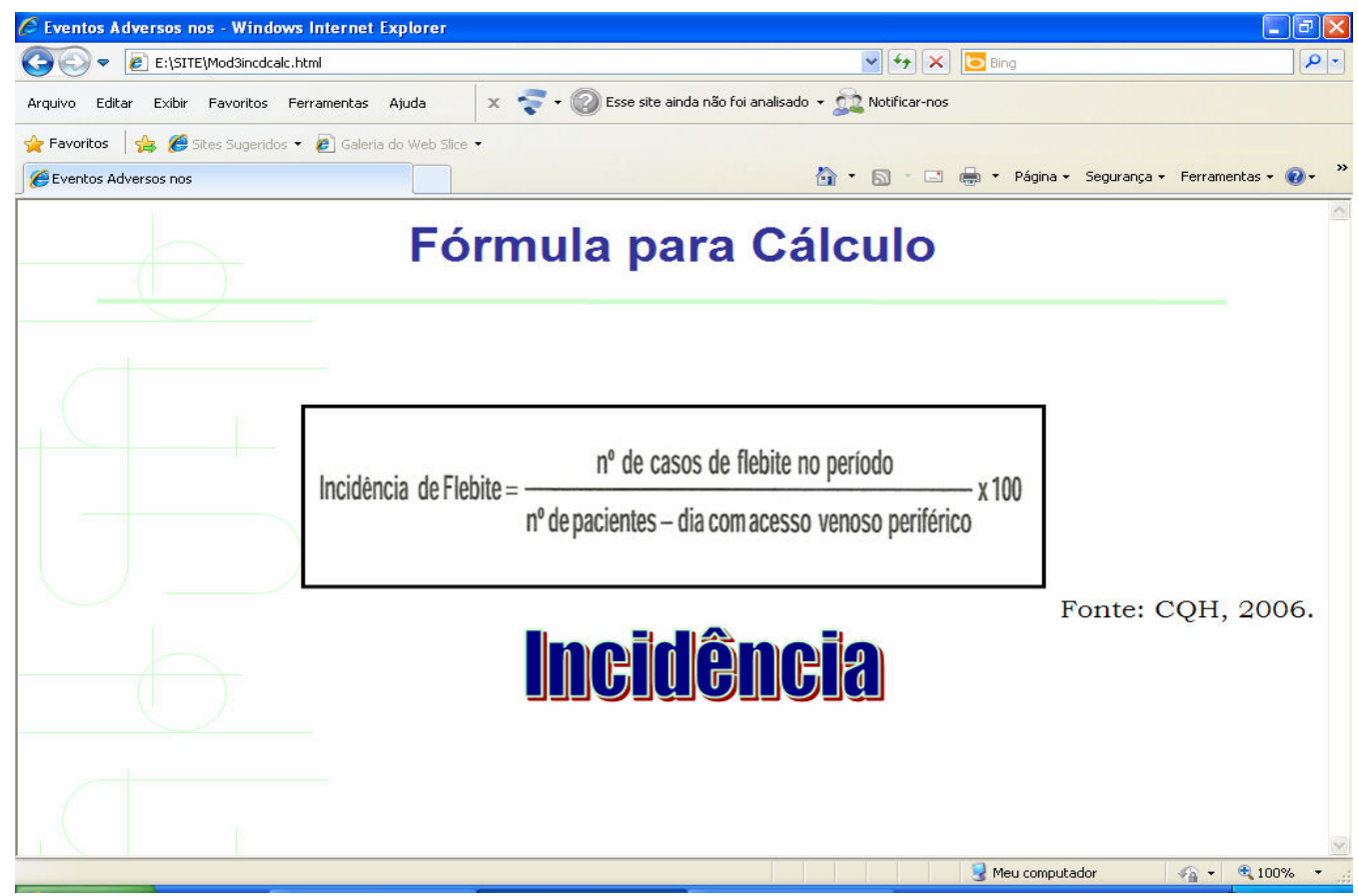

Figura 17. Tela de acesso ao link Fórmula para Cálculo do Módulo 3 - Flebite do AVA sobre "Gerenciamento em Eventos Adversos nos Serviços de Enfermagem". Ribeirão Preto, 2010. 
Considerando o link Exercícios, este oferece três exercícios de fixação em cada módulo, sendo um no formato de Palavra Cruzada (JCross) e dois no formato de teste de Múltipla Escolha (JQuiz).

A Figura 18 ilustra a tela de acesso ao exercício de Palavra Cruzada do Módulo 5 (Perda de Sonda Nasogastroenteral). Quando o usuário clica sob um número na grade, é possível visualizar a pista e inserir a palavra. Ao completar todas as palavras da grade, deve-se clicar no botão Verificar Reposta. Automaticamente será aberta uma tela com a pontuação do exercício, dessa forma o usuário obterá um feedback do que foi aprendido.

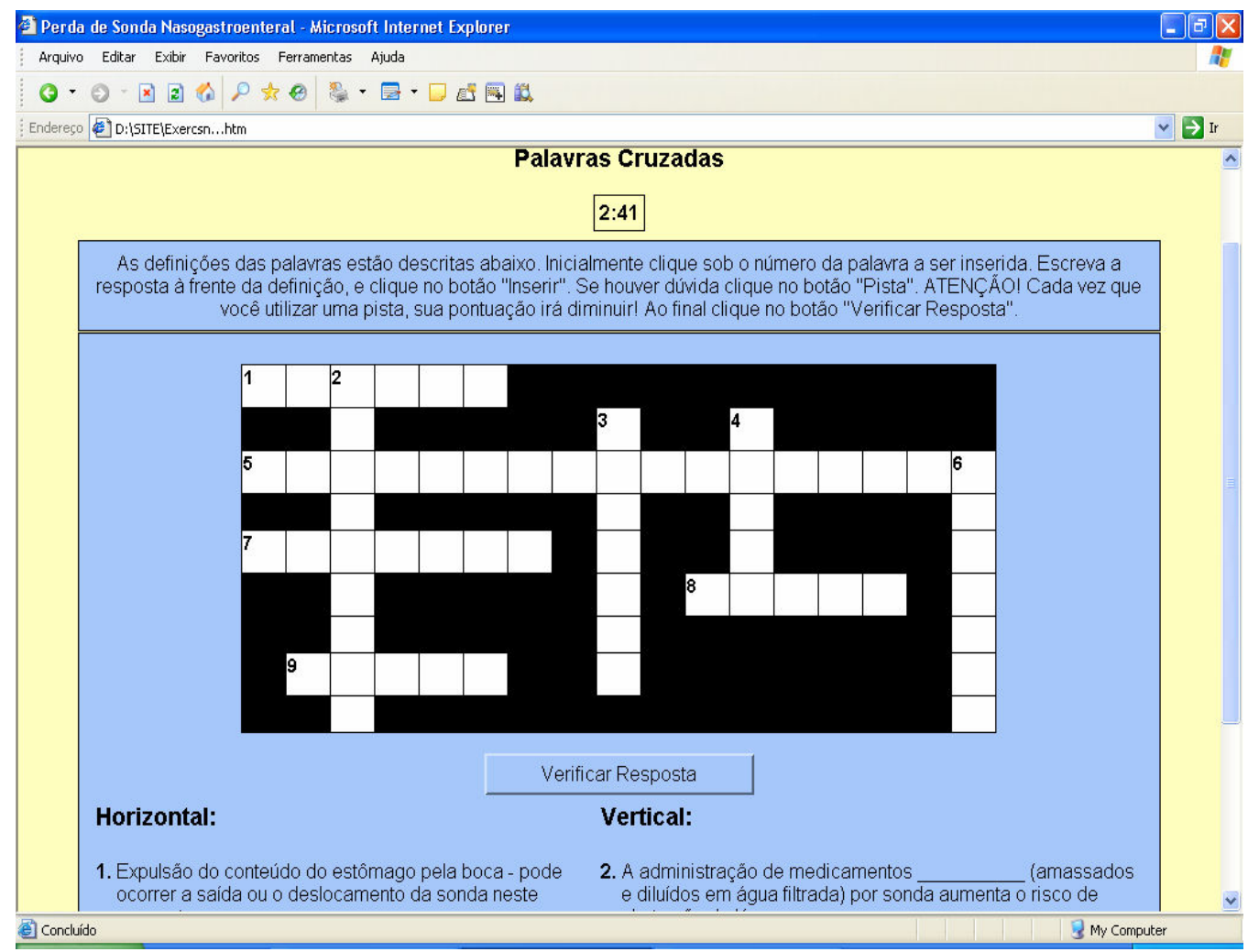

Figura 18. Tela de acesso ao link Exercícios - Palavras Cruzadas do Módulo 5 - Perda de Sonda Nasogastroenteral do AVA sobre "Gerenciamento em Eventos Adversos nos Serviços de Enfermagem". Ribeirão Preto, 2010.

Na Figura 19 é visualizada a tela de acesso dos exercícios de Múltipla Escolha do Módulo 1 (Úlcera por Pressão). Quando o usuário opta por uma das alternativas do exercício, de forma automática será aberta uma tela com a informação de "Correta", se a alternativa estiver certa, ou "Tente novamente", se a alternativa estiver incorreta. A pontuação do exercício também será exibida, devolvendo ao usuário, o seu desempenho. 


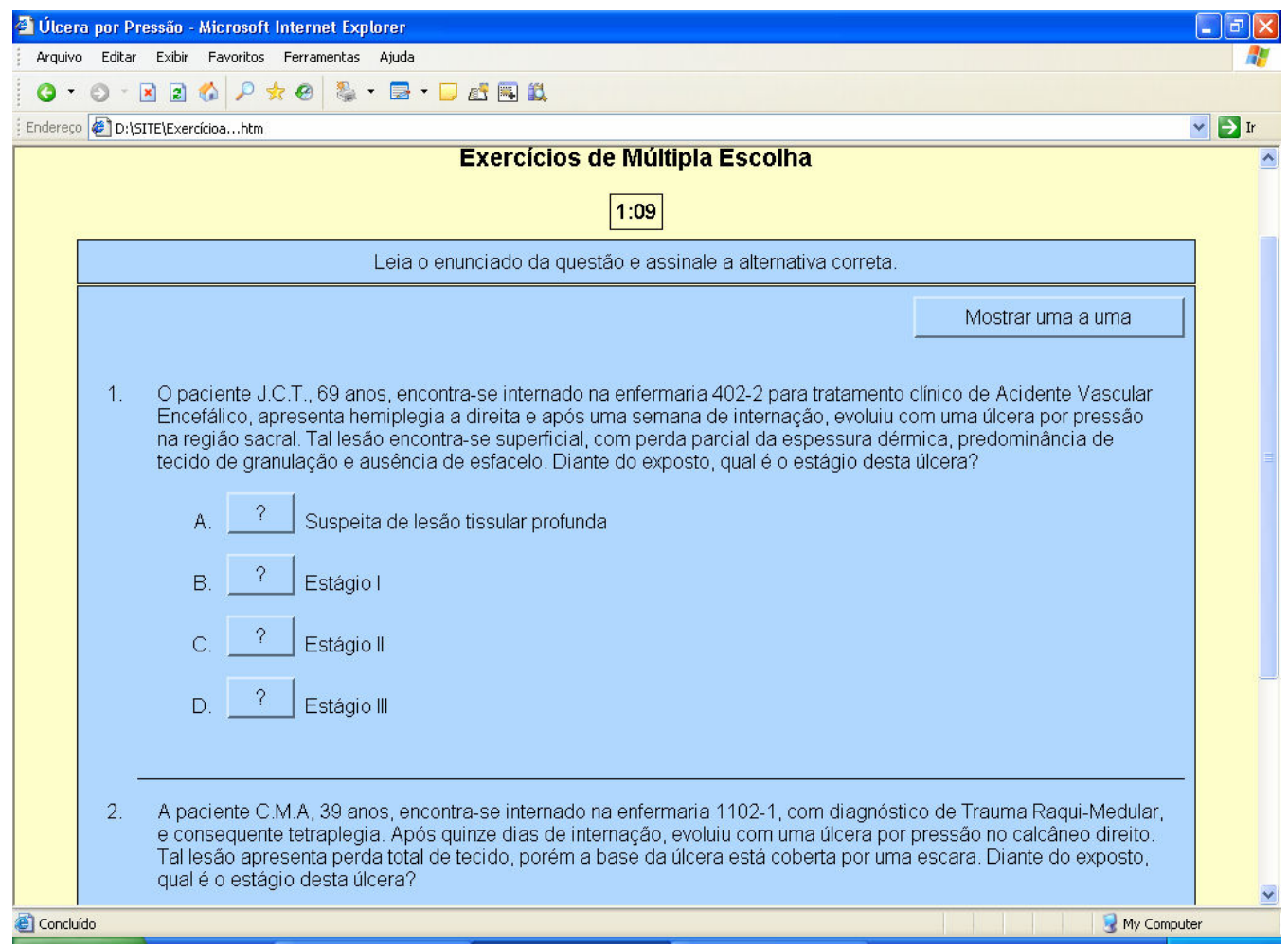

Figura 19. Tela de acesso ao link Exercícios - Múltipla Escolha do Módulo 5 - Perda de Sonda Nasogastroenteral do AVA sobre "Gerenciamento em Eventos Adversos nos Serviços de Enfermagem". Ribeirão Preto, 2010.

No link Referências foi exposto as literaturas consultadas para o desenvolvimento do conteúdo do módulo (Figura 20) e, no link Textos de Apoio, as referências indicadas para o aprimoramento da temática (Figura 21). Vale destacar que nas referências on line foram incluídos links direcionados à fonte de origem para acesso direto e consulta na íntegra dos materiais. 


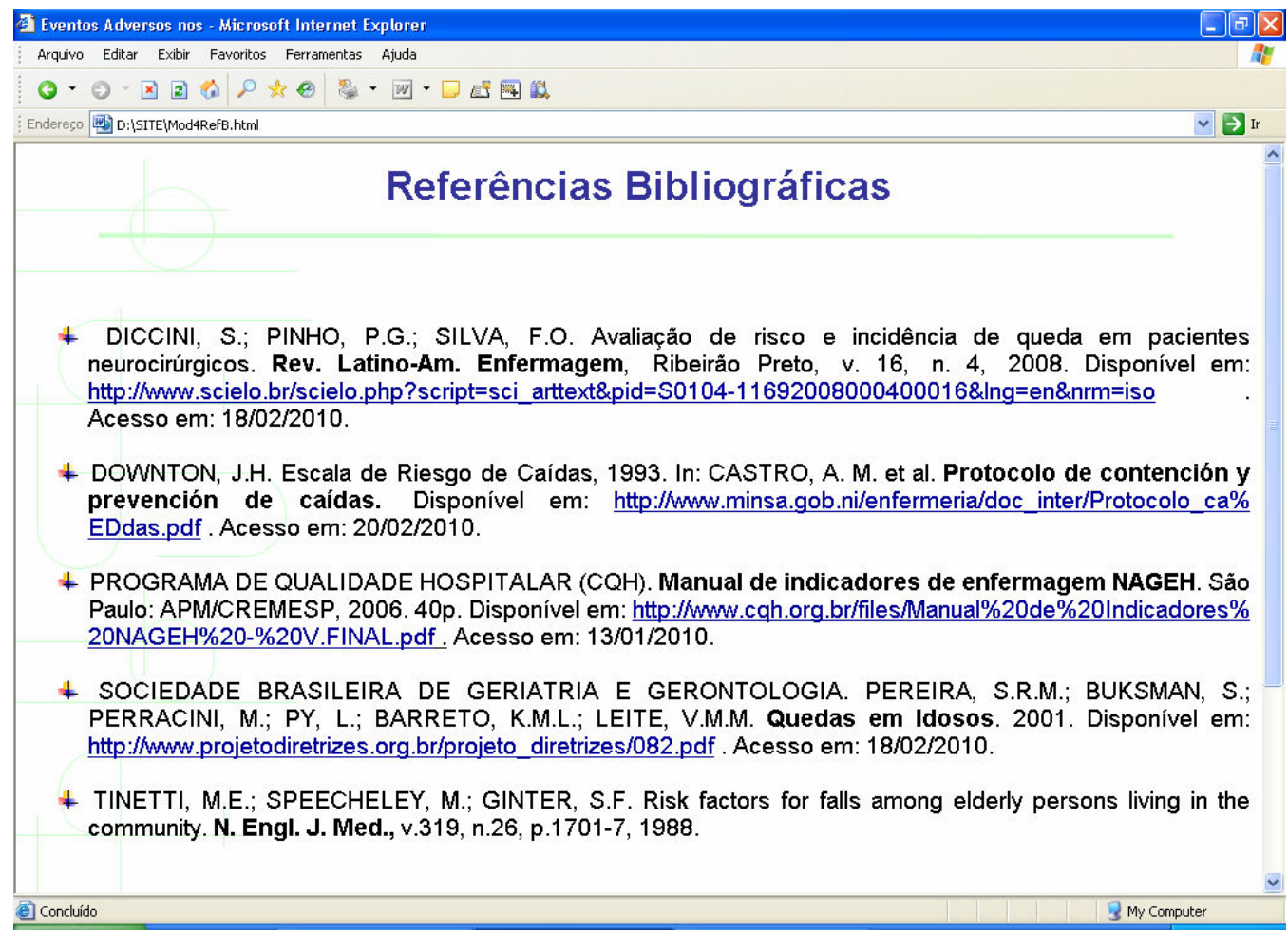

Figura 20. Tela de acesso ao link Referências do Módulo 4 - Queda do AVA sobre "Gerenciamento em Eventos Adversos nos Serviços de Enfermagem". Ribeirão Preto, 2010.

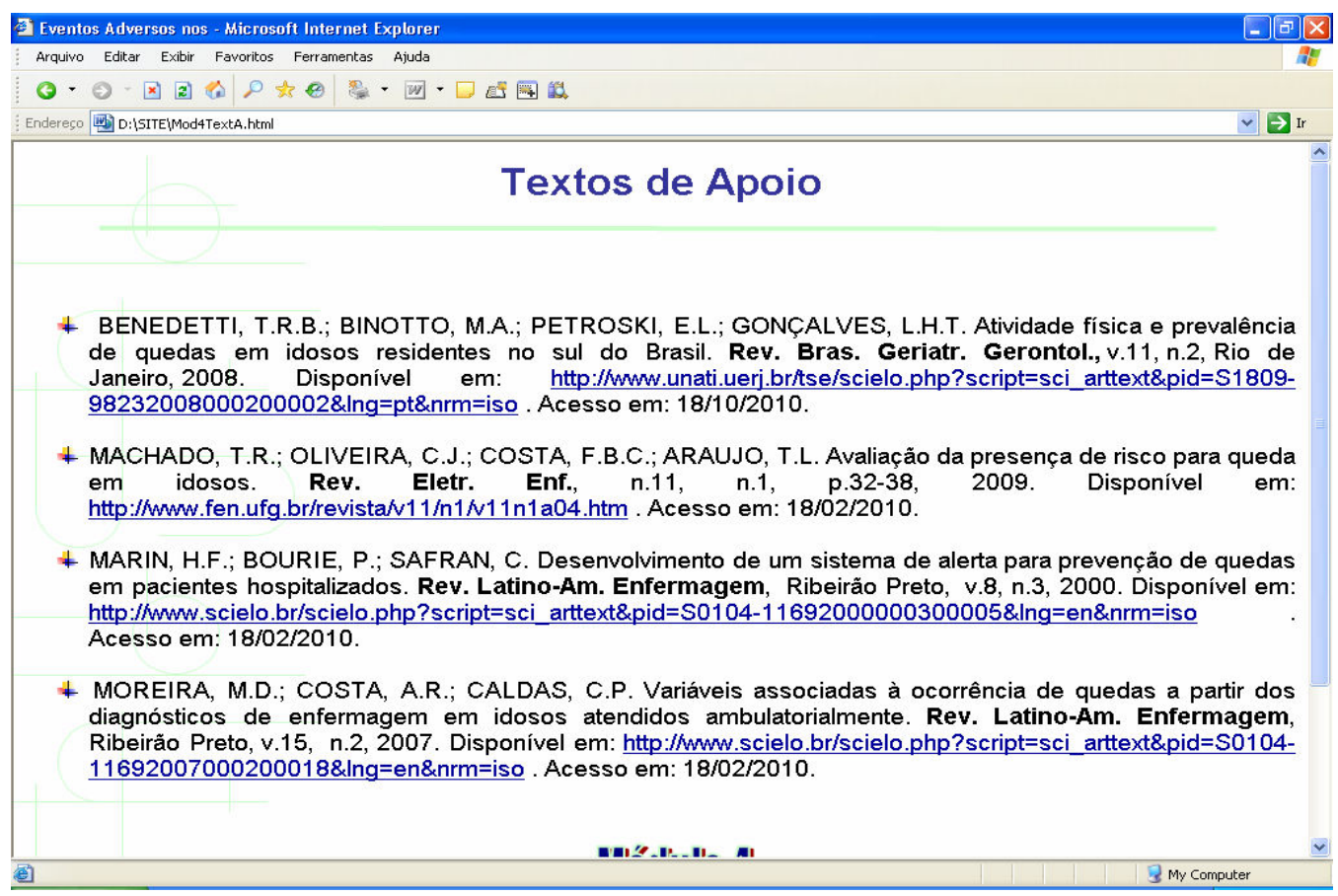

Figura 21. Tela de acesso ao link Textos de Apoio do Módulo 4 - Queda do AVA sobre "Gerenciamento em Eventos Adversos nos Serviços de Enfermagem". Ribeirão Preto, 2010. 
Quanto ao link Estágios referente ao Módulo 1 (Úlcera por Pressão), segue na Figura 22 a tela de acesso e, posteriormente exemplificando, a descrição de um dos estágios e suas ilustrações (Figuras 23 e 24).

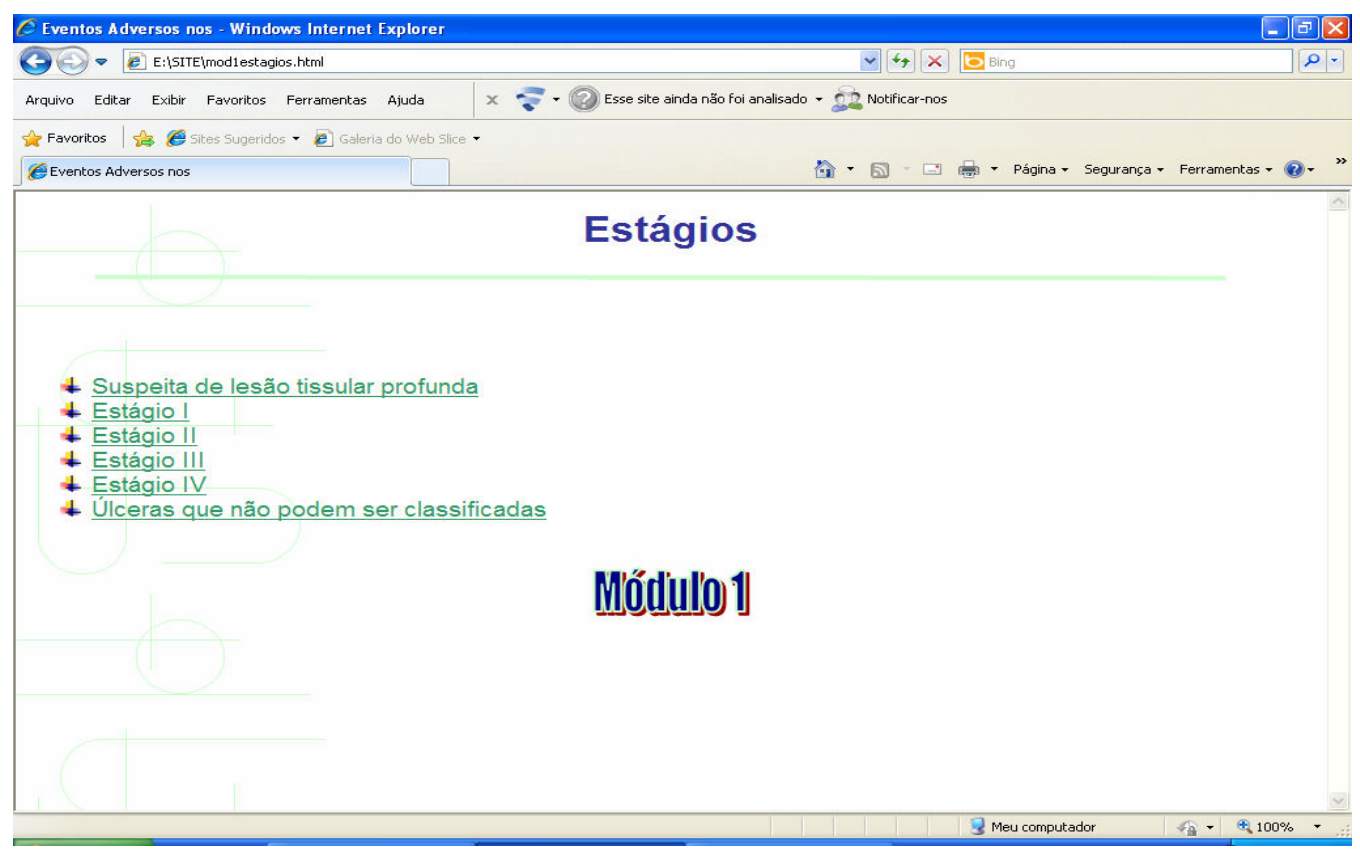

Figura 22. Tela de acesso ao link Estágios do Módulo 1 - Úlcera por Pressão do AVA sobre "Gerenciamento em Eventos Adversos nos Serviços de Enfermagem". Ribeirão Preto, 2010.

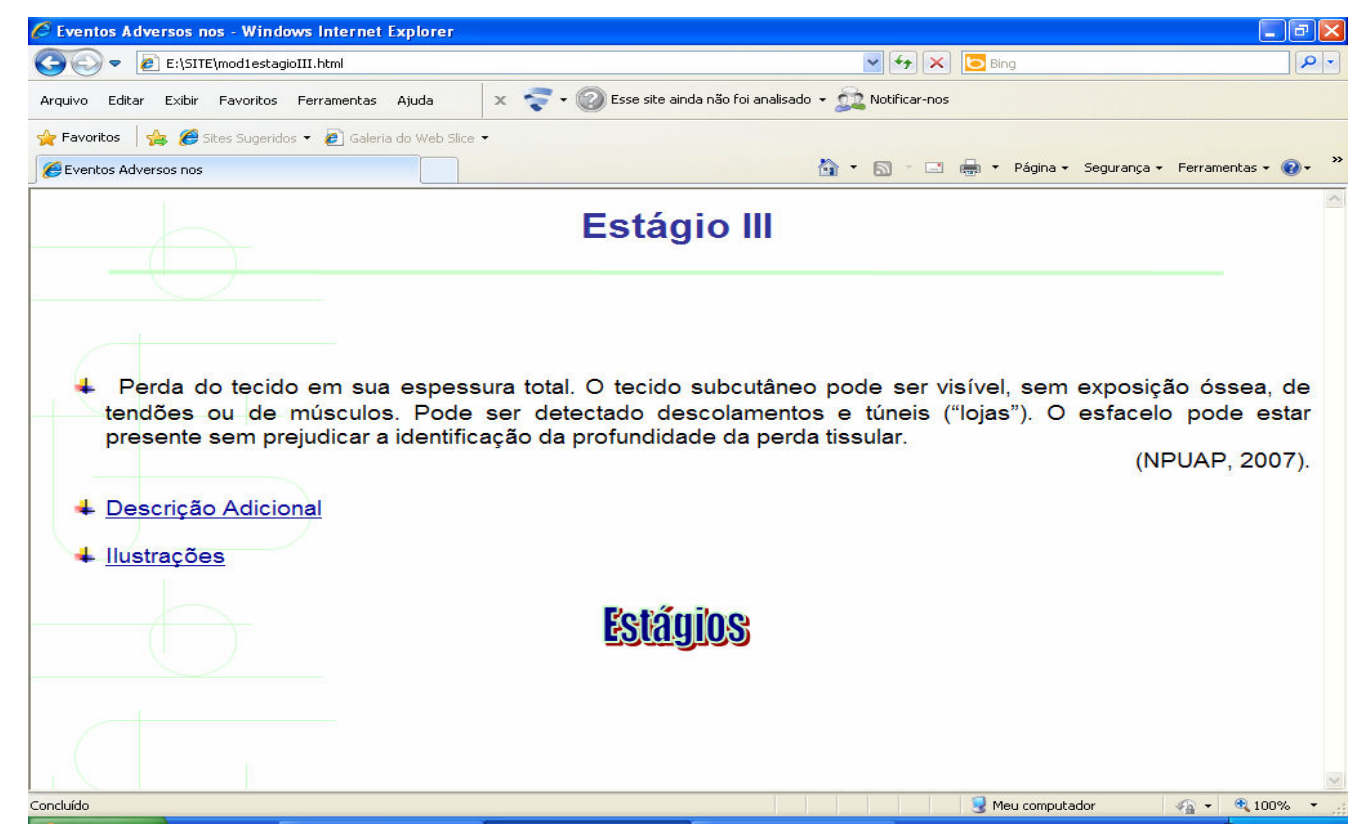

Figura 23. Tela de acesso ao link Estágio III do Módulo 1 - Úlcera por Pressão do AVA sobre "Gerenciamento em Eventos Adversos nos Serviços de Enfermagem". Ribeirão Preto, 2010. 


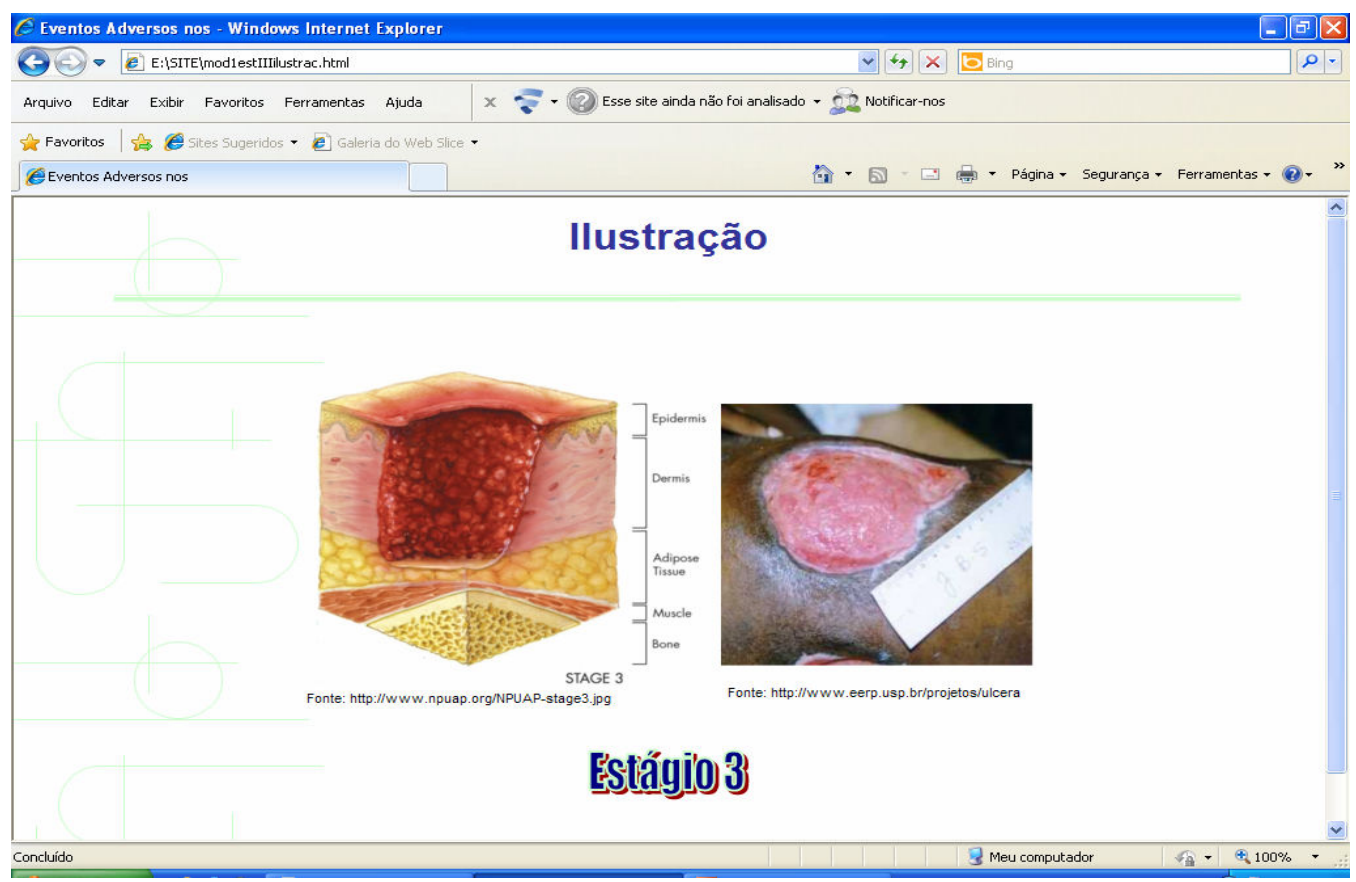

Figura 24. Tela de acesso ao link Ilustrações do Estágio III do Módulo 1 - Úlcera por Pressão do AVA sobre "Gerenciamento em Eventos Adversos nos Serviços de Enfermagem". Ribeirão Preto, 2010.

Em relação aos links Classificação e Graduação referente ao Módulo 3 (Flebite), são apresentadas as telas de acesso nas Figuras 25 e 26 . No link Classificação, se clicado sobre o tipo de flebite é aberto uma nova janela com a descrição e os sinais e sintomas.

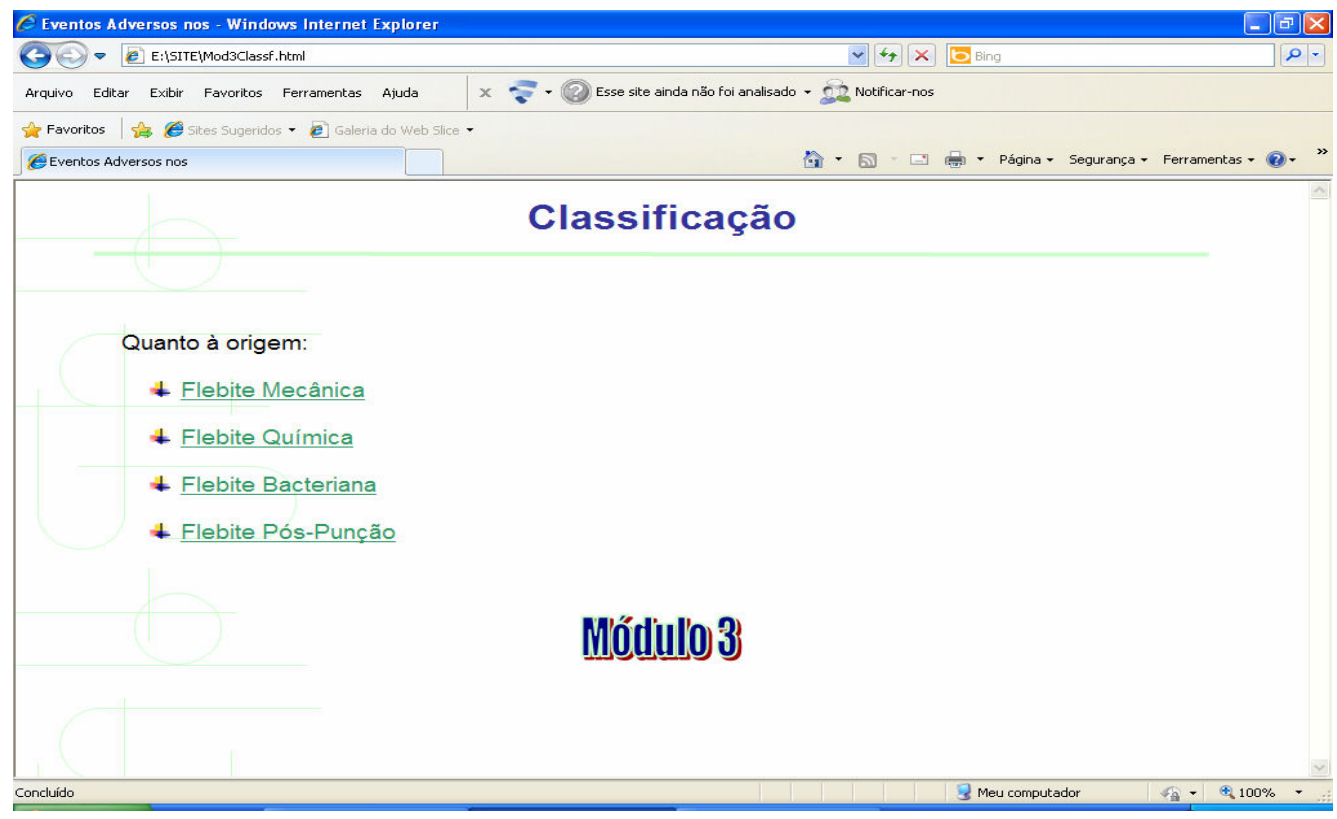

Figura 25. Tela de acesso ao link Classificação do Módulo 3 - Flebite do AVA sobre "Gerenciamento em Eventos Adversos nos Serviços de Enfermagem". Ribeirão Preto, 2010. 


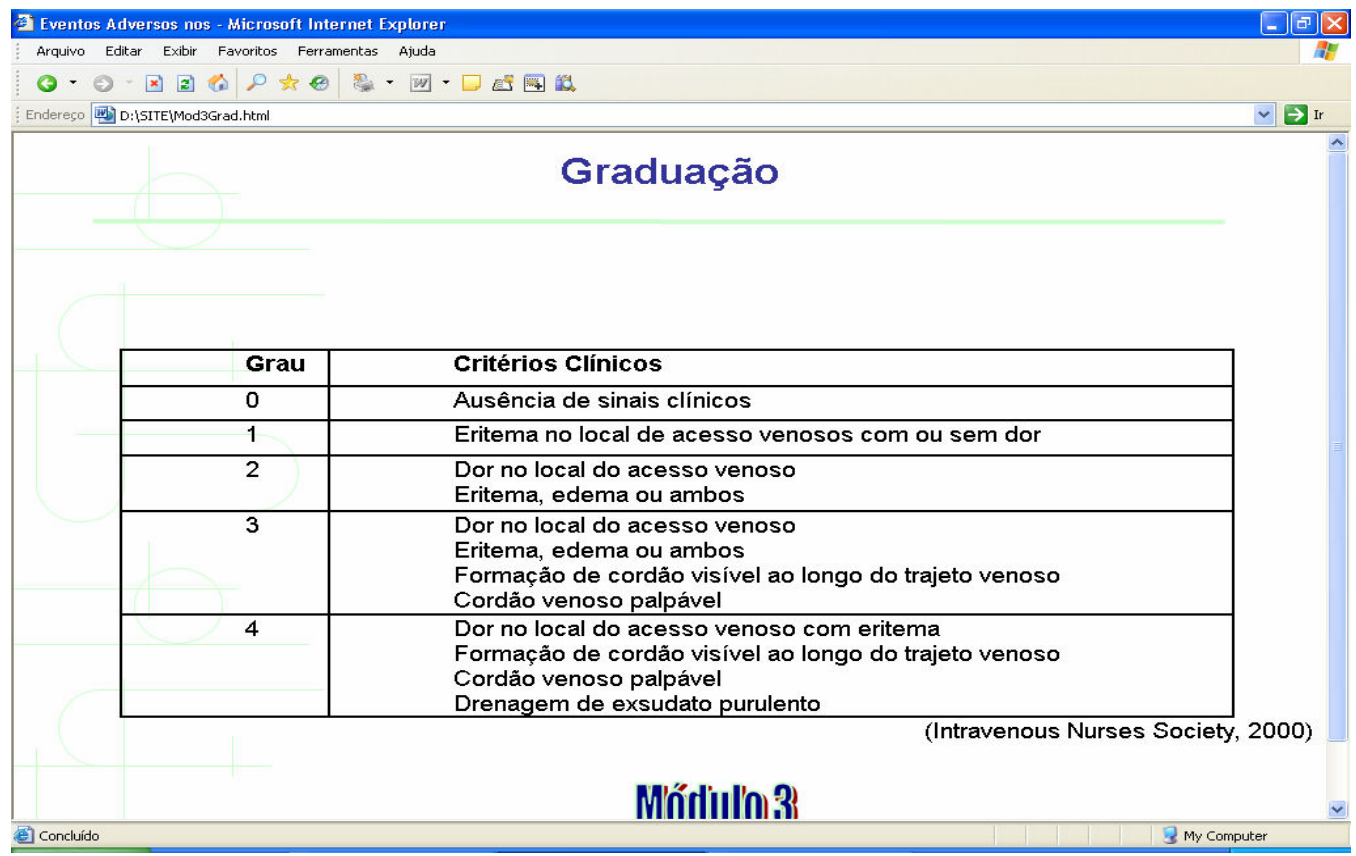

Figura 26. Tela de acesso ao link Graduação do Módulo 3 - Flebite do AVA sobre "Gerenciamento em Eventos Adversos nos Serviços de Enfermagem". Ribeirão Preto, 2010.

Quanto aos Vídeos inseridos nos Módulos 1 (Úlcera por Pressão), 2 (Erros de Medicação) e 4 (Queda), todos estão direcionados ao site <http://www.youtube.com>. Abaixo, a Figura 27 ilustra a tela de acesso do vídeo do módulo sobre Erros de Medicação.

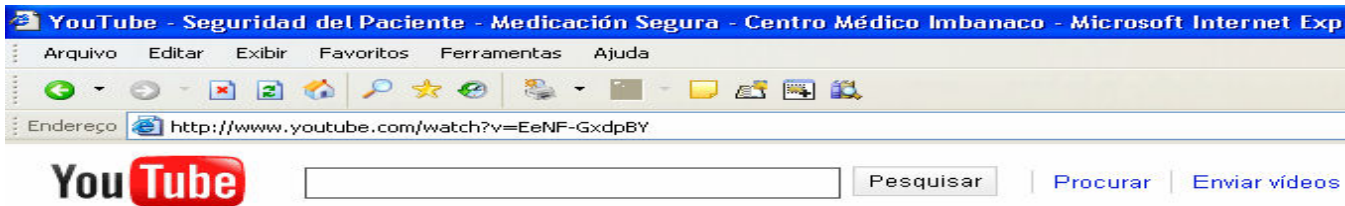

\section{Seguridad del Paciente - Medicación Segura - Centro Médico Imbanaco centromedimbanaco $\approx 9$ vídeos Inscrever-se}

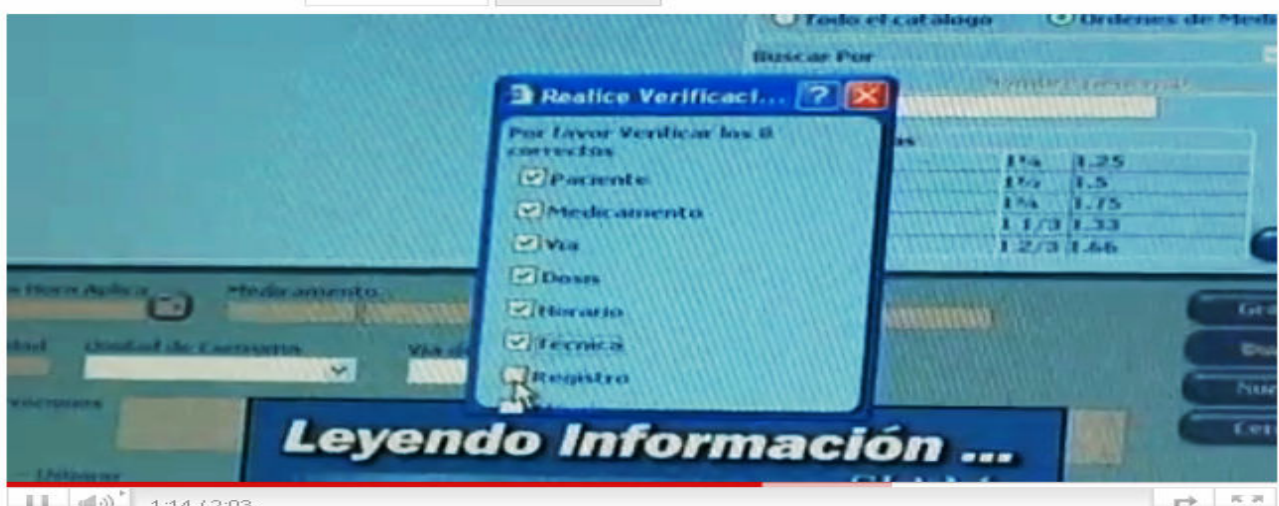

Figura 27. Tela de acesso ao Vídeo inserido ao Módulo 3 - Erros de Medicação do AVA sobre "Gerenciamento em Eventos Adversos nos Serviços de Enfermagem". Ribeirão Preto, 2010. (Fonte: <www.youtube.com>). 


\subsection{DIRETRIZES PARA A INTERFACE DO AMBIENTE VIRTUAL DE APRENDIZAGEM (AVA) E CONTEXTUALIZAÇÃo COM A ÁREA DE ENFERMAGEM}

Atualmente, vive-se na Sociedade da Informação, sociedade esta caracterizada por sua cultura de aprendizagem, que demanda a busca contínua por conhecimento. A reciclagem e a formação permanente dos profissionais são indispensáveis para o mercado de trabalho dessa sociedade, que se apresenta em constante mudança (FREITAS; LOYOLA; PRATES, 2002).

Os profissionais de enfermagem estão sendo solicitados a demonstrar novas competências, além daquelas necessárias à execução de suas atividade, para atender as transformações políticas, sociais e produtivas do trabalho humano. Sendo assim, tais profissionais precisam adquirir conhecimento sobre os novos recursos proporcionados pelas tecnologias da informática em sua área como fonte de informação e de estratégia de atuação (AGUIAR; CASSIANI, 2007).

Diante da tendência de introdução de novas tecnologias no ensino de enfermagem é que foi construído o AVA sobre "Gerenciamento em Eventos Adversos nos Serviços de Enfermagem", para fazer parte do processo de educação permanente do enfermeiro.

No desenvolvimento deste ambiente foram percorridas as seguintes etapas no processo de criação: desenvolvimento do conteúdo, programação, testes de navegação e criação de uma interface.

Segundo Salles, Costa e Cardoso (2006), interface é definida como a ligação entre o sistema e o usuário, o meio que permite o acesso ao sistema. Ao se definir uma interface, têm-se a responsabilidade de demonstrar, por meio de ícones e menus, todo o conteúdo do ambiente, todas as suas funcionalidades, devendo assim otimizar os recursos disponíveis no sistema. Contudo não é aconselhável demonstrar seu conteúdo em uma única tela, visto que isso causaria um excesso de informação para o usuário, o que poderia confundi-lo. 
Quanto à linguagem utilizada nas interfaces, esta deve apresentar uma simplicidade expositiva. Clareza, objetividade e acessibilidade são as características mais importantes na linguagem oferecida por ambientes de educação a distância. A função é tornar os conteúdos mais acessíveis ao usuário, de maneira que ele possa aprender e avançar no programa com maior facilidade (FREITAS; LOYOLA; PRATES, 2002; NASCIMENTO, 2006).

Alguns autores destacam a utilização de técnicas que facilitam o estudo em ambientes via Web, como: o estilo de linguagem adotado deve ser simples e adaptado ao sentido habitual; as fontes de letra sem serifas (como Arial, Verdana e Tahoma) devem ser escolhidas por serem mais legíveis na tela; os parágrafos e sentenças devem ser curtos; a passagem de hiperlinks ao final de cada tela deve ser estimulada; o conteúdo maciço de informações deve ser dividido em partes; a redução da quantidade de texto por tela deve ser reduzida; as citações e bibliografias devem ser de fontes idôneas; entre outros (FREITAS; LOYOLA; PRATES, 2002; NASCIMENTO, 2006).

Em relação ao posicionamento das informações na tela, a mesma informação durante uma atividade ou nas várias atividades de um módulo, deve aparecer sempre na mesma posição. A utilização de várias janelas oferece ao usuário a vantagem de acesso a múltiplas fontes de informação. A sinalização de uma atividade pode ser feita através do título desta atividade, da opção em uso marcada na barra de menu ou por ícones. Os links devem ser indicados claramente ao usuário, sendo apresentados em cores e estilos diferentes do texto padrão (NASCIMENTO, 2006).

Quanto ao uso de cores na interface, estas devem ser atribuídas com parcimônia, pois podem causar distração do objetivo principal. É desaconselhável a utilização de cores de fundo de tela escuras ou com texturas que reduzem a legibilidade do texto ou que não permitam aos usuários a impressão (NASCIMENTO, 2006).

No que se refere à inclusão de exercícios, Évora et al. (2008) consideram que a utilização desse recurso propicia ao usuário a avaliação dos conhecimentos adquiridos e a obtenção das respostas fornece um feedback do aprendizado. 
Sobre a inclusão de vídeos, Nascimento (2006) destaca que sua utilização na educação evoca uma resposta emocional imediata no usuário. Esta reação pode ser determinante no processo motivacional e de engajamento em uma determinada tarefa.

Partindo das diretrizes apresentadas para o desenvolvimento de AVA, encontra-se a iniciativa de construção por parte de alguns enfermeiros e professores da área de enfermagem.

Rangel (2009) avaliou um AVA sobre o ensino de fisiologia em um curso de Licenciatura em Enfermagem e destaca que, com a utilização desse tipo de tecnologia, o aluno tem a possibilidade de oferta de diferentes estilos de aprendizagem para um determinado conteúdo em múltiplos formatos e seqüências, reservando a ele o caminho que lhe melhor convier.

Edwards et al. (2008) desenvolveram um AVA para graduandos de enfermagem de uma universidade australiana sobre cuidados com os idosos e concluíram que o uso de tal tecnologia foi atraente para os estudantes, envolvendo-os em atividades significativas de aprendizagem, além de fornecer recursos abrangentes e links.

Aguiar e Cassiani (2007) desenvolveram e avaliaram um AVA em um curso profissionalizante de enfermagem e estimulam educadores e estudantes a navegar na grande rede de ofertas de possibilidade, de informações, e trabalhar o conhecimento disponibilizado, seja pela Internet ou através dos meios tecnológicos existentes, não só para auxiliar no processo ensino/aprendizagem, mas também, para o desenvolvimento de futuros profissionais, principalmente na enfermagem.

Green et al. (2006) utilizaram um AVA para apoiar estudantes de enfermagem de uma universidade do Reino Unido em um módulo sobre anatomia humana e fisiologia e avaliaram que o usuário, podendo escolher quando e onde aprender, tem oportunidades de aprendizagem independentes e auto-dirigidas.

Contudo Caetano (2006), que desenvolveu e avaliou um AVA em administração em enfermagem, relata que essa é uma estratégia que ainda 
precisa ser melhor desenvolvida, necessitando de mais pesquisas para validação de metodologias e estratégias educacionais específicas à profissão.

Cogo et al. (2003) utilizaram um AVA para o ensino de suportes básicos e avançados de vida e concluíram que o uso de tecnologias da comunicação e informação proporcionou aos usuários melhor aproveitamento dos conceitos teóricos, que se tornam mais atrativos, personalizando a sua aprendizagem na medida em que podem acessar o ambiente em local e tempo a critério das suas disponibilidades. 
7. Canclusães 
Mediante os resultados encontrados frente aos objetivos propostos, conclui-se que:

- A busca pelo conhecimento na temática Eventos Adversos pode revelar aos profissionais como produzir uma assistência de enfermagem com qualidade e segurança;

- A utilização de novas tecnologias educacionais, como um ambiente virtual de aprendizagem, é uma estratégia inovadora e uma mudança de paradigma na capacitação de profissionais nas instituições de saúde;

- O desenvolvimento de um ambiente virtual de aprendizagem sobre gerenciamento em eventos adversos, abordando as temáticas: úlcera por pressão, erros de medicação, flebite, queda e perda de sonda nasogastroenteral contribuirá para a conscientização dos enfermeiros em relação aos tipos de eventos, fatores de risco, classificação e incidência;

- O referencial pedagógico fundamentado nos estudos de Gagné (1980) e a metodologia, utilizando o Modelo de desenvolvimento de programas de Instrução Auxiliada pelo Computador (Computer Assisted Instruction - CAI) proposto por Price (1991), revelaram-se adequados para o desenvolvimento desta pesquisa;

- O objetivo deste estudo foi alcançado e o ambiente virtual de aprendizagem intitulado "Gerenciamento em Eventos Adversos nos Serviços de Enfermagem" pode ser consultado na íntegra no endereço: <http://www.eerp.usp.br/nepien/eventosadversos>;

- O desenvolvimento deste ambiente de ensino baseado na Internet ainda tem um "longo caminho a percorrer", pois existe a necessidade de aprofundar a exploração da temática, tanto no aspecto pedagógico como ao que se refere a recursos técnicos;

- As limitações encontradas no desenvolvimento deste estudo dizem respeito à carência de material ilustrativo e vídeos sobre a temática - eventos adversos. 
- O custo da produção de um material educativo on line é oneroso, podendo intimidar iniciativas de criação na área de enfermagem;

- Como meta futura, a autora do presente estudo realizará a etapa de avaliação técnica e de conteúdo do ambiente virtual de aprendizagem "Gerenciamento em Eventos Adversos nos Serviços de Enfermagem", visando a utilização desse material educativo na educação permanente dos enfermeiros em instituições de saúde. 
Referências 
AGUIAR, R.A.; CASSIANI, S.H.B. Desenvolvimento e avaliação de ambiente virtual de aprendizagem em curso profissionalizante de enfermagem. Revista Latino-Americana de Enfermagem, Ribeirão Preto, v. 15, n. 6, 2007. Disponível em: <http://www.scielo.br/scielo.php?script=sci_arttext\&pid=S0104$11692007000600005 \&$ Ing =en\&nrm=iso\&tlng=pt $>$. Acesso em: 05/06/2010.

ALMEIDA, M.E.B. Educação a distância na internet: abordagens e contribuições dos ambientes digitais de aprendizagem. Educação e Pesquisa, São Paulo, v.29, n.2, p. 327-340, 2003.

ALVES, V.L.S., CUNHA, I.C.K.O., MARIN, H.F., OLIVEIRA, O. Criação de um web site para enfermeiros sobre pé diabético. Acta Paulista de Enfermagem, São Paulo, v.19, n.1, p.56-61, 2006.

AMERICAN ASSOCIATION OF HOSPITAL PHARMACISTS (ASHP). Guidelines on preventing medication errors in hospitals. American Journal of Hospital Pharmacy, v.50, p. 305-314, 1993.

BRASIL. Ministério da Ciência e Tecnologia. Conselho Nacional de Informática e Automação. Secretaria Especial e Informática. Proposta de plano setorial de informática em saúde: relatório de comissão especial. Brasília: Ministério da Saúde, 1988.

- Ministério da Saúde. Agência Nacional de Vigilância Sanitária (ANVISA). Disponível em: <http://portal.anvisa.gov.br>. Acesso em: 23 de abril de 2010.

CAETANO, K.C. Desenvolvimento e avaliação de um ambiente virtual de aprendizagem em administração em enfermagem. Dissertação (Mestrado). 2006. Escola de Enfermagem, Universidade de São Paulo, São Paulo, 155p, 2006.

CAETANO, K.C.; PERES, H.H.C. Metodologia para estruturação de hipertexto aplicada ao ensino de enfermagem. Acta Paulista de Enfermagem, São Paulo, v.20, n.2, p.175-179, 2007. 
COGO, A.L.P.; SILVEIRA, D.T.; LÍRIO, A.M.; SEVERO, C.L. A utilização de ambiente virtual de aprendizagem no ensino de suportes básico e avançado de vida. Revista Gaúcha de Enfermagem, Porto Alegre, v.24, n.3, p.373-9, 2003.

COMPROMISSO COM A QUALIDADE HOSPITALAR (CQH). Programa de Qualidade Hospitalar. Manual de indicadores de enfermagem NAGEH. São Paulo: APM/CREMESP, 2006. 40p. Disponível em: <http://www.cqh.org.br/files/Manual\%20de\%20Indicadores\%20NAGEH\%20\%20 V.FINAL.pdf $>$. Acesso em: 13/01/2010.

DAL SASSO, G.T.M.; BARBOSA, S.F.F. Perspectivas futuras à informática em enfermagem: aplicabilidade dos ambientes hipermídias no processo ensinoaprendizagem. Texto \& Contexto Enfermagem, Florianópolis, v.9, n.1, p.79$92,2000$.

DIAS, D.C.; CASSIANI, S.H.B. Educação sem distância: utilização do WebCT como ferramenta de apoio para o ensino da Terapia Intravenosa na graduação em enfermagem. Revista Brasileira de Enfermagem, Brasília, v.56, n.4, p.443-446, jul/ago 2003.

DICCINI, S.; PINHO, P.G.; SILVA, F.O. Avaliação de risco e incidência de queda em pacientes neurocirúrgicos. Revista Latino-Americana de Enfermagem, Ribeirão Preto, v. 16, n. 4, 2008. Disponível em: <http://www.scielo.br/scielo.php?script=sci_arttext\&pid=S01041169200800040 0016\&lng=en\&nrm=iso $>$. Acesso em: 18/02/2010.

DIOGO, R.C.S. Desenvolvimento do web site educacional sobre intervenção de enfermagem: aspiração de secreções traqueobrônquicas. 2001. 126p. Dissertação (Mestrado) - Escola Paulista de Medicina, Universidade Federal de São Paulo, São Paulo, 2001.

EDWARDS, H.; NASH, R.; SACRE, S.; COURTNEY, M.; ABBEY, J. Development of a virtual learning environment to enhance undergraduate nursing students' effectiveness and interest in working with older people. Nurse Education Today, v.28, n.6, p.672-9, 2008.

ÉVORA, Y.D.M. A informática na pesquisa em enfermagem. Acta Paulista de Enfermagem, São Paulo, v.13, n. especial, p. 184-189, 2000. 
As possibilidades de uso da internet na pesquisa em enfermagem. Revista Eletrônica de Enfermagem [periódico online], Goiás, v.6, n.3, 2004. Disponível em: <http://www.fen.ufg.br/revista/revista6_3/pdf/11_Revisao1.pdf>. Acesso em: 10/02/2007.

ÉVORA, Y.D.M; DALRI, M.C.B. O uso do computador como ferramenta para a implantação do processo de enfermagem. Revista Brasileira de Enfermagem, Brasília, v.55, n.6, p.709-13, 2002.

ÉVORA, Y.D.M.; MELO, M.R.A.C.; BERNARDES, A.; SEIXAS, C.A. O uso da tecnologia interativa no ensino de Administração Aplicada à Enfermagem. Anais eletrônicos do Congresso Brasileiro de Informática na Saúde (CBIS) 2008. Disponível em: <http://www.sbis.org.br/cbis11/arquivos/979.pdf>. Acesso em 24/08/2009.

FALKEMBACH, G.A.M. Concepção e desenvolvimento de material educativo digital. Revista Novas Tecnologias na Educação [periódico online], Rio Grande do Sul v.3, n.1, p.1-15, 2005. Disponível em <http://www.cinted.ufrgs.br/renote/>. Acesso em 04/05/2009.

FERNANDES, L.M.; CALIRI, M.H.L. Uso da escala de Braden e de glasgow para identificação do risco para úlceras de pressão em pacientes internados em centro de terapia intensiva. Revista Latino-Americana de Enfermagem, v.16, n.6, p.973-978, 2008.

FERREIRA, L.M.; CALIL, J.A. Etiopatogenia e tratamento das úlceras por pressão. Diagnóstico \& Tratamento, v.6, p.36-40, 2001.

FONSECA, L.M.M. Semiotécnica e semiologia do recém-nascido pré-termo: desenvolvimento e validação de um software educacional. 2007. 185p. Tese (Livre- Doutorado) - Escola de Enfermagem de Ribeirão Preto, Universidade de São Paulo, São Paulo, 2007.

FONSECA, S.; WITAKER, I.; MARIN, H. Desenvolvimento de um website educacional em primeiros socorros. Anais eletrônicos do Congresso Brasileiro de Informática na Saúde (CBIS) 2006. Disponível em: <http://sbis.org.br/cbis/arquivos/247.doc>. Acesso em: 10/02/2007. 
FRANCO, M.A.; CORDEIRO, L.M.; CASTILHO, R.A.F. O ambiente virtual de aprendizagem e sua incorporação na Unicamp. Educação e Pesquisa, São Paulo, v.29, n.2, p. 341-353, jul./dez. 2003.

FREITAS, A.A.; LOYOLLA, W.; PRATES, M. Linguagem e arquitetura de conteúdos em educação à distância mediada por computador. 2002. Disponível em: <http://www.abed.org.br/Congresso2002/trabalhos/texto03.htm>. Acesso em 04/06/2010.

GAGNÉ, R.M. Princípios essenciais da aprendizagem para o ensino. Trad. de Rute V. Ângelo. Porto Alegre: Globo, 1980.

GALLOTTI, R.M.D. Eventos adversos: o que são? Revista da Associação Médica Brasileira, São Paulo, v.50, n.2, 2004. Disponível em: $<$ http://www.scielo.br/scielo.php?script=sci_arttext\&pid=S01044230200400020 0008\&lng=en\&nrm=iso > . Acesso em: 17 de abril de 2010 .

GREEN, S.M.; WEAVER, M.; VOEGELI, D.; FITZSIMMONS, D.; KNOWLES, J. HARRISON, M.; SHEPHARD, K. The development and evaluation of the use of a virtual learning environment (Blackboard 5) to support the learning of préqualifying nursing students undertaking a human anatomy and physiology module. Nurse Education Today, v.26, n.5, p.388-95, 2006.

HANNAH, K.J.; SHAMIAN, J. Integrating a nursing professional practice model and nursing informatics in a collective bargain environment. Nursing Clinics North America, v.27, n.1, p.31-45, 1992.

INTRAVENOUS NURSES SOCIETY. Infusion nursing standards of practice. Journal Intravenous Nursing, v.23, n.6, p.1-46, 2000.

KOHN, L.T.; CORRIGAN, J.M.; DONALDSON, M.S., editors. To err is human: building a safer health system. Washington (DC): National Academy Press; 2000. 
Docência) - Escola de Enfermagem de Ribeirão Preto, Universidade de São Paulo, São Paulo, 2000.

LEAPE, L.L.; BRENNAN, T.A.; LAIRD, N.; LAWTHERS, A.G.; LOCALIO, A.R.; BARNES, B.A. et al. The nature of adverse events in hospitalized patients. Results of the Harvard Medical Practice Study II. New England Journal of Medicine, v.324, p.377-384, 1991.

LEAPE, L.L. et al. Systems analysis of adverse drug events. ADE Prevention Study Group. Journal of the American Medical Association, v.5274, n.1, p.35-43, 1995.

MACKLIN, D. Phlebitis: A painful complication of peripheral IV catheterization that may be prevented. American Journal of Nursing, v.103, n.2, p.55-60, feb. 2003.

MARIN, H.F.; BOURIE, P.; SAFRAN, C. Desenvolvimento de um sistema de alerta para prevenção de quedas em pacientes hospitalizados. Revista LatinoAmericana de Enfermagem, Ribeirão Preto, v.8, n.3, p.27-32, 2000.

MENDES, W.; TRAVASSOS, C.; MARTINS, M.; NORONHA, J.C. Revisão dos estudos de avaliação da ocorrência de eventos adversos em hospitais. Revista Brasileira de Epidemiologia, São Paulo, v.8, n.4, p.393-406, 2005.

MITUSHIMA, S.M. Desenvolvimento de um web site educacional sobre monitorização hemodinâmica. 2004. 126p. Dissertação (Mestrado) - Escola Paulista de Medicina, Universidade Federal de São Paulo, São Paulo, 2004.

MOTTA, M.C.S. Software educacional de enfermagem em puericultura: desenvolvimento e validação. 2000. 195p. Tese (Doutorado) - Escola de Enfermagem Anna Nery, Universidade Federal do Rio de Janeiro, Rio de Janeiro, 2000.

MURFF, H.J.; PATEL, V.L.; HRIPCSAK, G.; BATES, D.W. Detecting adverse events for patient safety research: a review of current methodologies. Journal of the American Medical Association, v.36, p.131-143, 2003. 
NASCIMENTO, C.A. Princípios de design na elaboração de material multimídia para a web. In: Núcleo de Educação a Distância/ UNISAL [online]. São Paulo; 2006. Disponível

em: $<$ http://www.nead.unisal.br/files/principios_de_design\%5B3\%5D.pdf $>$. Acesso em: 04/06/10.

NASCIMENTO, C.C.P.; TOFFOLETTO, M.C.; GONÇALVES, L.A.; FREITAS, W.G.; PADILHA, K.G. Indicadores de resultados da assistência: análise dos eventos adversos durante a internação hospitalar. Revista Latino-Americana de Enfermagem, Ribeirão Preto, v.16, n.4, julho-agosto 2008. Disponível em: <http://www.scielo.br/pdf/rlae/v16n4/pt_15.pdf>. Acesso em: 23/04/2010.

NATIONAL COORDINATING COUNCIL FOR MEDICATION ERROR REPORTING AND PREVENTION - NCCMERP. Taxonomy of medication errors. 1998. Disponível em: <http://www.nccmerp.org/public/aboutmederror.html>. Acesso em: 03/02/10.

NATIONAL PRESSURE ULCER ADVISORY PANEL (NPUAP). Pressure ulcer stages revised by NPUAP. February, 2007. Disponível em: <http://www.npuap.org>. Acesso em: 04/01/2010.

NOVAES, C.C. Os recursos da tecnologia de informática: um estudo sobre sua utilização no ensino de graduação nas Escolas de Enfermagem do Município de São Paulo. 2005. 196p. Dissertação (Mestrado) - Escola de Enfermagem, Universidade de São Paulo, São Paulo, 2005.

PAIVA, M.C.M.S.; PAIVA, S.A.R.; BERTI, H.W.; CAMPANA, A.O. Caracterização das quedas de pacientes segundo notificação em boletins de eventos adversos. Revista da Escola de Enfermagem da USP, São Paulo, v.44, n.1, p. 134138, 2010.

PERES, H.H.C.; LEITE, M.M.J. Informática no ensino de enfermagem. In: KALINOWSKI, C.; MARTINI, J.G.; FELLI, V.E.A. Programa de Atualização em Enfermagem: saúde do do adulto (PROENF/ABEN) - Ciclo 1, Módulo 1. Porto Alegre: Artmed/Panamericana Editora, 2006. p.58-74.

PETERLINI, M.A.S.; PEREIRA, S.R. Os erros humanos: abrangência e tipos. In: HARADA, M.J; PEDREIRA, M.L.G.; PETERLINI, M.A.S.; PEREIRA, S.R. O erro humano e a segurança do paciente. São Paulo: Atheneu, 2006. p. 19-26. 
PHILLIPS, L. D. Complicações da Terapia Intravenosa. In: Manual de

Terapia Intravenosa. Porto Alegre: Artmed, 2001. p. 236-268.

POLIT, D.F.; BECK, C.T.; HUNGLER, B.P. Fundamentos de pesquisa em enfermagem - métodos, avaliação e utilização. Trad. de Ana Thorell. Porto Alegre: Artmed, 2004.

POTTER, P.; PERRY, A.G. Nutrição. In: Fundamentos de enfermagem. 7aed.

Rio de Janeiro: Elsevier, 2009. 1528p.

PRESSMAN, R.S. Engenharia de software. Trad. de José Carlos Barbosa dos Santos. São Paulo, Makron Books, 1995.

PRICE, R.V. Computer-aid instruction: a guide for authors. Pacific Grove, Brooks/ Cole Publishing Co, 1991.

RANGEL, E.M.L. Avaliação do ambiente virtual de aprendizagem no ensino de fisiologia em um curso de licenciatura em enfermagem. 2009. 208p. Tese (Doutorado) - Escola de Enfermagem de Ribeirão Preto, Universidade de São Paulo, São Paulo, 2009.

RIBEIRO, M.A.S., LOPES, M.H.B.M. Desenvolvimento, aplicação e avaliação de um curso à distância sobre tratamento de feridas. Revista Latino-Americana de Enfermagem, Ribeirão Preto, v.14, n.1, p.77-84, 2006.

RODRIGUES, M.L. Prescrição eletrônica de medicamentos. In: CASSIANI, S.H.B.; UETA, J. A segurança de pacientes na utilização da medicação. 1 aed. São Paulo: Artes Médicas, 2004. p.33-41.

ROGENSKI, N.M.B.; SANTOS, V.L.C.G. Estudo sobre a incidência de úlceras por pressão em um hospital universitário. Revista Latino-Americana de Enfermagem, Ribeirão Preto, v.13, n.4, p.474-80, 2005. 
ROHDE, J.M.; MYERS, A.H.; VLAHOV, D. Variation in risk for falls by clinical department: Implications for prevention. Infection Control and Hospital Epidemiology, v.11, p.521-4, 1990.

RUBENSTEIN, L.Z.; POWERS, C.M; MACLEAN, C.H. Quality indicators for the management and prevention of falls and mobility problems in vulnerable elders. Annals of Internal Medicine., v.135, p.686-93, 2001.

SALLES, J.A.G.; COSTA, C.A.; CARDOSO, R.C. Necessidades para o desenvolvimento de uma interface adequada para resultados de ensinoaprendizagem bem sucedidos. In: Anais do $4^{\circ}$ Seminário Nacional de Educação a Distância; 2006; [online]. Brasília (DF): ABED; 2006. Disponível em: <http://www.abed.org.br/seminario2006/pdf/tc047.pdf>. Acesso em: 04/06/2010.

SANTOS, J.A.; PARRA Fo, D. Metodologia científica. São Paulo: Futura, 1998.

SEIXAS, C.A., MENDES, I.A.C. E-learning e educação à distância: guia prático para implementação e uso de sistemas abertos. São Paulo: Atlas, 2006.

SILVA, A. E. B. C.; CASSIANI, S. H. B. Administração de medicamentos: uma visão sistêmica para o desenvolvimento de medidas preventivas dos erros na medicação. Revista Eletrônica de Enfermagem, Goiás, v.6, n.2, 2004. Disponível em: <http://www.fen.ufg.br/revista/revista6_2/administra.html>. Acesso em: 24/04/2010.

SOCIEDADE BRASILEIRA DE GERIATRIA E GERONTOLOGIA. PEREIRA, S.R.M.; BUKSMAN, S.; PERRACINI, M.; PY, L.; BARRETO, K.M.L.; LEITE, V.M.M. Quedas em Idosos. 2001. Disponível em: <http://www.projetodiretrizes.org.br/projeto_diretrizes/082.pdf>. Acesso em: $18 / 02 / 2010$.

TELLES FILHO, P.C.P. Utilização da plataforma TelEduc no ensino da administração de medicamentos em um curso de graduação em enfermagem: a busca pela excelência. 2006. 254p. Tese (Doutorado) Escola de Enfermagem de Ribeirão Preto, Universidade de São Paulo, Ribeirão Preto, 2006. 
TINETTI, M.E.; SPEECHELEY, M.; GINTER, S.F. Risk factors for falls among elderly persons living in the community. New England Journal of Medicine, v.319, n.26, p.1701-7, 1988.

VIANA, A.B.N. Estatística aplicada à administração: análise do uso em pesquisas na área e construção de ambiente virtual de ensinoaprendizagem. 2005. 218p. Tese (Livre-Docência) - Faculdade de Economia, Administração e Contabilidade de Ribeirão Preto, Universidade de São Paulo, São Paulo, 2005. 
